Aus dem Zoologischen Institut der Universität Frankfurt/M.

\title{
Konstruktion und Signalfunktion der Sandpyramide der Reiterkrabbe Ocypode saratan Forsk. (Decapoda Brachyura Ocypodidae) $\left.)^{1}\right)^{2}$ )
}

\author{
Von K. Eduard Linsenmair
}

Mit 29 Abbildungen

Eingegangen am 17. Februar 1967

I n halt: A. Einleitung und Problemstellung S. 403. - B. Der Lebensraum von Ocypode saratan S. 405. - C. Die Errichtung der Pyramidenanlage S. 406. - I. Das Normalverhalten beim Neubau der Pyramidenanlage S. 407. - II. Analyse des Bauverhaltens: a) Dic Signalrcize für den Wiederaufbau S. 409. - b) Die periodischen Schwankungen der Baubercitschaft S. 412. - c) Analyse der einzelnen Bauhandlungen: 1. Sockel- und Spitzenbau S. 414. - 2. Der Wegbau S. 417. - 3. Der Ausbau des Eingangs und Vorplatzes S. 418. - d) die Lagebezichung der Pyramide zur Höhle S. 420. - e) Form und Größe der Pyramide S. 428. - f) Farbe und Konsisten $\%$ der Pyramide S. 431. - D. Die sozialen Funktionen der Pyramidenanlage S. 432. - a) Die sozial gleichstimmende Wirkung der Pyramiden: 1. Die Ursachen der Koloniebildung S. 432. - 2. Rivalenkampf und Drehsinı der Höhle S. 435. - 3. Das Erkennen der Pyramide durch Eindringlinge S. 436. b) Die Siedlungsdichte innerhalb der Kolonic: 1. Die natürlichen Pyramidenabstände S. 440. - 2. Dic Bedeutung der Pyramiden bei der Regelung der Wohndichte in der Kolonic S. 440. - 3. Das Territorialverhalten von Ocypode saratan S. 441 . - c) Die Bedeutung der Pyramiden für die $O$ ㅇ S. 443. - d) die Pyramiden als kurzzeitige Orientierungshilfe S. 443. - E. Beobachtungen an Ocypode saratan in Athiopien S. 444. F. Zur Frage der Stammesgeschichte des Pyramidenbauverhaltens S. 446. - Zusammenfassung S. 450. - Summary S. 453. - Literaturverzeichnis S. 455.

\section{A EINLEITUNG UND PROBLEMSTELLUNG}

In den letzten Jahren wurde das Verhalten der semiterrestrischen Winkerkrabben (Uca) ausgiebig untersucht (Altevogt 1955, $1957 \mathrm{a}, \mathrm{b}, 1959,1962$; Crane $1941 \mathrm{a}, \mathrm{b}, 1943,1957,1958$; Gordon; v. Hagen $1961 \mathrm{a}, \mathrm{b}, 1962,1967$; Peters; Salmon; Schöne und Schöne; Vervey u. a.). Von ihren nächsten Verwandten, etwa 20 Arten der Gattung Ocypode dagegen wuBten wir bisher kaum etwas. Uber das Fortpflanzungsverhalten von Ocypode und damit zusammenhängende Fragen teilen die wenigen Bearbeiter — vor allem CoTT; Cowles; Koepke; Magnus; Milne und Milne; Parenzan; Takahasi — fast nichts mit.

An einem von $O$. saratan bewohnten Strand fallen zu bestimmten Jahreszeiten stärker als die futtersuchenden oder höhlenbauenden Krabben kegelförmige Sandanhäufungen im Supralitoral auf (Abb. 1). Gräbt man die zugehöri-

1) Dissertation der Naturwissenschaftlichen Fakultät der Universität Frankfurt/M.

2) Der Studienstiftung des Deutschen Volkes und der Stiftung Volkswagenwerk danke ich für die großzügige Unterstützung. 


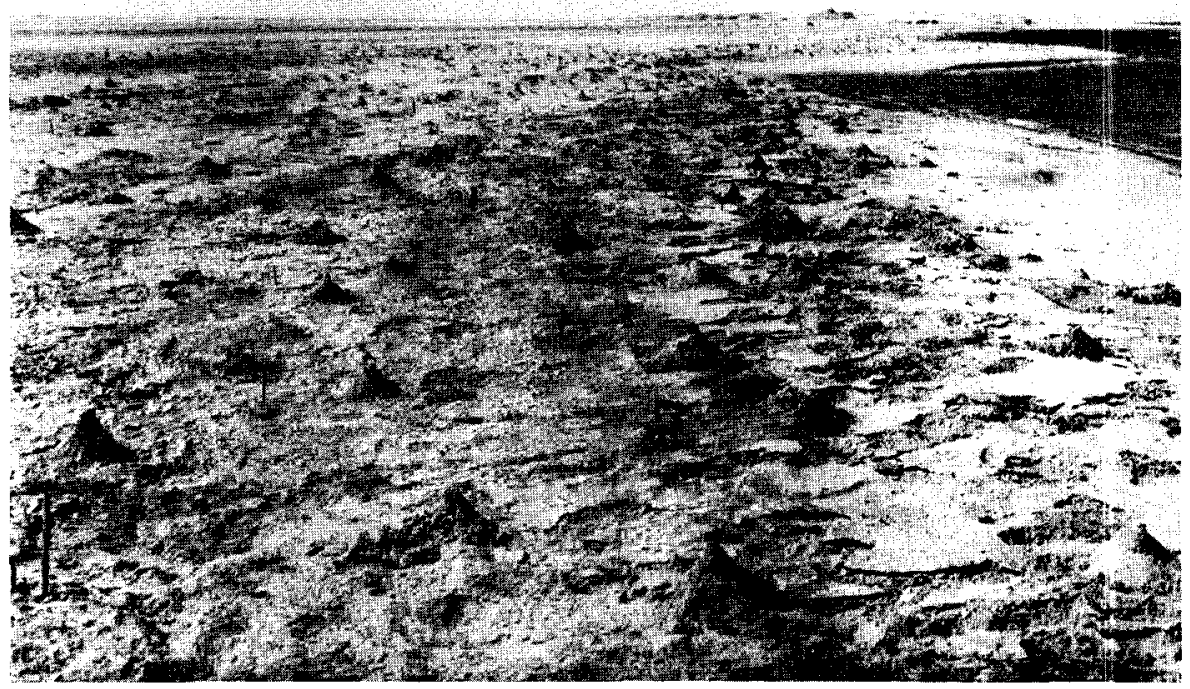

Abb. 1: Nördliche Hälfte des Hauptbeobachtungsgebietes; Sandstrand mit zahlreichen Pyramiden

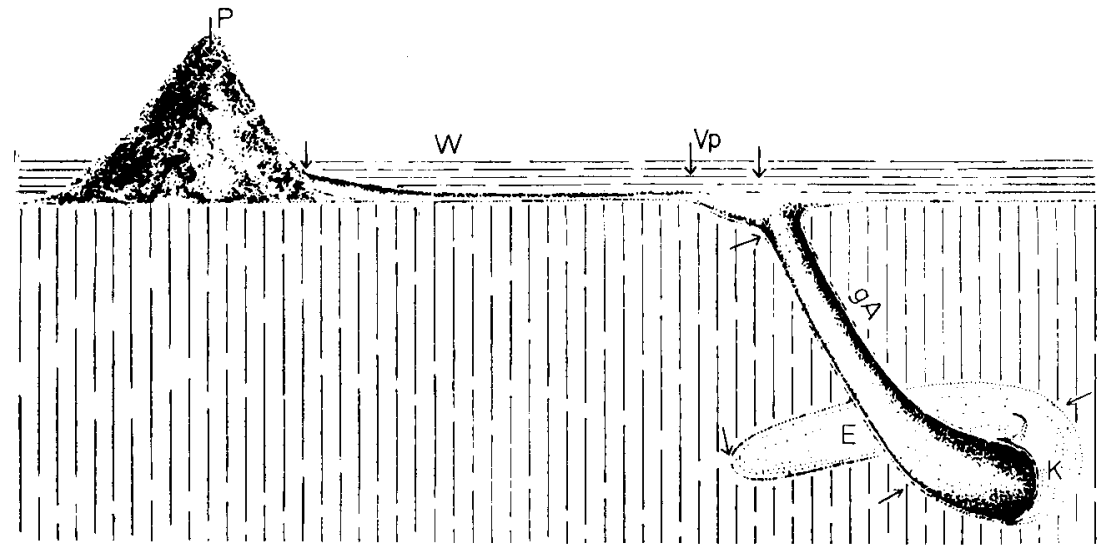

Abl. 2: Die Pyramidenanlage besteht aus: Pyramide (P), Weg (W), Vorplatz (Vp) und Spiralhöhle, die unterteilt wird in gerades Anfangsstück ( $\mathrm{gA}$ ), Knick (K) und Endstück (E)

gen Höhlen auf (Abb. 2), so findet man an ihrem Ende stets eine erwachsene männliche Reiterkrabbe. Die "P y r a m id e n a n lag e n "liegen immer in Gruppen beisammen, die im folgenden "K o 1 o n i e n " genannt werden.

Neben diesen spiraligen Höhlen bauen die adulten Ocypoden noch Schlaf-, Brut-, Häutungs-, Eß- und Wohnhöhlen ohne Sandpyramide. Sie alle sowie u. a. agonistisches Verhalten, Vibrationserzeugung, Gonadenzyklus und Verhalten der $q$, Verhaltensphasen der $O^{\prime} O^{\prime}$, Fortbewegung und Nahrungserwerb werden an anderer Stelle behandelt.

Diese Abhandlung gilt dem Bau und der bisher unbekannten biologischen Bedeutung der Pyramidenanlagen. 
Großen Dank schulde ich meinem verehrten Lehrer Professor Dr. M. Lindauder, der die Arbeit ideell und materiell großzügig unterstützte, ferner Herrn Dozent Dr. R. Jander für vielfältige Anregungen und kritische Durchsicht des Manuskriptes, sowie Herrn Professor Dr. D. Magnus für die Diskussion einiger Probleme. Zu großem Dank verpflichtet bin ich außerdem: dem Ehepaar Helga und Helmut Freissner (Kairo-Maadi) und Herrn Ibrahim Helmy, vor allem aber meinem Freund cand. phil. nat. J. Kiepenheuer, mit dem ich die Reise 1963 gemeinsam unternahm und meiner Frau, die mich 1964 und 1965/66 begleitete.

\section{B DER LEBENSRAUM VON Ocypode saratan}

Die Art kommt überall an den Küsten und auf den Inseln des Roten Meeres vor, wo der Sandstrand erlaubt, durch höchstens anderthalb $\mathrm{m}$ tiefes Graben das Grundwasser oder zumindest sehr feuchten Sand zu erreichen. Das Nahrungsangebot ist weniger wichtig, da eine Reiterkrabbe so gut wie überall Verzehrbares findet.

\section{a) Untersuchungsgebiete und -zeit}

Dic Hauptuntersuchungsgebicte lagen in Agypten $18 \mathrm{~km}$ sïdlich des Ortes Ghardaqa und in Äthiopien etwa $15 \mathrm{~km}$ nördlich der Hafenstadt Massawa. In Agypten beobachteten wir ferner kurzzeitig an mehreren Plätzen auf der Halbinsel Sinai und am Festland (Abb. 3),

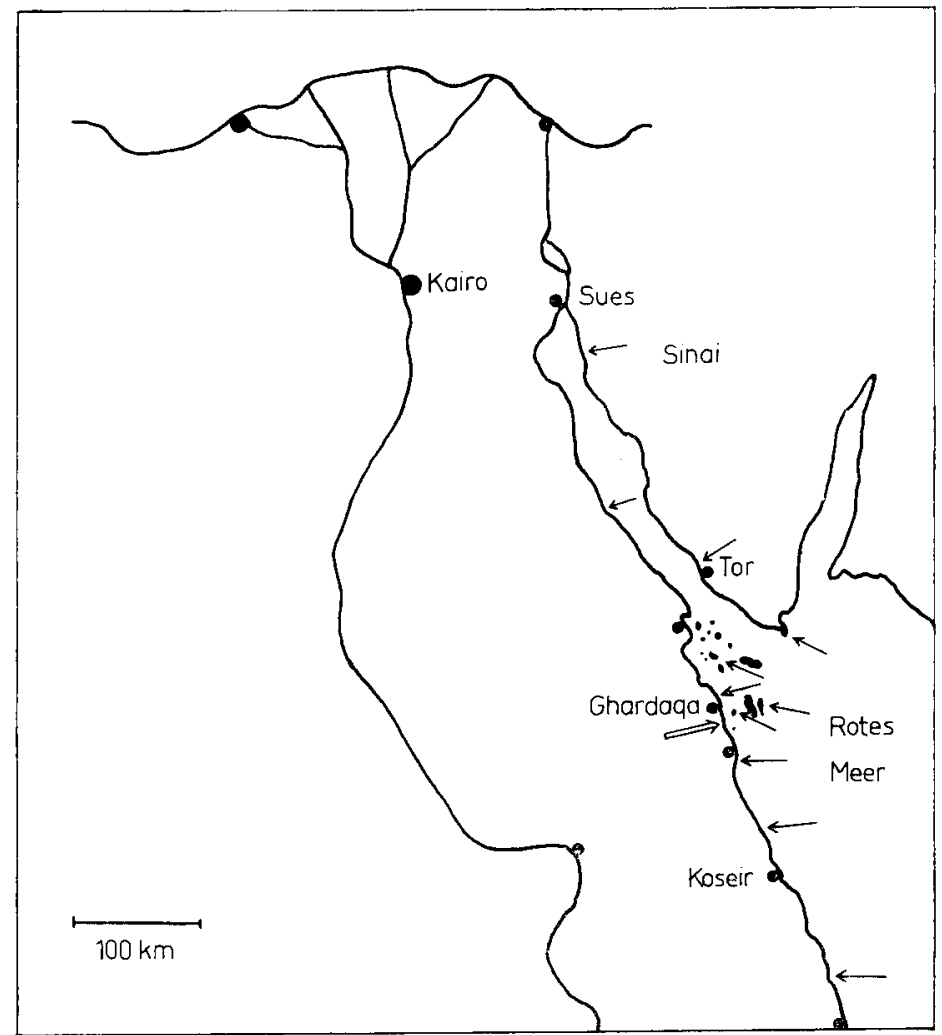

Abb.3: Die Beobachtungsgebiete am Roten Meer in Ägypten (Pfeile)

ferner bei Port Sudan und südlich von Massawa. In Agypten arbeiteten wir 1963 im Juli und August, 1964 im März und April, 1965 von Mai bis Oktober und im Januar 1966, in Athiopien im Dezember 1965.

\section{b) Das Hauptuntersuchungsgebiet}

Der Strandbiotop der Ocypoden im Hauptuntersuchungsgebiet in Agypten (dicker Pfeil in Abb. 3) läßt sich vom Infralitoral landeinwärts in mehrere Zonen untergliedern, deren Breite je nach den örtlichen Gegebenheiten beträchtlich schwanken kann (Abb. 4): 


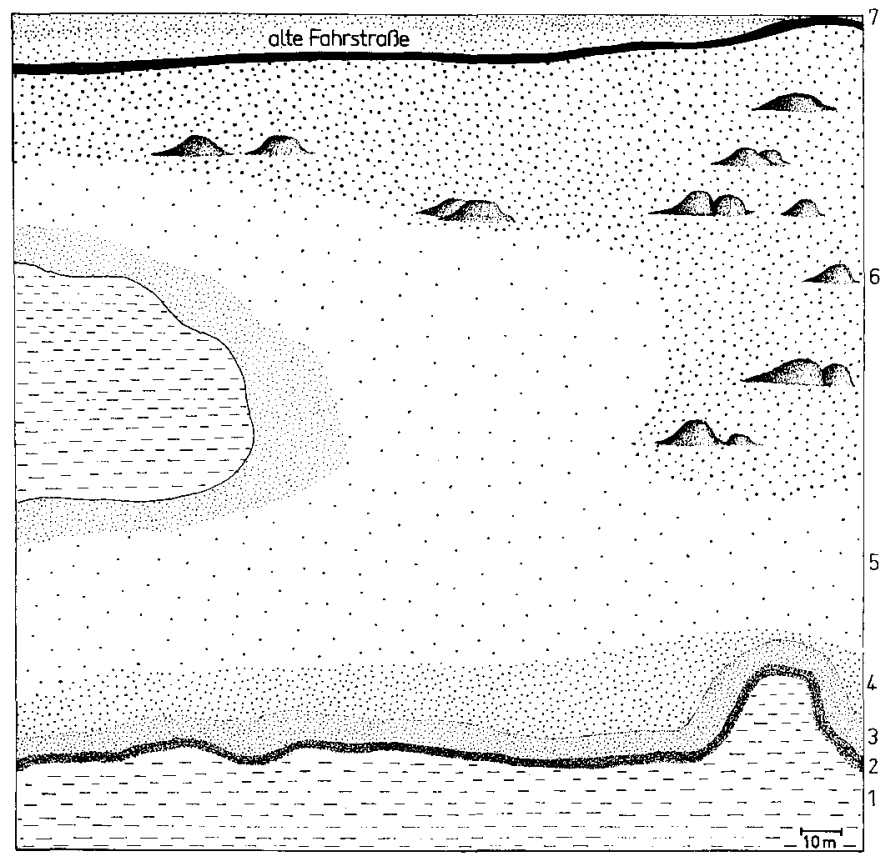

Abb. 4: Zonen der Küstenregion im Hauptuntersuchungsgebiet bei Flut: 1 = Infralitora!, $2=$ Spülsaum, 3 und 4 spülsaumnahes Supralitoral, $5=$ Harschzone, $6=$ Hügelzone, $7=$ Geröllwüste; links im Bild eine Lagune, deren Größe je nach Jahreszeit stark wechselt

1. Eine $50-500 \mathrm{~m}$ breite Gezeitenstufe mit einer flachen Feinsand- oder Schlickschicht als Untergrund. Dieses Areal ist für die Ocypoden Weide- und Jagdgrund.

2. Der $0,5-2 \mathrm{~m}$ breite Spülsaum; ebenso wie Zone 1 dient er als Weidegebiet, außerdem wie auch die Randgebiete des Infralitoral, als Baugelände für Schlaf-, Brut- und Eßhöhlen.

3. Eine 2-6m breite Zone, in deren sehr feuchtem Sand jüngere Tiere ihre Wohnbauten, alte zuweilen ihre Schlafhöhlen anlegen. bauten.

4. Eine $10-25 \mathrm{~m}$ breite Zone lockeren, trockenen Sandes. Hier liegen die Pyramiden-

5. Die etwa $80-200 \mathrm{~m}$ breite "Harschzone“ mit sehr harter, stark salzhaltiger Oberfläche; bei Winterspringfluten ist sie regelmäßig überschwemmt. Im Frühjahr bauen die Reiterkrabben auch hier Pyramidenanlagen.

6. Daran anschließend steigt der Untergrund leicht an und ist von lockerem, grobem Sand und vereinzelten subfossilen Korallenbruchstiicken bedeckt. In Abständen von wenigen $\mathrm{m}$ erheben sich kleinere, mit niederen Büschen bewachsene Sanddünen. Einige wenige Ocypoden wohnen immer in dieser Zone, vor allem im Winter, wenn höhere Fluten großc Teile der Zone 4 überschwemmen.

7. Die letzte Zone, für unsere Untersuchungen fast bedeutungslos, ist die bis über einen $\mathrm{km}$ breite Geröllwüste, dic, sanft ansteigend, in eine Hügelzone übergeht und schließlich am Gebirge der Arabischen Wüste endet. Hin und wieder wandern Gruppen von Reiterkrabben weit in dieses Gebiet hinein (vgl. MaGnus).

\section{DIE ERRICHTUNG DER PYRAMIDENANLAGE}

In Ägypten bauen die Reiterkrabben nach eigenen Beobachtungen und den Angaben zuverlässiger Gewährsleute etwa von Mitte Dezember bis Mitte März keine Pyramiden. Im Frühjahr 1964 begannen sie am 26. März in vielen weit auseinanderliegenden Siedlungsgebieten schlagartig. An diesem Tag zählten wir an einem knapp $3 \mathrm{~km}$ langen Küstenabschnitt unseres Beobachtungs- 
gebietes 7 bewohnte Pyramidenbauten, am 27.3. waren es 11, am 28.3. 35, am 2. 4. 147, am 3. 4. 281, am 6. 4. 970, am 14. 4. etwa 1400, am 22.4. über 2300.

Wir fanden keine einzige frische Spiralhöhle ohne Pyramide und ebensowenig eine nicht spiralige Höhle mit einer Pyramide. Spiralböble und Pyramide bilden eine untrennbare Baueinbeit.

Wie durch Ausgrabungen von ungefähr 1000 Spiralhöhlen und weit mehr Beobachtungen Bauender festgestellt wurde, errichten nur erwachsene $\sigma^{\prime} \sigma^{\prime}$ Pyramidenanlagen. Alle 60 sezierten Pyramidenbesitzer hatten voll entwickelte Hoden.

\section{Das Normalverhalten beim Neubau der Pyramidenanlage}

Das $\sigma^{\prime}$ wählt den Bauplatz nach folgenden Gesichtspunkten aus: Der oberflächliche Sand soll locker sein, die trockene Schicht darf nicht tiefer als $5 \mathrm{~cm}$ reichen. In spätestens etwa $80 \mathrm{~cm}$ Tiefe muß der Sand naß sein. Außerdem soll das Siedlungsgebiet möglichst nahe am Spülsaum liegen, darf aber auch bei hohen Fluten nicht überschwemmt werden. Diese Bedingungen sind nur in der schmalen Zone 4 erfüllt.

Beim Neubau lassen sich sieben Bauabschnitte unterscheiden, denen bestimmte Verhaltensweisen entsprechen:

1. Beim „Ausschachten“ benutzt die Reiterkrabbe lediglich die Pereiopoden der "Grabseite“. Die Krabben graben immer nur mit den Beinen auf der Seite der Kleinen Schere. Ausgelöst wird dieses Verhalten durch trockenen, nicht verklumpenden Sand. Die Pereiopoden schleudern wie mit einem Spaten den Sand in Richtung des zukünftigen "Weges“. Im Mittel erreichen sie nach zwei- bis viermaligem $(n=22)$ Scharren Sand, der so feucht ist, daß er zusammenklebt.

2. Dann benutzen sie neben den Laufbeinen der Grabseite auch noch die kleine Schere: Der Sand wird vor allem mit den vier Laufbeinen aus dem Untergrund "ausgestochen“ und zu einem Klumpen geformt. Diese ungefähr

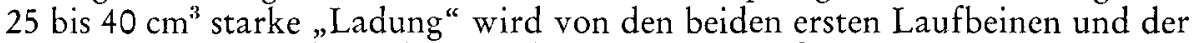
kleinen Schere gepackt und gegen den Körper gepreßt ausgetragen. Die ersten $10 \pm 3$ Ladungen $(n=22)$ verwenden sie zum Bau des Weges. Dabei trägt das ungestörte Tier den Sand immer ein Stück weit in die Wegrichtung und schleudert ihn dann erst mit Schwung weg. Normalerweise geht der Bauende ungefähr bis zum Ende der Aufschüttung und wirft den Sandklumpen ein Stück darüber hinaus, so daß der Weg jedesmal etwas länger wird.

3. Die nächsten $19 \pm 5(\mathrm{n}=20)$ Ladungen, die beim Bau des „Knicks“ anfallen, werden zum "Sockelbau"verwendet. Grab- und Austragtechnik bleiben von nun an dieselben wie während der 2. Phase. Beim Sockelbau wird der Sand nicht mehr in einer ungefähren Geraden aufgeschüttet, sondern engfächerförmig (Abb. 29).

4. Auf den Sockel werden die folgenden $30 \pm 7$ Ladungen $(n=33)$ aufgetürmt. Im Gegensatz zu den vorherigen Bauabschnitten wird das Material beim "Spitzenbau“ nicht mehr weit weggeschleudert, sondern hingesetzt, umso vorsichtiger, je höher der Sandkegel schon ist. Das $\sigma^{\prime \prime}$ besteigt seine Pyramide immer seitlich, die große Schere voran. Anfänglich häuft es den Sand auf den Sockel, später, wenn die Pyramidenspitze im $\varnothing$ höchstens $4 \mathrm{~cm}$ mißt, preßt es den Sand seitlich an (Abb. 5) und drückt ihn mit den Beinen und der Kleinen Schere zur Spitze hoch. Die Große Schere dient dabei als Widerlager. 


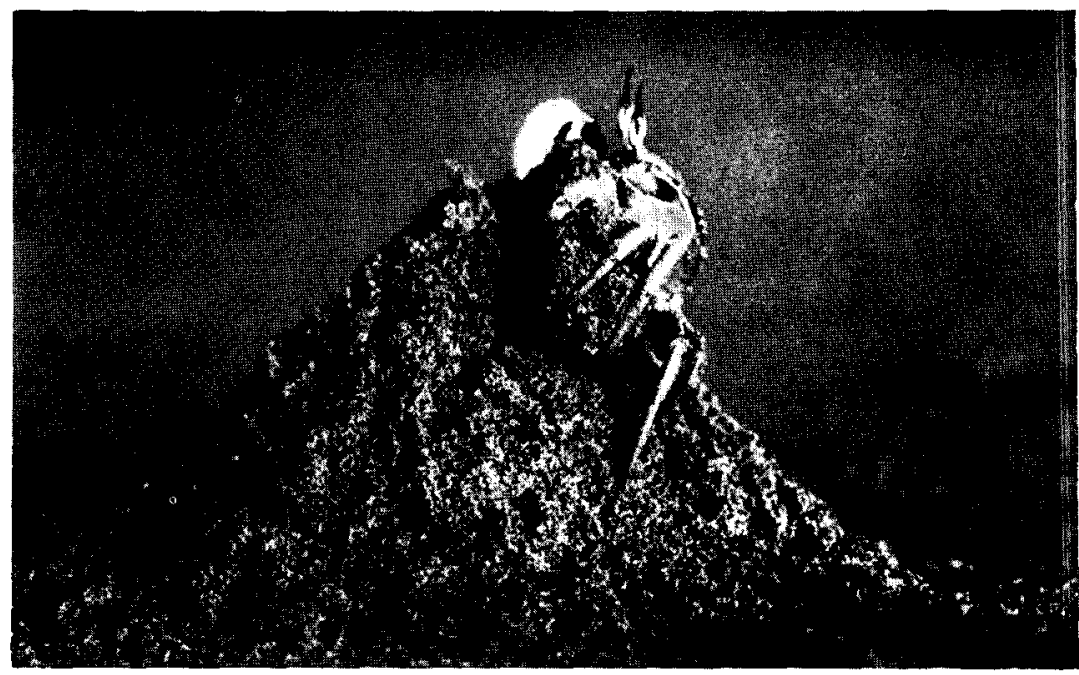

Abb. 5: Ocypode saratan beim Festpressen einer Sandportion an der Pyramidenspitzc. Die gerade noch $z$. T. sichtbare große Schere dient dabei als Widerlager

Während der ersten vier Bauphasen entsteht die gesamte Spiralhöhle. An dieser lassen sich die folgenden 4 Abschnitte unterscheiden (Abb. 2): der "Eingang", der im Winkel von 30-60 nach unten führende "gerade" oder "leicht gebogene Abschnitt", der "Knick" und das mehr oder weniger waagrechte "Endstück".

5. Das die folgende Phase kennzeichnende "Planieren" (die Oberseiten der beiden Scheren, of auch die nach innen umgeknickten Dactylopoditen stampfen den Untergrund fest) beginnt fast regelmäßig schon in den Phasen 2 bis 4 als Wegchen-, seltener auch als Sockelplanieren. Den Höhepunkt der Planiertätigkeit erreichen die Neubauer immer erst nach Abschluß der Grabarbeiten.

6. Beim „Ausbau des Eingangs" sitzt der Baumeister zu einem Viertel bis zur Hälfte in der Höhle; mit den Beinen der Große-Scheren-Seite scharrt er zunächst den trockenen Oberflächensand in die Höhle, befördert dann den darunter liegenden feuchten Sand ebenso zur Höhle und klopft ihn am inneren Unterrand des Höhleneingangs fest, der so die erforderliche Weite erhält. Durch das Scharren entsteht vor dem Höhleneingang der "Vorplatz" (z. B. Abb. 13).

Die fertige Pyramidenanlage besteht also aus folgenden, durch spezifische Bauhandlungen geformten Teilstrukturen: Spiralböble, Vorplatz, Weg und Sandpyramide (Abb. 2).

Im Mittel ist die Spiralhöhle $67 \pm 7,5 \mathrm{~cm}(\mathrm{n}=50)$ lang und in der Zone 4 des Hauptbeobachtungsgebietes 25 bis $35 \mathrm{~cm}$ tief. Der Eingang ist um 5 bis $9 \mathrm{~mm}$ höher als der Längsdurchmesser des Besitzers $(M=5,2 \pm 0,45 \mathrm{~cm}$, $\mathrm{n}=30$ ). Da Reiterkrabben immer seitlich in "aufrechter" Haltung in ihre Höhlen laufen, bestimmt der Längsdurchmesser die Höhe.

Die Pyramiden sind im Mittel 16,5 $\pm 2 \mathrm{~cm}(\mathrm{n}=100)$ hoch und am Grunde $28 \pm 5 \mathrm{~cm}(\mathrm{n}=100)$ breit (vgl. MaGNus).

Für eine neue Pyramide werden durchschnittlich $1850 \pm 550 \mathrm{~cm}^{3}(\mathrm{n}=45)$ Baustoff verwendet. 
Zum Neubau einer Pyramidenanlage benötigen die $\sigma^{7} \sigma^{7}$ etwa $80 \pm 15$ Minuten $(\mathrm{n}=25)$.

Hier ist noch ein Orientierungsverhalten zu erwähnen, das die Reiterkrabben regelmäßig nach Fertigstellung eines Pyramidenbaus zeigen. Im typischen Fall gehen sie auf ihrem Weg vom Höhleneingang zur Pyramide und dann in gleicher Richtung langsam mit wiederholten Pausen 1-2 m weiter. In dieser Entfernung laufen sie einen Teilkreis von $40-100^{\circ}$ rund um den Pyramidenbau. Plötzlich, in der Regel ohne erkennbare äußere Veranlassung, laufen sie auf ihre Pyramide zu und von dieser aus, meist wiederum dem Wegchen folgend, zum Höhleneingang. Dort bleiben sie eine zeitlang stehen, und das Ganze kann sich bis zu viermal wiederholen. Danach machen sie nicht mehr den Umweg über die Pyramide, sondern kehren geradewegs zum Höhleneingang zurück.

\section{Analyse des Bauverhaltens}

In Agypten baut der Besitzer seine Pyramide, die der Wind im Lauf eines Tages teilweise oder ganz zerstört, regelmäßig wieder auf. Es fragt sich, wodurch dieser Wiederaufbau ausgelöst wird, welche Reize die einzelnen Bauhandlungen auslösen und richten und wie sich die Einzelhandlungen zum Gesamtverhalten zusammenfügen.

\section{a 1) Die Signalreize für den Wiederaufbau von Pyramiden}

Über die Baubereitschaft, d. h. die für den Wiederaufbau verantwortlichen Innenfaktoren vgl. S. 412-414.

Als Außenreize kommen in Frage: Windschaden an der Pyramide und in die fast immer offene Spiralhöhle eingewehter Sand. Folgende drei Versuchsserien sollten weiteren Aufschluß geben:

A. Nach Abschluß des turnusmäßigen Wiederaufbaus (S. 412) der Pyramiden wurde einer ersten Gruppe von Versuchstieren $500 \mathrm{~cm}^{3}$ Sand in die Höhlen geschïttet, ohne die zugehörigen Pyramiden zu entfernen.

B. Bei dieser Gruppe wurde dieselbe Sandmenge in die Höhle eingefüllt, zugleich aber die Pyramide vollständig entfernt. $500 \mathrm{~cm}^{3}$ Sand füllen meist gerade den Anfangsabschnitt der Höhle bis zum Knick auf, wo sich dann der Baustoff staut.

C. Der dritten Gruppe wurde nur die Pyramide entfernt und kein Sand in die Höhlen geschüttet.

Sämtliche Versuche während einer Bauphase (Tab. 1) wurden nach Abschluß des turnusmäßigen Wiederaufbaus durchgeführt. Bei der experimentell ausgelösten Baureaktion handelt es sich deshalb immer um einen zusätzlichen Wiederaufbau.

Der Begriff Bauphase bezeichnet den Zeitraum (normalerweise morgens und nachmittags vgl. S. 412), in dem mehr als etwa $5 \%$ der Pyramidenbesitzer in einem Wohngebiet bauen.

Wie Tab. 1 belegt, lösen sowohl das Signal „Füllsand in der Höhle“ als auch das "Fehlen der Pyramide" Wiederaufbauverhalten während der Bauphasen aus. Beide Signalreize wurden quantitativ analysiert.

1. Befund: Der Signalreiz fehlende Pyramide löst erst bei einem Verkleinern der Pyramide unter etwa $3 \mathrm{~cm}$ Höhe Wiederaufbau aus, dann aber in voller Stärke. Die Reaktion scheint dem Alles-oder-Nichts-Gesetz zu unterliegen. 
$7_{a} a b .1:$ Wiederaufbauverhalten von Höhlenbesitzern nach A: Verschütten der Höhle mit Sand bei vorhandener Pyramide. B: Entfernen der Pyramide und Verschütten mit Sand. C: Entfernen der Pyramide ohne Sandgabe $(n=$ je Spalte 100 Versuche). Die Zahlen in Klammern geben den Prozentsatz der Tiere an, die den Sand erst kurz vor Beginn der nächsten Bauphase in die Höhle scharrten, bzw. derer, die ihre Pyramide erst während der nächsten (oder übernächsten $=2$. Klammer) Bauphase errichteten

\begin{tabular}{|c|c|c|c|c|c|c|}
\hline & Zeitpunkt des Zuschüttens & $\begin{array}{l}\% \text { Versuchst } \\
\text { von } 2 \mathrm{~h} \text { der } \\
\text { Höhle schar }\end{array}$ & $\begin{array}{l}\text { ie innerhalb } \\
\text { in die }\end{array}$ & $\begin{array}{l}\% \text { versu } \\
\text { von } 2 \mathrm{~h} \\
\text { beginnen }\end{array}$ & $\begin{array}{l}\text { stiere, die } \\
\text { it Pyram }\end{array}$ & $\begin{array}{l}\text { nnerhalb } \\
\text { nbau }\end{array}$ \\
\hline \multirow{3}{*}{ A } & Während einer Bauphase & $96 \%$ & $(4 \%)$ & $64 \%$ & $(36 \%)$ & \\
\hline & Am Ende einer Bauphase & $74 \%$ & $(26 \%)$ & $5 \%$ & $(90 \%)$ & $(5 \%)$ \\
\hline & Zwischen zwei Bauphasen & $28 \%$ & $(72 \%)$ & $0 \%$ & $(100 \%)$ & \\
\hline \multirow{3}{*}{ B } & Während einer Bauphase & $98 \%$ & $(2 \%)$ & $74 \%$ & $(26 \%)$ & \\
\hline & Am Ende einer Bauphase & $79 \%$ & $(21 \%)$ & $14 \%$ & $(86 \%)$ & \\
\hline & Zwischen zwei Bauphasen & $18 \%$ & $(82 \%)$ & $9 \%$ & $(84 \%)$ & $(7 \%)$ \\
\hline \multirow{3}{*}{ c } & Während einer Bauphase & \multicolumn{2}{|c|}{-} & $88 \%$ & $(8 \%)$ & $(4 \%)$ \\
\hline & Am Ende einer Bauphase & \multicolumn{2}{|c|}{-} & $14 \%$ & $(76 \%)$ & $(10 \%)$ \\
\hline & Zwischen zwei Bauphasen & \multicolumn{2}{|c|}{ - } & $10 \%$ & $(82 \%)$ & $(8 \%)$ \\
\hline
\end{tabular}

2. Befund: Wenn die Pyramide stehen geblieben ist, muß man mindestens $200 \mathrm{~cm}^{3}$ Sand in die Höhle schütten, um dadurch Wiederaufbau auszulösen. Bei fehlender Pyramide dagegen trägt die Krabbe schon $25 \mathrm{~cm}^{3}$ (= eine kleine Ladung) aus der Höhle. Der Signalreiz fehlende Pyramide senkt also auch die Schwelle des Wiederaufbautriebes.

Zwar genügen bei vorhandener Pyramide meist auch schon $100 \mathrm{~cm}^{3}$ trockenen Sandes, um eine Teilbauhandlung - nämlich das In-den-Knickscharren - auszulösen (s. u.); aber weiter geht der Wiederaufbau dann nicht. Offenbar werden demnach die sicherlich taktilen Reize der Füllmasse quantifiziert. Es spielt keine Rolle, ob man die notwendigen $200 \mathrm{~cm}^{3}$ auf einmal oder nach und nach in die Höhle schüttet.

3. Befund: Die Auslösung des Wiederaufbauverhaltens durch Füllsand zeigt keine Abhängigkeit von dem Zustand einer vorhandenen Pyramide, auch eine vollständige oder sogar vergrößerte Pyramide (S. 428) hemmt das Bauverhalten nicht.

Handelt es sich bei der Auslösung durch die beiden verschiedenen Signalreize um dieselbe Reaktion?

Folgende Punkte sprechen dafür:

1. Sowohl das Entfernen der Pyramide als auch das Verschütten der Höhle führen zu einem Austragen von Bausand, d. h. beide Signalreize lösen dieselben Instinktbewegungen aus.

2. In beiden Fällen dient der herausgetragene Sand ausschließlich dem Pyramidenbau (vgl. Befund 3), er ist also „z w e c k gebunden“.

3. Entfernt man nur die Pyramide, ohne Sand in die Höhle zu schütten, so kann die Reiterkrabbe nur bauen, wenn noch ein kleiner Rest Füllsand in der Höhle liegt. Das ergaben sowohl Mengenvergleiche von hineingeschürtetem und ausgetragenem Sand als auch Ausmessungen neuer und schon mehrere Tage lang bewohnter Höhlen, sowie unmittelbare Beobachtungen. Auch bei experimentell herbeigeführtem, tagelangem völligem Mangel an Baustoff (bei manchen Bauten in der Harschzone erreichbar) und bei fehlender Pyramide, ist O. saratan nicht in der Lage, sich Sand von außerhalb der Höhle, wie es 
Parinzan behauptet, oder durch Vergrößern der Höhle zu beschaffen: Der Baustoffgewinn ist starr or $\mathrm{t} s$ gebunden.

Ausschließlich bei sehr starkem Mangel wird der gesamte Füllsand ausgetragen. Sonst bleibt immer noch ein kleiner Rest $\left(M=58 \pm 34 \mathrm{~cm}^{3}, \mathrm{n}=38\right)$ in der Höhle, den die Krabbe dann bei fehlender Pyramide zusammenscharrt und austrägt. Bei Fehlen jeglichen Bausandes kann man eine Aktivierung der Wiederaufbauhandlung an der erhöhten Planierrate (S. 408) erkennen.

Diese drei Befunde sprechen dafür, daß es sich wirklich um dieselbe Baureaktion handelt, die von den beiden Signalreizen Füllmaterial und fehlende Pyramide ausgelöst wird.

Wenn also beide Signalreize dasselbe Wiederaufbauverhalten auslösen, liegt die Frage nahe, ob sich ihre Wirkungen summieren. Dann wäre der höchste Prozentsatz Bauender im Versuch B zu erwarten gewesen. Wie aus Tab. 1 ersichtlich, ist schon aus statistischen Gründen ( $B$ kann weder gegen $A$ noch gegen $C$ gesichert werden) eine Aussage über etwaige Summation der beiden Signalreize, gemessen als Erhöhung des Prozentsatzes von Pyramidenbauern, auf Grund der durchgeführten Versuche nicht möglich. Erschwerend kommt hinzu, daß manche beim Verschütten der Höhlen erschreckten Tiere sich am Höhlenende eingraben.

Dieselben unvermeidbaren Störungen machten auch die Beantwortung der weiteren Frage unmöglich, welche Menge Füllsand ebenso stark auslösend wirkt, wie der Signalreiz fehlende Pyramide.

\section{a 2) Die Bedeutung der Signalreize Füllsand und fehlende Pyramide unter natürlichen Bedingungen}

Die obigen Versuchsergebnisse werfen die weitere Frage auf, ob die beiden Signalreize unter natürlichen Umständen die Auslösung des notwendigen turnusmäßigen Wiederaufbauverhaltens gewährleisten oder ob noch andere Reize hinzukommen müssen.

Da die Spiralhöhle als einziger Höhlentyp auch bei Sandsturm in der Regel rom Besitzer nicht verschlossen wird (nur ausnahmsweise tat er es doch, und zwar immer erst, wenn eine bestimmte Menge Sand in die Höhle gefallen war, etwa $600 \pm 200 \mathrm{~cm}^{3}, \mathrm{n}=30$ ), bedeutet die Zerstörung der Pyramide immer zugleich Materialgewinn. Das Umgekehrte muß nicht der Fall sein, z. B. wenn der Höhleneingang einbricht oder die aus stark salzhaltigem Sand gebaute Pyramide windfest ist. Außer dem Wind zerstören in den uns bekannten Biotopen nur noch hohe Springfluten einige Pyramidenanlagen, und auch dann wird Baustoff in die Höhle geschwemmt. Weitaus die meisten Bewohner eines überschwemmten Wohnraums verlassen ihn. Sie befreien sich aus der vollständig verstopften Höhle, indem sie senkrecht aufwärts einen Gang graben.

Da die Spiralhöhle als Kopulationsplatz dient (S. 443), erscheint es biologisch geradezu notwendig, daß der Signalreiz Füllsand das Wiederaufbauverhalten unabhängig vom Pyramidenzustand auszulösen vermag. Eine Hemmung des Sandausgrabens durch die Pyramide würde bei jedem Materialgewinn ohne Zerstörung der Pyramide zur Funktionsunfähigkeit der Spiralhöhle führen. Auf Grund der ökologischen Gegebenheiten und der Tatsache, daß die Spiralhöhlen auch bei Sandsturm nicht verschlossen werden, ist die Starrheit im Gewinnen von Baustoff (vgl. dagegen die Plastizität des Verhaltens beim Reparieren des Eingangs S. 418) nicht erstaunlich. In allen mir bekannten Biotopen genïgt der Füllsand zum Wiederaufbau der Pyramide (zur Bedeutung der Pyramidengröße bei ihrer Signalfunktion vgl. S. 437), weshalb keine „Notwendigkeit" - in Form eines entsprechenden Selektionsdruckes - besteht, sich Baustoff von anderswoher zu beschaffen.

Ob die Bereitschaft zum Pyramidenbau nach einem Sandsturm deshalb zunimmt (Abb. 6), weil beide Signalreize Füllsand und fehlende Pyramide zusammenwirken, oder ob der Sandsturm selbst die Tiere aktiviert, muß offen 


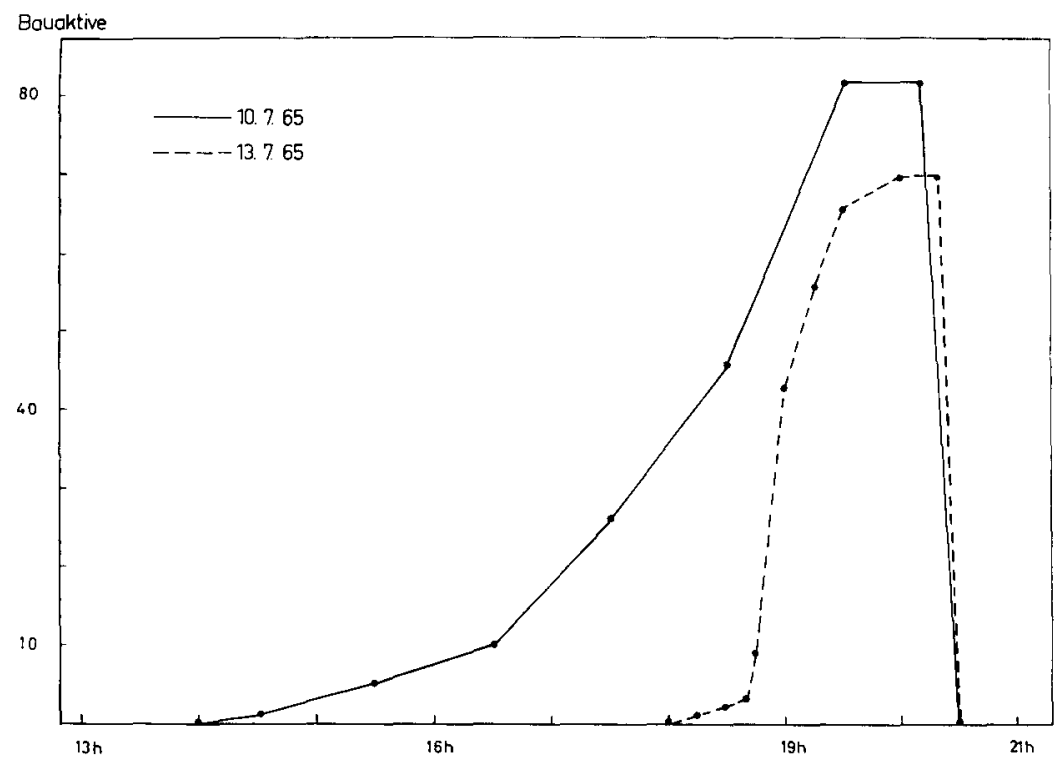

$A b b$. 6: Anzahl bauaktiver $\hat{\delta} \hat{\delta}$ (Ordinate) an je 100 markierten Pyramidenanlagen während einer nachmittäglichen Bauphase bei gutem Wetter (durchgezogene Linie) und nach einem Sandsturm (gestrichelte Linie)

bleiben. Sicher spïrt die Krabbe in der Höhle den Sandsturm: sowie er nachläßt, tauchen viele Höhlenbesitzer schlagartig auf. Daß es sich dabei nicht um Begleiterscheinungen des Sandsturms handelt, etwa Verdunkelung der Höhle oder Sandrieseln, lehrten viele Verschüttungsversuche (S. 409 ff). Obwohl sich die Höhle in beiden Fällen in gleicher Weise verändert, kommen die bei ruhigem Wetter Verschütteten nicht alle zu einem bestimmten Zeitpunkt schlagartig aus ihren Höhlen. Verschüttet man dagegen die Höhlen vor einem Sandsturm, so erscheinen die Versuchstiere synchron, sobald dieser nachläßt.

b) Die periodischen Schwankungen der Baubereitschaft

An der Pyramide bauen die $O^{\prime \prime} O^{7}$ unter natürlichen Umständen mindestens einmal, meist jedoch zweimal am Tage. In Ägypten wird nicht gebaut, wenn die $5 \mathrm{~cm}$ über dem Boden gemessene Schattentemperatur unter 25 oder über $40^{\circ} \mathrm{C}$ liegt, wenn die Windgeschwindigkeit $15 \mathrm{~cm}$ über dem Boden 8,5 bis $10 \mathrm{~m} / \mathrm{sek}$. übersteigt und die Lichtintensität unter 1 Lux sinkt. Dagegen waren die Reiterkrabben derselben Art in Athiopien rein nachtaktiv (S. 445 ff). Mit Ausnahme der Dunkelheit hemmen die aufgezählten limitierenden Faktoren nicht nur den Pyramidenbau, sondern die gesamte Aktivität. (Die Höchstwerte, bei denen einzelne Individuen noch Nahrung suchten oder Höhlen bauten, lagen bei 19 bzw. $42{ }^{\circ} \mathrm{C}$ und $10,5 \mathrm{~m} / \mathrm{sek}$. Windgeschwindigkeit.)

Keinen Einfluß auf die Bautätigkeit haben die Gezeiten, mit Ausnahme sehr hoher Springfluten, die Teile des Wohnraumes überschwemmen. Bedingt durch die Kälte liegt die Hauptbauzeit ( $=$ Bauphase $=$ mehr als $5 \%$ der Spiralhöhlenbesitzer eines Strandabschnittes bauen) im Frühjahr zwischen 11 und 15 Uhr. Sobald die Temperatur es erlaubt, verschiebt sich die Bauphase auf den späten Nachmittag. Ab Mitte April beginnt die nachmittägliche Bauphase zwischen 15 und 16 Uhr und endet bei Eintritt der Dunkelheit (je nach Jahreszeit zwischen 19.00 und 20.30 Uhr). Gleichzeitig mit dern nachmittäglichen 
Baumaximum entsteht eine zweite, nicht so bedeutsame Bauphase am Morgen zwischen 6.00 und 9.00 Uhr (jeweils ägyptische Ortszeit).

Die zeitliche Lage dieser Bauphasen kann nur durch die Baubereitschaft begrenzende Faktoren verschoben werden, nicht aber durch günstige, gleichmäßige Bedingungen während des ganzen Tages.

Während der Bauruhe zwischen 9 und 15 Uhr sind die Reiterkrabben bei günstigen Außenbedingungen keineswegs ganz untätig, vielmehr fällt oft der Höhepunkt der täglichen Wander- und Freßaktivität gerade in diese Zeit. Auch in den durch Tab. 1 und ab S. 409 beschriebenen Versuchen schwankte die Baubereitschaft parallel mit den natürlichen Bauphasen periodisch. In jenen Versuchen war keine Abbängigkeit der Baubereitschaft von der Baubandlung - über eine Triebreduktion - nachweisbar. In einzelnen Versuchen ist es durch ständig wiederholtes Verschütten gelungen, den Besitzer einer Höhle während einer einzigen Bauphase bis zu $5000 \mathrm{~cm}^{3}$ Sand austragen zu lassen, ohne daß sein Eifer erkennbar nachgelassen hätte. Das ist etwa zweieinhalbmal so viel, wie beim Neubau zur Verfügung steht, und das Fünffache des bei durchschnittlichem Wiederaufbau geförderten Sandes (S. 408). An reiner Bauzeit benötigt der Bauherr bei dieser Menge etwa 3 Std. In einem anderen Versuch haben von 52 Versuchstieren 15 je 3 und 4 Versuchstiere je 4 vollständige Pyramiden während einer Bauphase errichtet, ohne zu ermüden: Der Durchschnittswert von 4 ausgetragenen Portionen in 5 Min. blieb unverändert. Der Umstand, daß das Bauverhalten nicht bei allen Krabben während einer Bauphase ausgelöst werden kann, hat seine Ursachen vor allem in den Störungen, die beim experimentellen Verschütten unvermeidbar sind.

Die Auslösbarkeit eines zusätzlichen Pyramidenbauverhaltens ist in vorhersehbarer Weise $\mathrm{n} \mathrm{u} \mathrm{r}$ von dem Zeitpunkt des Zuschüttens und nicht von der Zahl der ausgeführten Bauhandlungen abhängig. Da die Auslösbarkeit auch weitgehend unabhängig von Außenfaktoren steigt und fällt (s.o.), sind diese periodischen Schwankungen der Bauaktivität sehr wahrscheinlich vorwiegend endogen bedingt.

Nachdem keine Ermüdbarkeit des Bautriebes durch eine „triebverzebrende Endhandlung" festgestellt werden konnte, stellte sich die Frage, ob sich die zeitlichen Schwankungen der Baubereitschaft durch einen Triebstau in ihrem Verlauf ändern lassen. Zur Klärung dieser Frage diente folgende Versuchsserie: Einer Gruppe von Höhlenbesitzern, die in der Harschzone (S. 406) 2-3 Tage pyramidenlos und ohne Baustoff geblieben war, wurde zu verschiedenen Tageszeiten $300 \mathrm{~cm}^{3}$ Sand in die Höhlen geschüttet. Als Kontrolltiere dienten Krabben, denen bisher immer reichlich Baustoff zur Verfügung gestanden hatte; ihnen füllten wir zur selben Zeit Sand in die Höhlen, zerstörten ihre Pyramiden aber erst unmittelbar vor dem Verschütten. Alle Versuche fanden wiederum nur bei günstiger Witterung statt, die ein Bauen in den Zwischenbauphasen erlaubt hạ̈tte.

Wie Tab. 2 zeigt, bestehen keine wesentlichen Unterschiede zwischen den beiden Gruppen. Bei einem stärkeren Triebstau müßten sich die Phasenwinkel des zeitlichen Verlaufs der Baubereitschaftshöhe bei der Kontroll- und der Versuchsgruppe stärker unterscheiden als in Abb. 7. Die Tatsache, daß es zu keinem länger andauernden Bautriebstau kommt, erklärt wahrscheinlich auch, warum es nie gelungen ist, ein $\sigma^{7}$ durch dauerndes Zerstören der Pyramide oder durch Entzug des Baustoffs zum Verlassen seiner Höhle zu bewegen (vgl. auch S. 415). 
Tab. 2: Prozentsatz der Pyramidenbesitzer, die auf ein Zuschütten ihrer Höhlen zu Beginn, während, am Ende und zwischen zwei Bauphasen (Abb. 7) mit ncuerlichem Pyramidenbau $(\%+)$ reagieren. Es wurde die Versuchsgruppe, der 2-3 Tage lang kein Baumaterial zur Verfügung gestanden hatte, mit einer Kontrollgruppe verglichen, die immer genügend Sand zum Wiederaufbau hatte

\begin{tabular}{|c|c|c|c|c|c|c|}
\hline & Gruppe & $\begin{array}{l}\text { Zeit in Min. 1) } \\
\text { 1. Kontrolle }\end{array}$ & $\%+$ & $\begin{array}{l}\text { Zeit in Min. } \\
\text { 2. Kontrolle }\end{array}$ & $\%+$ & $n$ \\
\hline a) 2$)$ & $\begin{array}{l}\text { Versuchs - } \\
\text { Kontroll- }\end{array}$ & $\begin{array}{l}60 \\
60\end{array}$ & $\begin{array}{l}60 \\
52\end{array}$ & $\begin{array}{l}90 \\
90\end{array}$ & $\begin{array}{r}100 \\
90\end{array}$ & $\begin{array}{l}27 \\
76\end{array}$ \\
\hline b) & $\begin{array}{l}\text { Versuchs - } \\
\text { Kontroll - }\end{array}$ & $\begin{array}{l}60 \\
60\end{array}$ & $\begin{array}{l}100 \\
100\end{array}$ & - & - & $\begin{array}{l}20 \\
30\end{array}$ \\
\hline c) & $\begin{array}{l}\text { Versuchs - } \\
\text { Kontroll- }\end{array}$ & $\begin{array}{l}60 \\
60\end{array}$ & $\begin{array}{r}100 \\
33\end{array}$ & $\begin{array}{l}- \\
120\end{array}$ & $\begin{array}{l}- \\
60\end{array}$ & $\begin{array}{l}10 \\
15\end{array}$ \\
\hline d) & $\begin{array}{l}\text { Versuchs - } \\
\text { Kontroll - }\end{array}$ & $\begin{array}{l}90 \\
90\end{array}$ & $\begin{array}{r}19 \\
6\end{array}$ & $\begin{array}{l}150 \\
150\end{array}$ & $\begin{array}{l}38 \\
14\end{array}$ & $\begin{array}{r}16 \\
100\end{array}$ \\
\hline e) & $\begin{array}{l}\text { Versuchs - } \\
\text { Kontroll - }\end{array}$ & $\begin{array}{l}90 \\
90\end{array}$ & $\begin{array}{r}10 \\
9\end{array}$ & $\begin{array}{l}150 \\
150\end{array}$ & $\begin{array}{r}10 \\
9\end{array}$ & $\begin{array}{r}20 \\
100\end{array}$ \\
\hline
\end{tabular}

1) "Zeit“ in Minuten vom Verschütten an gerechnet, in welcher der in der dritten und fünften Spalte genannte Prozentsatz von Versuchsticren reagierte.

2) $\mathrm{Zu}$ den Buchstaben vgl. Abb. 7.

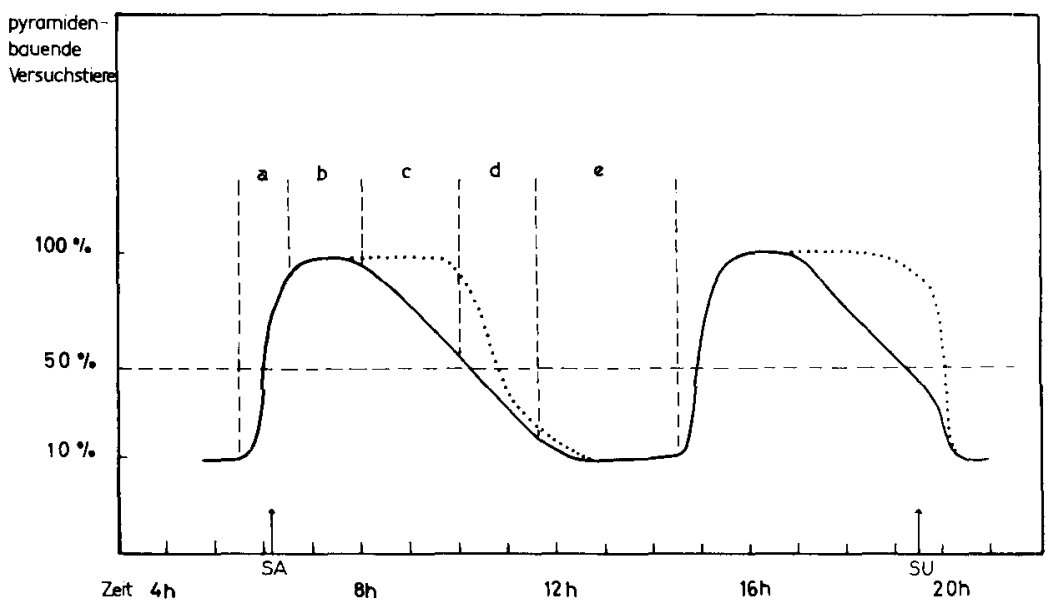

Abb. 7: Schwankungen der endogenen Pyramidenbaubereitschaft im Laufe eines Tages. Das Maß für die Baubereitschaft ist der Prozentsatz von Versuchsticren (Ordinate), der spätestens 2 Std. nach dem Verschütten der Höhle und Entfernen der Pyramide eine neue baut. Durchgezogene Linie Kontrollgruppe; gepunktete Versuchsgruppe. SA und SU: Sonnenaufund -untergang

Demnach sind die periodischen Schwankungen der Pyramidenbauaktivität Fluktuationen der Baubereitschaft. Das Bauverhalten selbst beeinflußt die Baubereitschaft weder über eine Triebreduktion, noch über einen Triebstau oder eine bemmende "Pyramidenreafferen $z^{\text {". }}$.

c) Analyse der einzelnen Bauhandlungen

\section{Der Sockel-und Spitzenbau}

Das Wiederaufbauverhalten ist keine starre Handlungskette, sondern vergleichsweise plastisch. Entscheidenden Einfluß auf seinen Ablauf haben zwei Faktoren: 


\section{Der Zustand der Pyramide und}

2. die Menge verfügbaren Baustoffs.

Bei den Verschüttungsversuchen (Tab. 1 und 2) ergab es sich nebenher, daß es nicht belanglos ist, wann innerhalb der Bauphase die Pyramide verändert oder entfernt wird: Eingriffe vor dem „ersten Auftauchen" zu Beginn einer Bauphase hatten nie eine erkennbare Beunruhigung der Versuchstiere zur Folge und lösten immer das dem Zustand der Pyramide gemäße Verhalten aus; dagegen ließen sich die Krabben durch Verändern ihrer Pyramiden wäbrend einer Bauphase oft erheblich stören (s. u.) und reagierten anders als auf denselben Eingriff vor ihrem ersten Erscheinen.

Bei der Beurteilung des Pyramidenzustandes schien deshalb dem ersten Eindruck zu Beginn jeder Bauphase eine entscheidende Bedeutung zuzukommen. Diese Vermutung wurde in zwei Versuchsreihen geprüf:

I. Zwei Gruppen von Versuchstieren wird in einer Zwischenphase, während welcher die Krabben nicht an der Oberfläche erscheinen, gleichviel Sand in ihre Höhlen geschüttet. Die einen (A) finden beim Auftauchen vollständige Pyramiden vor, während die Sandkegel der anderen (B) restlos entfernt wurden. Beide Gruppen verhalten sich situationsgemäß: Die erste Gruppe baut sofort an der Pyramidenspitze, während die zweite mit dem Sockelbau (S. 407) beginnt.

II. Derselbe Versuch wird wiederholt, die Situation aber sofort nach der ersten Inspektion verändert, bevor die Versuchstiere mit dem Austragen begonnen haben, indem man nun der ersten Gruppe (A) die Pyramiden entfernt und der zweiten Pyramiden hinsetzt. Keines der Versuchstiere verhält sich zunächst der Situation entsprechend: Alle sind immer stark beunruhigt, kriechen wiederholt in ihre Höhlen, betrachten und betasten jedesmal ausgiebig die „überraschend" vorhandenen Pyramiden oder die leeren, ehemaligen Standorte derselben, oft länger als eine Std., bevor sie die erste Portion austragen. Die 12 B$\sigma^{7}$ mit Pyramiden warfen ihre ersten $8 \pm 4$ Ladungen an den Sockel, ohne den Zustand der vorhandenen Pyramide zu beachten, der Spitzenbau erfordert hätte. Von den $14 \mathrm{~A}-\mathrm{O}^{7} \mathrm{O}^{7}$, die sich bereits auf den Spitzenbau eingestellt hatten, setzten 6 schon die erste Ladung vorsichtig auf den leeren Bauplatz (Spitzenbauweise!), die anderen 8 spätestens die dritte.

Da ein Verändern vor dem ersten Auftauchen immer „selbstverständlich“ hingenommen wird, muß man zu dem Schluß kommen, daß der Pyramidenzustand zu Beginn jeder Bauphase neu beurteilt wird. Im Gegensatz zur Sandwespe Ammophila, bei der ein vergleichbarer Primäreindruck während eines "Inspektionsbesuches" starr festlegt, wieviele Raupen in eine Bruthöhle eingetragen werden müssen (BAERENDS), kann das Bauverhalten von O. saratan auch durch Sekundäreindrücke modifiziert werden.

In dem oben geschilderten Versuch (II B) trugen die Versuchstiere, die sich auf den Sockelbau eingestellt hatten, im Mittel $8 \pm 4(n=12)$ Ladungen in Sockelbauweise aus. 15 Kontrolltieren, deren Pyramiden vor dem ersten Auftauchen entfernt worden waren, stand ebensoviel Sand zur Verfügung $\left(1000 \mathrm{~cm}^{3}\right)$. Sie verwendeten im Mittel $14 \pm 3$ Ladungen für ihren Sockel. Beide Mittelwerte sind mit $\mathrm{p}=0,005$ gegeneinander gesichert.

Einzelne Versuchstiere setzten schon ihre erste Ladung auf der Spitze der überraschend vorhandenen Pyramide $a b$, jedoch frïhestens 30 bis 120 Min. nach dem Erkennen der Veränderung. Diese Beobachtungen und Versuche beweisen die Wirksamkeit des Sekundäreindrucks; im Gegensatz zum Primäreindruck spricht er aber immer mit großer Trägheit an. 
Was den zweiten ebenso wichtigen Außenfaktor, die Baustoffmenge angeht, erweist sich die Zahl der zum Wiederaufbau verwendeten Ladungen dem verfügbaren Vorrat ungefähr proportional (Tab. 3). Der Besitzer berücksich-

Tab. 3: Zahl der beim Wiederaufbau verwendeten Portionen für den Sockel bei verschiedener Baustoffmenge

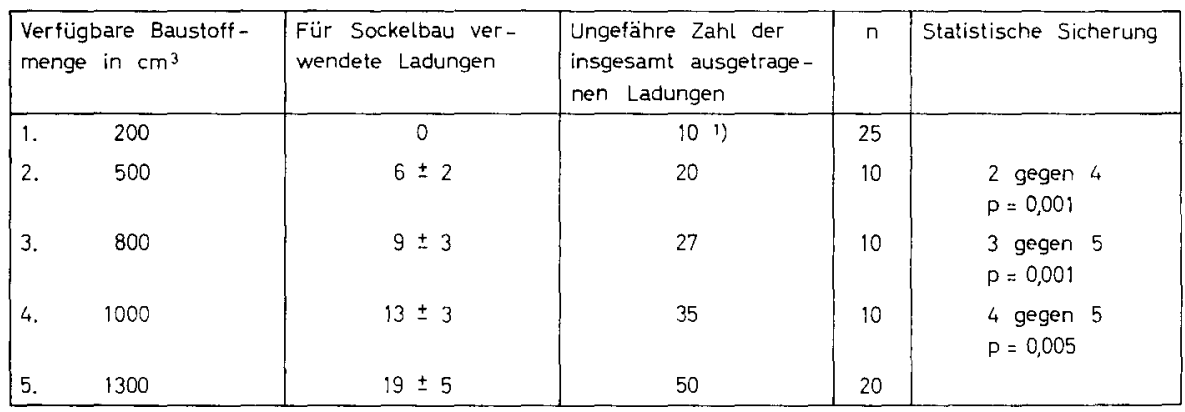

1) Bei Baustoffmangel wird auch der letzte Rest zusammengescharrt und ausgetragen; im Mittel sind die Ladungen deshalb kleiner als bei größerer Bausandmenge.

tigt auch bei der Beurteilung des Pyramidenzustandes den Vorrat an Baustoff. Sind es etwa $300-500 \mathrm{~cm}^{3}$, so genügt schon eine $3 \mathrm{~cm}$ hohe, $5 \mathrm{~cm}$ breite Erhebung als Sockel, und er beginnt gleich mit dem Spitzenbau. Dagegen wirkt dieselbe Erhebung bei $1000 \mathrm{~cm}^{3}$ oder mehr Füllsand nur richtend und löst noch Sockelbau aus. Erst eine $4 \mathrm{~cm}$ hohe, $10 \mathrm{~cm}$ breite Sandaufschüttung verhindert das Sockelbauen unabhängig von der Bausandmenge.

Sockel- und Spitzenbauverhalten gehen beim Neubau oft fließend ineinander über: Zwischen dem Wegschleudern beim typischen Sockelbau und dem vorsichtigen Ablegen beim typischen Spitzenbau kann ein Fallenlassen der Sandklumpen vermitteln. Künstlich induzierter Sockelbau bei vorhandener Pyramide (vgl. S. 415) dagegen schlug immer übergangslos in Spitzenbau um.

Bei der Entscheidung Spitzen- oder Sockelbau richtet sich der Besitzer immer sowohl nach dem Zustand der Pyramide als auch der Bausandmenge. Je weniger Sand er hat, um so schneller beginnt er Spitzen zu bauen (Tab. 3), und desto kleiner kann eine richtende Erhebung sein, um den Sockelbau vollständig $\mathrm{zu}$ unterdrücken. So können sie nach vollständigem Entfernen der Pyramide mit etwa $200 \mathrm{~cm}^{3}$ immerhin noch ungefähr $7 \mathrm{~cm}$ hohe Pyramiden bauen, während sie bei mehr als $1200 \mathrm{~cm}^{3}$ Vorrat mit zwei- bis dreimal so viel Sand lediglich einen nur 2-3 cm hohen Sockel bauen. Da bei einer derartigen Bausandmenge immer auch entsprechend mehr Material für den Spitzenbau vorhanden ist, bleibt das Verhältnis von Sockelumfang zu Pyramidenhöhe stets ungefähr gleich. Ocypode saratan baut - soweit das mit dem verfügbaren Baustoff und der arteigenen Bauweise möglich ist - mit jeder Sandmenge einen "idealen" Kegel, oder etwas anders gesehen: Die $\sigma^{7} \sigma^{\prime}$ bauen mit jeder Sandmenge die böcbstmögliche Erhebung. Die Beschaffenheit des Sandes und die Bauweise führen dann ganz automatisch zum Kegel.

Es ist nicht gelungen, einen hemmenden Einfluß einzelner Bauhandlungen auf die allgemeine Baubereitschaft zu finden (vgl. S. 413). Die Spitzenbauweise ist nicht nachweislich ermüdbar, dagegen wirken der Wegchenund Sockelbau triebreduzierend. Dies beweist die weitgehende Unfähigkeit, bei vorhandenen Signalreizen die zeitliche Dauer einer dieser Handlungen zu verlängern oder auf das vorhergehende Glied der Verhaltenskette (z. B. vom Spitzen- zum Sockelbau) zurïckzugreifen (vgl. S. 417 und Tab. 4). 


\section{Der Bau des Weges}

Beim Wiederaufbau wird nur selten cin Weg (vgl. S. 407) angelegt.

Die Versuche, durch das Entfernen des Weges neuerbauter Pyramidenanlagen zusätzlichen Wegbau auszulösen, verliefen negativ. Die Besitzer bemerkten die Veränderung, was sie vor allem durch eifriges Betasten und Planieren der ehemaligen Wegstrecke zeigten; nie verwendeten sie aber auch nur eine einzige Sandportion für zusätzlichen Wegbau. Allerdings füllen sie $1-2 \mathrm{~cm}$ breite und mindestens $2 \mathrm{~cm}$ tiefe ausschließlich ertastete Gruben mit Pyramidenbaustoff auf, wenn sie gerade welchen "zur Hand" haben und die Vertiefung beim Sandaustragen bemerken; sonst scharren sie mit ihren Beinen Sand aus der Umgebung zusammen, den sie dann noch mit den Scheren festplanieren können.

Wie zahlreiche Beobachtungen zeigten, ist der Bau eines vollständigen Wegchens immer mit dem Gesamtwiederaufbau einer Pyramide von mehr als $1000 \mathrm{~cm}^{3}$ Inhalt gekoppelt. Wie bereits erwähnt, scharren die Reiterkrabben in ihre Höhlen gefallenen Sand, ehe sie ihn heraustragen, in den Knick und das Endstück der Höhle. Dort lassen sich, wie in Verschüttungsversuchen festgestellt wurde, höchstens etwa $1200 \mathrm{~cm}^{3}$ speichern. Was darüber ist, bleibt im Anfangsabschnitt der Spiralhöhle liegen und dient dann zum Wegbau; auch beim Neubau stammt der Sand für den Weg ausschließlich aus dem Anfangsstück der Höhle (S. 408).

Signalreiz für den Wegbau ist somit Sand im Anfangsabscbnitt der Höble.

Während beim Neubau stets ein Weg entsteht, baut die Krabbe keinen wieder auf, wenn sie beim ersten Auftauchen zu Beginn einer Bauphase einen Sockel, eine vollständige Pyramide oder eine künstliche Wegchenaufschüttung vorfindet, und auch dann nicht, wenn Sand im Anfangsabschnitt der Höhle liegt. Die oben gemachte Aussage muß also eingeschränkt werden: Sand im Anfangsabschnitt löst nur dann Wegchenbau aus, wenn nicht ein anderer Signalreiz gleichzeitig Spitzen- oder Sockelbau auslöst.

Manche $\hat{\partial} \hat{\delta}$ werfen auch bei einer Bausandmenge zwischen etwa 500 und $1000 \mathrm{~cm}^{3}$ noch einige, nach unseren Beobachtungen höchstens 5 Ladungen auf den Weg; sind aber weniger als $500 \mathrm{~cm}^{3}$ verfügbar, so verwendet der Baumeister allen Sand stets nur zum Sockel- und/oder Spitzenbau.

Da unter natïrlichen Umständen gewöhnlich nicht mehr als $1000 \mathrm{~cm}^{3}$ Baustoff bereit liegen, lassen sich deshalt Neubau und Wiederaufbau am Vorhandensein oder Fehlen einer neuen Wegaufschüttung unterscheiden.

Nie sah ich einen Neubau ohne Weg, auch dann nicht, wenn die Krabbe ihre Spiralhöhle zu einer künstlichen Pyramide baute (S. 408). Selbst wenn sie bei Neubaubeginn ein künstlich aufgeschüttetes Wegchen vorfindet, baut sie doch noch selber eines.

Wie der Sockelbau wirkt auch der Wegbau triebverzehrend. Nie konnte ich diesen auslösen, nachdem die Krabbe schon am Sockel baute. Selbst 100 bis $200 \mathrm{~cm}^{3}$ feuchten in den Anfangsabschnitt gestopften Sand verbraucht sie dann für den Sockel, und ebenso wie beim Sockelbau hemmt das einmal begonnene Wegbauverhalten die Auslösbarkeit der in der Verhaltenskette folgenden Bauschritte.

Die Suche nach den richtenden Reizen beim Neubau eines Wegchens war schwierig, da die beim Neubaubeginn schr störungsempfindlichen Krabben nur zu oft ihren Bauplatz verlassen.

Die Grundrichtung des Weges ist durch den Verlauf der Höhle und damit letztlich durch die Händigkeit festgelegt (S. 420). Die Beobachtung des Wegbauverhaltens (S. 407) hatte gezeigt, daß die Krabben neben der Grundorientierung (die die Richtung des Wegverlaufes bestimmt) noch über eine Nahorientierung 
verfügen müssen, denn sie schleudern die Sandklumpen meistens so weg, daß jeder sich dem vorhergehenden ungefähr anschließt. Um festzustellen, ob die Krabbe das Wegende sieht, ertastet, oder ob sie nur von Mal zu Mal die Austragsweite vergrößert, verlängerte ich in 25 Versuchen den Weg, während sie noch daran baute, jeweils um 5-10 cm. Stets nahm das O" diese "Hilfe“ an und warf seine Sandladung an das künstliche Wegende; bei einer Verlängerung um mehr als $20 \mathrm{~cm}$ tat dies jedoch keines der geprüften 10 Versuchstiere. Die Verlängerung erkannten sie immer, denn sie liefen regelmäßig, die Aufschüttung ausgiebig betastend, bis zum neuen Wegende; ihren herausgeschafften Sand hatten sie aber jeweils schon vorher weggeworfen.

Diese Versuche zeigen, daß richtende Reize, die vom Weg selbst ausgehen, zwar wahrgenommen werden können, aber nur in einem engen Bereich wirksam werden, der durch die ungefähr festgelegte Austragweite bestimmt wird (Zur Reaktion auf einen künstlich aufgeschütteten Weg beim Wiederaufbau vgl. S. 426).

Ob die Austragweite durch die Länge des schon ausgegrabenen Höhlenabschnittes oder durch die Zahl der ausgetragenen Ladungen festgelegt wird, muß noch offen bleiben, da alle 10 am geraden Anfangsabschnitt beschäftigten Neubauer auf ein Verschütten hin den Bauplatz verließen.

\section{Der Ausbau des Eingangs und Vorplatzes}

Der Ausbau des Eingangs schließt normalerweise die Gesamtbauhandlung ab. Im Versuch läßt er sich aber zu jedem Zeitpunkt der Bauphase und unabhängig von anderen Bauverhaltensweisen auslösen, indem man den Eingang teilweise ausbricht, ihn verengt oder feinen, trockenen Sand vor den Eingang schüttet.

Beschädigungen werden ertastet, aber auch gesehen, denn das $\sigma^{7}$ bemerkt auch ein Ausbrechen am Oberrand des immer schräg nach außen mündenden Eingangs. Wollte es den Schaden ertasten, so müßte es sich auf den Rücken legen, was wir hierbei nie beobachten konnten.

Den Baustoff zum Ausbessern des Eingangs beschaffen sich die Krabben ganz im Gegensatz zum Sockel- und Spitzenbau - auf sehr verschiedene Weise: Bei stärkeren Zerstörungen benützen sie Sand aus der Höhle, vom Vorplatz (durch Scharren S. 407) oder tragen ihn aus der Umgebung herbei.

Schäden am seitlichen und unteren Rand des Eingangs beheben sie durch Festklopfen des Sandes mit der großen Schere. Den oberen Rand, den sie nicht unmittelbar erreichen können, bessern sie dadurch aus, daß sie den Unterrand soweit erhöhen, bis der Eingang wieder ungefähr den alten Durchmesser aufweist.

Als ich in einer Versuchsserie unmittelbar am Eingang feinen, trockenen Sand aufschüttete, klopften 41 von 58 Versuchstieren einige Ladungen feuchten Sandes zu einem kleinen Wall am Unterrand des Eingangs fest, so daß beim Ein- und Ausschlïpfen kein Sand mehr in die Höhle fiel.

Wie sich bei allen Versuchen deutlich zeigte, entsteht ein Vorplatz nur dann, wenn feuchter Sand für den Ausbau des Eingangs benötigt wird. Wenn der Eingang ganz unversehrt ist, so stets bei den wenigen Bauten, die in bis zur Oberfläche feuchtem Sand des Spülsaumes liegen, wird kein Vorplatz gebaut. Wenn man diesen einebnet, nachdem die Krabbe ihren Eingang fertig hat, so löst das nie erneutes Ausscharren aus und beunruhigt die Krabben nicht $(n=100$ Versuche). Demnach käme der Vorplatz lediglich als Nebenprodukt einer spezifischen Bauverhaltensweise zustande. Ob es als solches den Krabben 


\section{Tab. 4: Zusammenfassende Darstellung des Pyramidenbauverhaltens in Ägypten}

Wahrscheinliche motivierende Faktoren für das Gesamtbauverhalten sind: 1. Ein bestinmter hormoneller Zustand: Ausschließlich adulte $\delta$ mit vollentwickelten Gonaden bauen Pyramidenanlagen. 2. Außenfaktoren, die vermutlich primär auch den Gonadenzustand beeinflussen. 3. Hormonelle und/oder zentralnervöse Faktoren, die für die Steuerung der immer nur cinige Tage dauernden "Verhaltensphasen" („nicht-aggressive Wander- und Freßphase“, "aggressive Wanderphase“ und "stationäre, aggressive Phase“) verantwortlich sind. Diese motivierenden Faktoren lösen ein Suchen nach passendem Pyramidenbaugelände aus

\begin{tabular}{|c|c|c|c|c|c|c|}
\hline $\begin{array}{l}\text { Verhaltens - } \\
\text { weise }\end{array}$ & Signalreize & richtende Reize & $\begin{array}{l}\text { hemmende Faktoren } \\
\text { bei vorhandenen } \\
\text { Signalreizen und } \\
\text { Baubereitschaft }\end{array}$ & $\begin{array}{l}\text { immer gekoppelt } \\
\text { mit }\end{array}$ & $\begin{array}{l}\text { Reparaturen? } \\
\text { ausgelöst } \\
\text { durch? }\end{array}$ & $\begin{array}{l}\text { verwendetes } \\
\text { Baumaterial }\end{array}$ \\
\hline $\begin{array}{l}\text { Suchen nach } \\
\text { Pyramiden- } \\
\text { baugelände }\end{array}$ & $\begin{array}{l}\text { lockerer Oberflä- } \\
\text { chensand } \\
\text { Pyramiden }\end{array}$ & die Küstenlinie & $?$ & $\begin{array}{l}\text { aggressivem Ver- } \\
\text { halten, Höhlen- } \\
\text { bauplatzsuche }\end{array}$ & - & - \\
\hline \multicolumn{7}{|c|}{$\begin{array}{l}\text { Da in der vorliegenden Arbeit nur ein kleiner Teil der verhaltensweisen der Eindringlinge behandelt } \\
\text { wird, soll hier nicht auf ihr verhalten während der aggressiven Wanderphase eingegangen werden. }\end{array}$} \\
\hline $\begin{array}{l}\text { Möhlenbau - } \\
\text { platzsuche }\end{array}$ & $\begin{array}{l}\text { Vertiefungen best. } \\
\text { Form; lockere } \\
5 \text { andschicht max. } \\
5 \mathrm{~cm} \text { tief }\end{array}$ & $\begin{array}{l}\text { Pyramiden, Spül- } \\
\text { saum (nicht } \\
\text { näher untersucht) }\end{array}$ & $?$ & $\begin{array}{l}\text { Aufsuchen des } \\
\text { Pyramidenbau - } \\
\text { geländes }\end{array}$ & - & - \\
\hline $\begin{array}{l}\text { Ausschach- } \\
\text { ten bzw. } \\
\text { Ausscharren } \\
\text { i) }\end{array}$ & trockener Sand & $\begin{array}{l}\text { Küstenverlauf } \\
\text { (Abb. 9) } \\
\text { Händigkeit } \\
\text { Richtmarken. }\end{array}$ & $\begin{array}{c}\text { beim Ausscharren: } \\
\text { wenig Baumaterial } \\
\text { 1) }\end{array}$ & $\begin{array}{l}\text { neuerliches } \\
\text { Suchverhalten } \\
\text { oder Weg-, } \\
\text { Sockel- und } \\
\text { Spitzenbau }\end{array}$ & - & - \\
\hline Wegbau & $\begin{array}{l}\text { feuchter Sand im } \\
\text { Anfangsabschnitt } \\
\text { der Höhle }\end{array}$ & $\begin{array}{l}\text { Richtmarken, } \\
\text { optische, taktile } \\
\text { Reize des Wegs, } \\
\text { Händigkeit }\end{array}$ & $\begin{array}{l}\text { Newbau: ausgetöste, } \\
\text { in Verhaltenskette } \\
\text { folgende Handlung. } \\
\text { Wiederaufbau: } \\
\text { Weg, Sockel, voll- } \\
\text { ständige Pyramide, } \\
\text { das Verhalten } \\
\text { selbst (5. 21) }\end{array}$ & $\begin{array}{l}\text { Socke! - und } \\
\text { Spitzenbau }\end{array}$ & $\begin{array}{l}\text { schmale } \\
\text { Vertiefungen }\end{array}$ & $\begin{array}{l}\text { Bau: nur aus } \\
\text { geradem An- } \\
\text { fangsabschnitt } \\
\text { der Höhle } \\
\text { Reparatur: wie } \\
\text { Bau, Herbei - } \\
\text { scharren aus } \\
\text { Umgebung }\end{array}$ \\
\hline Sockelbau & $\begin{array}{l}\text { feuchter Sand im } \\
\text { Knick, Weg, je } \\
\text { nach Bausandmenge } \\
\text { verschieden hoher } \\
\text { Sockel (Tab. 3), } \\
\text { fehlende Pyramide }\end{array}$ & $\begin{array}{l}\text { Wegende, rich- } \\
\text { tende Erhöhung } \\
\text { in von Händigkeit } \\
\text { bestimmtem Win- } \\
\text { kel-und Ent - } \\
\text { fernungsbereich }\end{array}$ & $\begin{array}{l}\text { ausgetöste vorher- } \\
\text { gehende oder nach- } \\
\text { folgende Bauhand- } \\
\text { lung, Sockel oder } \\
\text { Pyramide bei Wie- } \\
\text { deraufbau, starker } \\
\text { Baustoffmangel. } \\
\text { das Verhalten } \\
\text { selbst. }\end{array}$ & Spitzenbau & $\begin{array}{l}\text { wie bei } \\
\text { Wegbau }\end{array}$ & $\begin{array}{l}\text { beim Bau: nur } \\
\text { Sand aus der } \\
\text { Spirathöhle, } \\
\text { Reparatur: } \\
\text { wie bei Weg }\end{array}$ \\
\hline Spitzenbau & $\begin{array}{l}\text { feuchter Sand im } \\
\text { Knick oder End- } \\
\text { stück, Sockel, bei } \\
\text { sehr geringer Bau- } \\
\text { materialmenge: } \\
\text { tehlende Pyramide } \\
\text { (Tab. 3) }\end{array}$ & wie beim Sockel & $\begin{array}{l}\text { ausgelöster Weg- } \\
\text { oder Sockelbau }\end{array}$ & $\begin{array}{l}\text { nicht notwendis } \\
\text { mit anderer Bau- } \\
\text { verhaltensweise } \\
\text { gekoppeit. }\end{array}$ & - & $\begin{array}{l}\text { nur Sand aus } \\
\text { Spiralhöhle }\end{array}$ \\
\hline Planieren & \multicolumn{6}{|c|}{$\begin{array}{l}\text { soli hier nicht aufgefihrt werden, da diese verhaltensweise in der vorliegenden Arbeit nur am Rande } \\
\text { erwähnt wird. }\end{array}$} \\
\hline $\begin{array}{l}\text { Ausbau des } \\
\text { Eingangs } u \text {. } \\
\text { vorplatzes }\end{array}$ & $\begin{array}{l}\text { Beschädigungen am } \\
\text { Eingang } \\
\text { vertiefung des ge- } \\
\text { samten vorplatzes } \\
\text { oder Teile davon }\end{array}$ & $=$ auslös. Reize & - & $\begin{array}{l}\text { kann isoliert auf- } \\
\text { treten (Planieren } \\
\text { ist eine Kompo- } \\
\text { nente des Ver- } \\
\text { haltens) }\end{array}$ & \begin{tabular}{|l|} 
Verengen. \\
Erweitern u. \\
Verändern \\
der Form \\
des Ein- \\
gangs \\
s. Signal- \\
reize
\end{tabular} & $\begin{array}{l}\text { aus Hohle, aus } \\
\text { Umgebung durch } \\
\text { Herbeischarren } \\
\text { bzw. Herbei- } \\
\text { tragen }\end{array}$ \\
\hline
\end{tabular}

1) Spiralhöhlenbesitzer, denen soviel Baustoff zur Verfügung steht, daß der Knick und das Endstück damit weitgehend angefüllt sind, scharren trockenen Sand, den man ihnen zu Beginn des Wiederaufbaus in die Höhle schüttet, nicht mehr nach unten. Dieser trockene Sand lïst ein Ausschachten, das man hier besser als "Ausscharren“ bezeichnet, aus. (In einigen wenigen Fällen konnte beobachtet werden, daß der auf diese Weise ausgescharrte Sand - wie mit einem Rechen - bis zur Pyramide befördert wurde.) 
Vorteile bietet, z. B. im Zusammenhang mit der Stellung "unter der Haustüre“ (S. 426), sei dahingestellt. Sicher dagegen folgt aus den Einebnungsversuchen, daß das Fehlen des Vorplatzes keinen Signalreiz für ein bestimmtes Bauverhalten liefert.

Ein Bauen am Vorplatz, das nichts mit Materialgewinn zu tun hat, läßt sich durch Vertiefen des gesamten Vorplatzes auslösen und zwar optisch: Alle Versuchstiere, denen man, z. B. während sie an der Pyramide bauen, den Vorplatz vertieft, so daß sie nicht mehr in üblicher Weise ,unter der Haustüre sitzend" die Umgebung überschauen können, erhöhen den Vorplatz sogleich. Schon bei einer Tiefe von $2,5 \mathrm{~cm}$, die auch natürlich oft erreicht wird, werfen sie hin und wieder eine Ladung auf ihren Vorplatz und planieren sie fest. Auch kleine Vertiefungen, die die Krabben ausschließlich ertasten, füllen sie mit Baustoff aus, den sie aus der Höhle oder deren Umgebung herbeitragen oder -scharren und meist noch festplanieren.

Eine tabellarische Zusammenfassung der Ergebnisse aus der vorwiegend experimentellen Analyse des Pyramidenbauverhaltens wird in Tab. 4 gegeben.

\section{d) Die Lagebeziehung der Pyramide zur Höhle}

Jedes $\sigma^{7}$ baut unter natürlichen Umständen nur an seiner eigenen Pyramide. Falls man sie ganz entfernt, errichtet es die neue genau oder fast genau an derselben Stelle.

Die Lagebeziehung der Pyramide zur Höhle ist vorbestimmt. $O^{\prime \prime} O^{\prime \prime} \mathrm{mit}$ linker kleiner Schere (Linkshänder) bauen im Uhrzeigersinn gewundene, also rechtsspiralige Höhlen, solche mit kleiner Schere rechts (Rechtshänder) linksgewundene (Abb. 8). Rechts- und Linkshänder sind in der untersuchten Population gleich häufig.

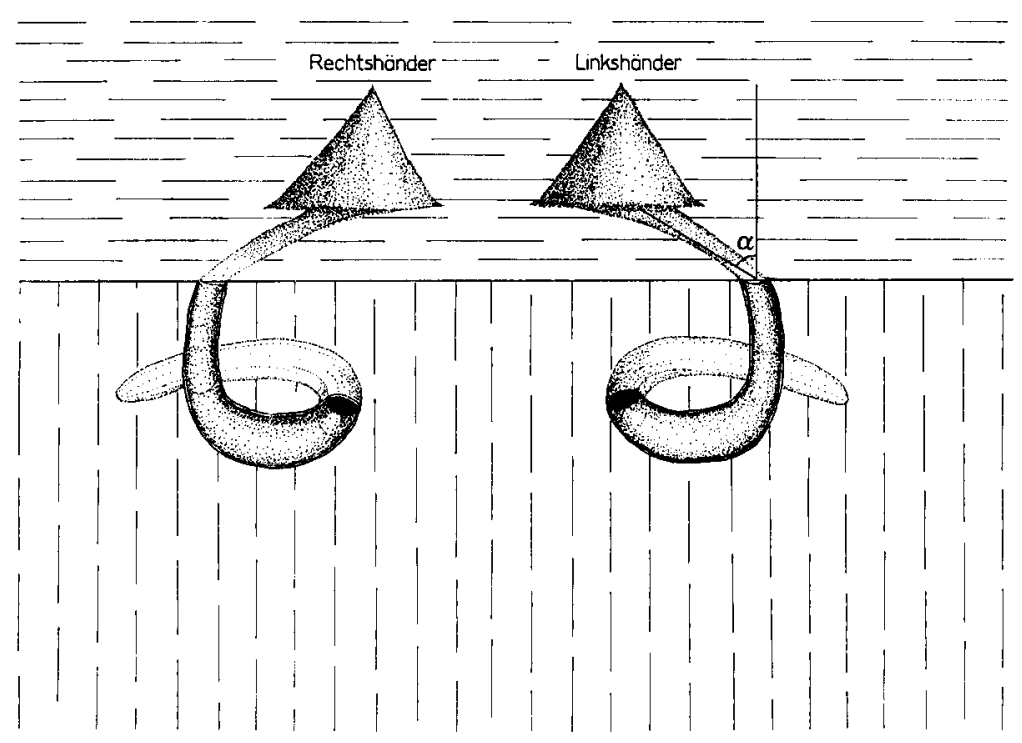

Abl. 8: Beziehungen zwischen der Händigkeit, dem Drehsinn der Spiralhöhle und der Layge der Pyramide: sie liegt immer auf der - auf die Oberfläche projizierten - Verlängerung der Höhlenspirale ( $\alpha=$ Winkel zur Nullinie, S. 23) 
Die Pyramide liegt immer ungefähr in der auf die Oberfläche projizierten Verlängerung der Höblenspiralc, also bei einer linksgewundenen rechts vom Eingang, bei einer rechtsgewundenen links vom Eingang. Die Richtung, in die sich die Spiralhöhlen öffnen, hängt vom Küstenverlauf $a b$ : Sie öffnen sich bevorzugt ungefähr zum Meer (Abb. 9) (vgl. MaGNus).

Ab6. 9: Die Offnungsrichtung $\left(0^{\circ}=\right.$ Norden $)$ der Spiralhöhlen bei zweierlei Küstenverlauf (Pfeil). Punkte gehören zum N-S-, Kreise zum NNO-ONO-Verlauf
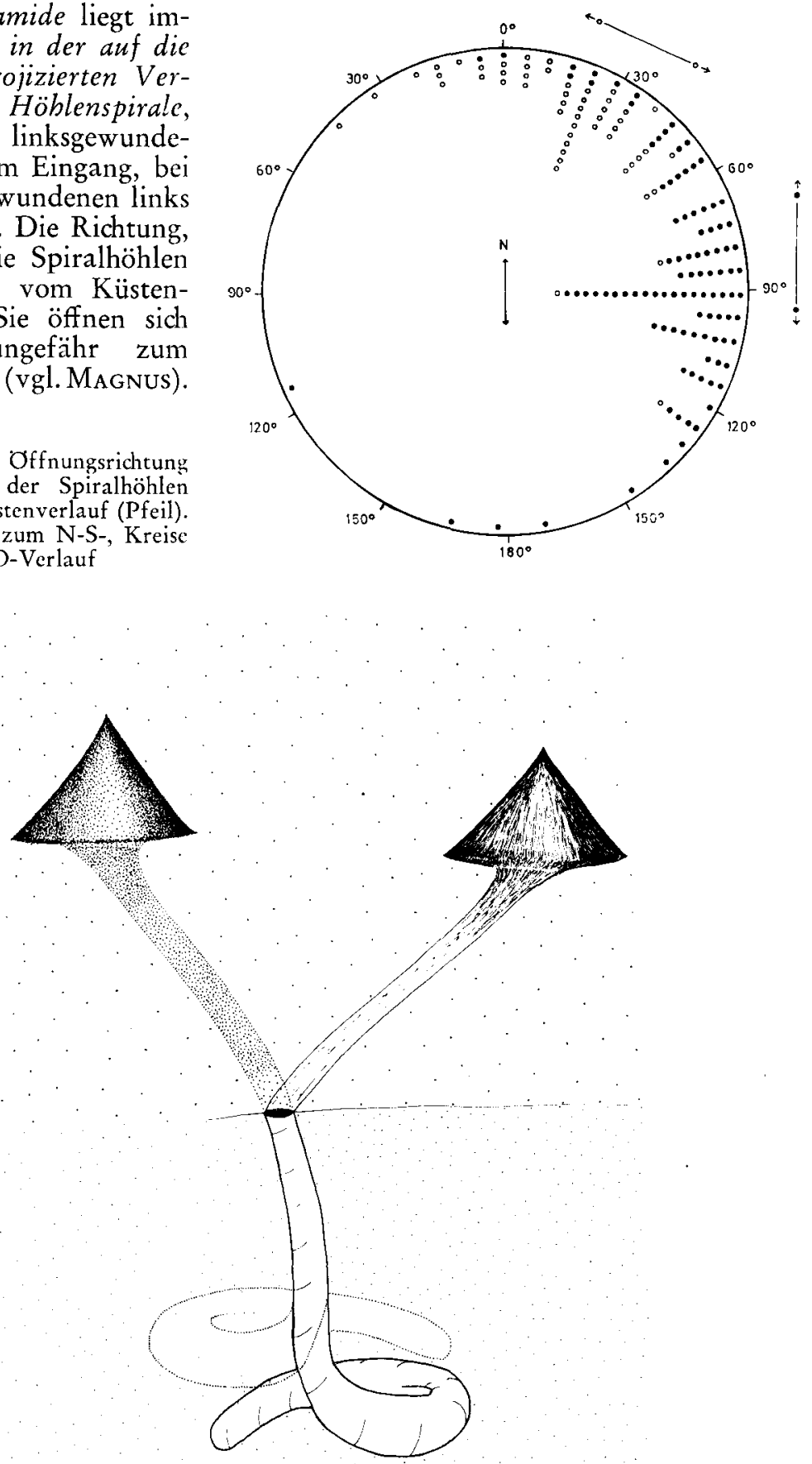

Abb. 10: Von cinem Eroberer mit anderer Händigkeit umgebaute Spiralhöhle. Der ursprüngliche Pyramidenbau punktiert, der neue schraffiert. Den Knick der alten Höhle verstopft der Eroberer frühestens in der zweiten Bauphase 


\section{Spiralböblen mit zwei Pyramiden}

Hin und wieder findet man Spiralhöhlen mit zwei zugehörigen Pyramiden (Abb. 10), sieht den Besitzer aber ausschließlich oder doch vorwiegend nur an einer der beiden bauen. Zerstört man sie beide und gibt ihm Sand, so baut er nur eine wieder auf, und zwar die mit derselben Lagebeziehung zur Höhle, wie die zuvor bevorzugte sie hatte. Beim Aufgraben der Höhle findet man immer nur eine Krabbe und zwar in dem Gang, in dem man sie entsprechend der Bevorzugung der einen Pyramide erwarten mußte. Das weist auf einen Besitzwechsel zwischen zwei ver $s c h$ iedenscherigen $\sigma^{7} \sigma^{7}$ hin. Mehr als 20 unmittelbare Beobachtungen bestätigten diese Deutung. Der Eindringling, der eine Höhle erobert, die nicht seiner Händigkeit entspricht, baut diese immer sofort um: Er benutzt das annähernd gerade Anfangsstück, gräbt aber an dessen Ende einen Knick und ein Endstück, deren Drehsinn dem der vorhandenen Höhlenabschnitte entgegengerichtet ist.

Auch durch noch so häufige Sandgaben und durch Vergrößern der Pyramide kann man den Besitzer nicht veranlassen, eine zweite Pyramide zu bauen, solange die Lagebeziehung der ersten zur Höhle stimmt (s. u.).

\section{Versetzen der Pyramide}

Nachdem Versuche und Beobachtungen gezeigt hatten, daß Veränderungen in der optischen Umgebung (durch Sandsturm, Überschwemmungen, künstliches Einebnen, Verlagerung möglicher, bereits vorhandener oder künstlicher Orientierungsmarken) keinen Einfluß auf die Orientierung zur Pyramide haben, galt es als nächstes, die Bedeutung der Lagebeziehung zwischen Pyramide und Spiralhöhle (S. 420) in diesem Zusammenhang zu untersuchen. Dazu versetzten wir die Pyramiden jeweils vor Beginn des Wiederaufbaus bei gleichbleibender Entfernung um bestimmte Winkelbeträge mit oder entgegen dem Drehsinn der Höhle (Tab. 5).

T'ab. 5: Prozentsatz der Versuchstiere, die eine um einen bestimmten Winkelbetrag im Drehsinn der Spiralhöhle ("mit“) und ihm entgegengesetzt („entgegen“) aus ihrer alten Richtung verschobene Pyramide noch annehmen, d.h. an ihr weiterbauen; jeweils $n=30$

Tab. 6: Prozentsatz $(\%+)$ der Versuchstiere, die eine Pyramide in einer bestimmten, nur auf die Nullinie bezogenen Lage (Abb. 11) annehmen. Die ursprüngliche, individuell verschiedene Lage der verschobenen Pyramide bleibt unberücksichtigt. $(n=$ je 30$)$

\begin{tabular}{|c|c|c|}
\hline entgegen $\%$ & Winke. ${ }^{\circ}$ & mit $\%$ \\
\hline 100 & 10 & 100 \\
\hline 100 & 20 & 100 \\
\hline 87 & 30 & 90 \\
\hline 97 & 40 & 67 \\
\hline 90 & 50 & 36 \\
\hline 23 & 60 & 27 \\
\hline 17 & 70 & 20 \\
\hline 13 & 80 & 20 \\
\hline 0 & 90 & 0 \\
\hline 0 & 100 & 0 \\
\hline 0 & 110 & 0 \\
\hline 0 & 120 & 0 \\
\hline
\end{tabular}

\begin{tabular}{|c|c|c|c|}
\hline Winkel & $\%+$ & Winkel & $\%+$ \\
\hline-30 & 0 & +50 & 100 \\
\hline-20 & 0 & +60 & 100 \\
\hline-15 & 7 & +70 & 100 \\
\hline-10 & 20 & +80 & 77 \\
\hline 0 & 87 & +90 & 47 \\
\hline+10 & 97 & +100 & 7 \\
\hline+20 & 100 & +110 & 0 \\
\hline+30 & 100 & +120 & 0 \\
\hline+40 & 100 & +130 & 0 \\
\hline
\end{tabular}

Tab.5 (links)

Tal. 6 (rechts)

Danach gibt es einen Winkelbereich, bezogen auf den Höhleneingang und die Nullinie, d. i. eine Verlängerung des geraden Anfangsabschnitts der Höhle 
(Abb. 11), in dem sich alle Pyramiden - unabhängig von ihrer ursprünglichen Lage - verschieben lassen (Tab. 6).

Abb. 11: Lagebeziehung der Pyramide zur Spiralhöhle (Rechtshänder). $\mathrm{H}=$ Höhleneingang, $\mathrm{V}=$ Vorzugslage der Pyramiden in Agypten. Zwischen den Teilkreisen 1 und 2 lassen sich im Winkelbereich $c$ alle Pyramiden verschieben; in $b+c+b$ findet man unter natürlichen Umständen Pyramiden; a $=$ die - jeweils mit oder entgegen der Drehrichtung - im Versuch erreichbare maximale Verschiebbarkeit. Zwischen den Kreisen 1 und 2 lassen sich alle Pyramiden, ohne abgelehnt $z u$ werden, in der Entfernung verschieben, hier entscheidet nur die Richtung der Pyramide über Ablehnung oder Annahme. Bis zum Kreis 3 nehmen noch $50 \%$ der Versuchstiere, jenseits von 4 keines mehr eine Pyramide an, deren Mittelpunkt auf dicsem Kreissektor liegt (nur noch im Winkelbereich $c$

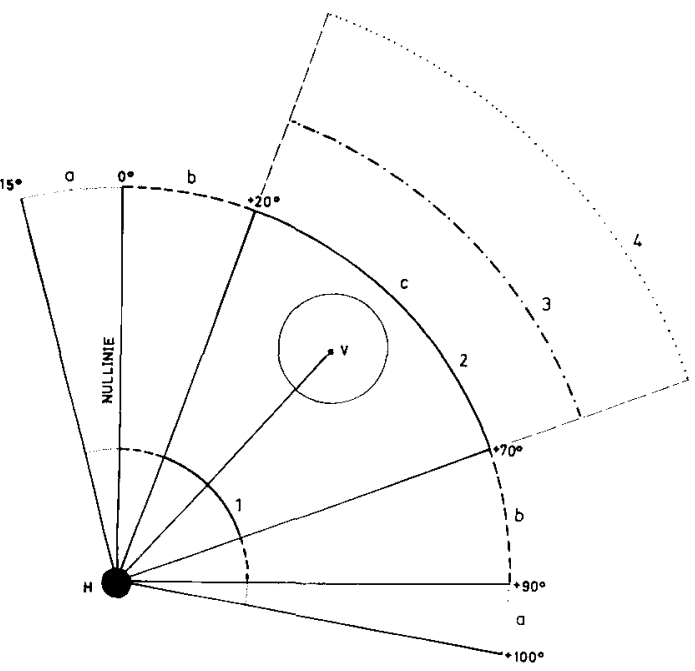
untersucht)

Unter natürlichen Bedingungen gebaute Pyramiden können in einem Winkelbereich von $0-90^{\circ}$ (bezogen auf die Nullinie) liegen $\left(\mathrm{M}=43 \pm 13,5^{\circ}\right.$, $n=100)$. Da Rechts- und Linkshänder hier gleich häufig sind, erhält man beim Ausmessen der Pyramidenrichtungswinkel - bezogen auf die Nullinie - eine gleichmäßige Rechts-Linksverteilung (Abb. 12). Im Versuch lassen sich diese Grenzen nur jeweils um 15 bzw. $10^{\circ}$ (auf -15 und $+100^{\circ}$ ) verschieben. Pyramidenbauten, die nicht zwischen +30 und $+60^{\circ}$ liegen, verdanken ihren Standort Richtmarken, kleinen, schon vor Baubeginn vorhandenen Erhöhungen, wie durch unmittelbare Beobachtung und Versuche bewiesen werden konnte.

Abb. 12: Infolge der 1:1 Verteilung der Rechts-Linkshändigkeit erhält man in jeder Population eine zweiseitige Verteilung der Pyramiden auf dic Nullinic bezogen $\left(M=43 \pm 13,6^{\circ}\right)$. Drehsinn und Händiskeit wurden in jedem Fall durch $\Lambda$ usgraben ïberprüft

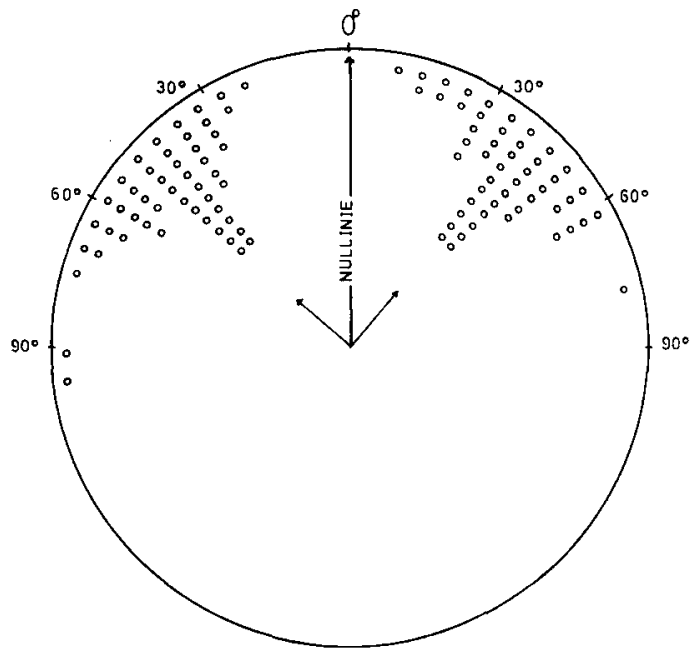

In homogener Umgebung genügen schon günstig gelegene, $1-2 \mathrm{~cm}$ hohe Erhebungen von $3-4 \mathrm{~cm} \phi$, um nach Entfernen der alten Pyramide immer zum Wiederaufbau an dieser Stelle zu führen. 
Die verfügbare Baustoffmenge, die die Krabbe recht genau abschätzt (S. 416), übt keinen Einfluß auf die Ablehnung oder Annahme einer versetzten Pyramide aus.

\section{Wablversuche mit zwei Pyramiden}

Den bisherigen Versuchen zufolge ist der Winkelbereich, in dem eine Pyramide liegen kann, für alle Krabben gleicher Händigkeit derselbe. Wir fragen weiter, wie die Krabbe nach dem Bau ihrer Höhlenspirale zwischen zwei Pyramiden - der alten und einer neuen, bzw. zwei neuen - wählen wird, die innerhalb des annehmbaren Winkelbereiches von -15 bis $+100^{\circ}$ liegen.

Als positive Reaktion (= Annahme der Pyramide) galten a) das Bauen an einer Pyramide und b) ihr Planieren.

$\mathrm{Zu} \mathrm{b}$ ): Wie unmittelbare Beobachtungen und die Art des Austragens lehrten, entscheiden sich etwa $15 \%$ der Versuchstiere, die in den äußeren Grenzbereichen noch positiv reagieren, erst nach längerem Schwanken. Solche $O^{7} \sigma^{7}$ tragen die erste Portion zum alten Platz, die nächste ein Stückchen näher zur künstlichen Pyramide, die nächste wieder näher usw., bis sie dann an der Pyramide selbst bauen (Abb. 13). Bei geringem Baustoffvorrat kann es natïlich ge-

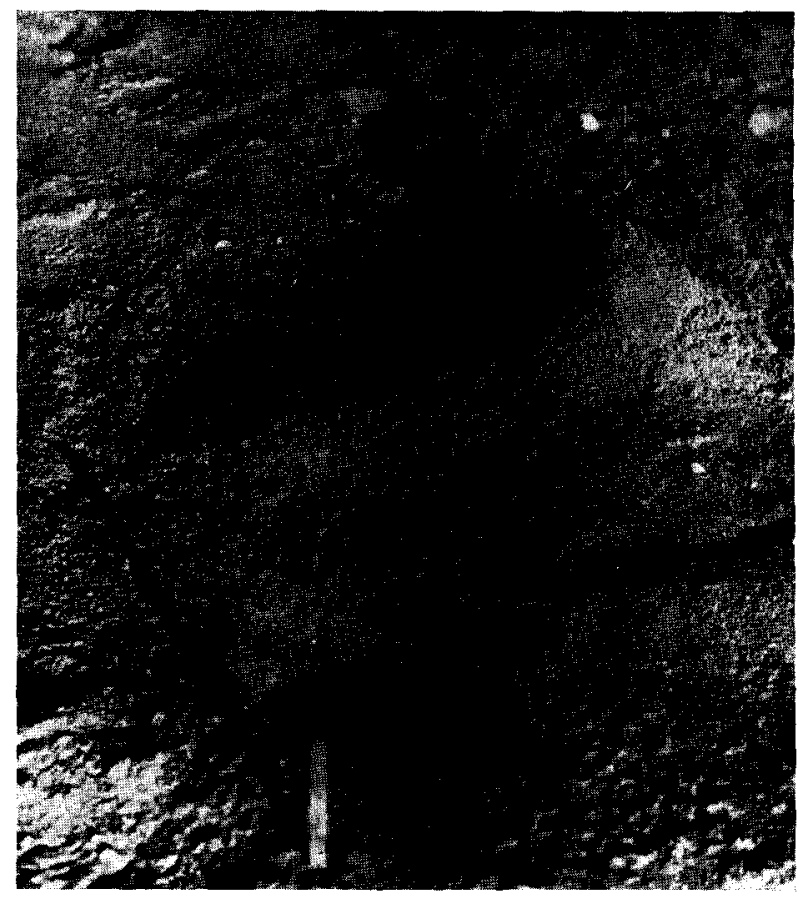

Abb. 13: Reaktionsweise einiger Versuchstiere auf sehr starkes Richtungsversetzen der Pyramide. Die ersten Ladungen werden am alten Pyramidenstandort abgesetzt (mittlerer Pfeil), die folgenden immer näher an der verschobenen Pyramide (rechter Pfeil), bis schließlich an dieser selbst gebaut wird. Der Vorplatz, links vom Eingang, ist deutlich zu erkennen. Der linke Pfeil zeigt den Verlauf der Nullinie an. (Licht kommt von rechts unten:)

schehen, daß ihnen dieser "unterwegs“ ausgeht, sie können dann nur noch planieren.

Faßt man die Ergebnisse der Versetzungsversuche zusammen, so erhält man folgende Gruppen $(n=70)$ :

1. 43 Höhlenbesitzer nehmen die der Nullinie nähere Pyramide an.

2. 10 wählen die weiter seitlich liegende. 
3. 12 bauen zwischen die Kunstpyramiden ihre eigene, zwischendurch aber auch meist etwas an den beiden von uns angelegten.

4. 5 bauen scheinbar gleich stark an beiden Pyramiden, aber in Wirklichkeit entscheiden sie sich nach anfänglicher Unsicherheit dann doch klar für eine von ihnen.

$\mathrm{Zu}$ 2: In 8 der 10 Fälle, in denen die $0^{\pi} O^{\pi}$ an der weiter seitlich der Nulllinie liegenden Pyramide bauten, lag die zweite Pyramide entweder auf der Nullinie oder im Minusbereich (Abb. 11).

$\mathrm{Zu}$ 3: Ein neuer Bau zwischen den beiden innerhalb des Annahmebereichs liegenden Pyramiden wurde nur dann errichtet, wenn die beiden zur Auswahl gestellten Pyramiden mit dem Eingang keinen größeren Winkel als $20-30^{\circ}$ bildeten.

Die Ergebnisse dieser Wahlversuche zwischen zwei Kunstpyramiden beantworten folgende drei Fragen:

1. Ob die Lage der vom Besitzer gebauten Pyramide die Wahl beeinflußt. Die Antwort lautet: nein.

2. Ob die Krabbe dieselben Winkelbereiche wie beim Neubau bevorzugt. Im Gegensatz zur Vorzugsrichtung von $43^{\circ}$, in der die Pyramiden unter natürlichen Umständen gebaut werden, liegt in den Versuchen mit zwei künstlichen Pyramiden die Vorzugsrichtung einer anzunehmenden bei etwa $10^{\circ}$. Von 25 $0^{\prime \prime} \sigma^{\prime \prime}$, die sich zwischen einer Pyramide bei $10^{\circ}$ und einer bei +30 bis $100^{\circ}$ oder von -10 bis $-20^{\circ}$ entscheiden mußten, wählten 22 die bei $10^{\circ}, 2$ diejenige bei $-10^{\circ}$ und nur eines seine alte Pyramide bei $40^{\circ}$. (Zur Erklärung der Tatsache, daß Bauvorzugsrichtung und bevorzugte Annahmerichtung nicht zusammenfallen, vgl. S. 446).

Weiterhin boten wir in einem Winkelbereich von -20 bis $+120^{\circ}$ einen $15 \mathrm{~cm}$ hohen Ringwall in einer dem mittleren Pyramidenabstand entsprechenden Entfernung $(50 \mathrm{~cm})$ von der Höhle. Die Versuchstiere entschieden sich immer erstaunlich schnell und genau für eine bestimmte Stelle am Ringwall. Von $21 \sigma^{\top} \sigma^{7}$ bauten nur 2 in einem Bereich von 10 und eines von $15^{\circ}$. Die neuen Baustellen lagen im Mittel bei $38 \pm 12^{\circ}$; die alten Pyramiden zeigten denselben mittleren Vorzugswinkel, aber eine signifikant $(p=0,01)$ höhere Streuung von $\pm 21^{\circ}$. Dieser Versuch verdeutlicht, daß gleichförmige Strukturen im entscheidenden Bereich wie fehlende wirken.

3. Von welcher Stellung aus und wann wird eine Pyramide als die eigene erkannt?

Bei allen Wahlen zwischen Kunstpyramiden trafen die Versuchstiere eine klare Entscheidung: Entweder nahmen sie eine der Pyramiden an oder bewiesen durch Ablehnung der ihnen gebotenen und Bau einer eigenen, daß sie keine fremde als eigene anerkennen.

Normalerweise laufen die Besitzer vom Eingang aus gerichtet auf eine der beiden Pyramiden zu; erst beim Näherkommen, manchmal noch direkt am Fuß der einen kann es vorkommen, daß sie inne halten und dann zur zweiten gehen. Nicht allzu selten sieht man $\sigma^{\prime} \sigma^{\prime \prime}$, die sich beim Austragen nie geirrt haben, während des Planierens und der Orientierungsgänge auch einmal die falsche Pyramide anlaufen oder beklopfen. In diesen Fällen waren sie dann immer aus einer anderen Richtung als gewöhnlich auf die Pyramide zugelaufen.

Diese Irrtümer sprachen dafür, daß den Krabben die Entscheidung für eine von zwei Pyramiden vom Eingang aus leichter fällt als in ihrer unmittelbaren Nähe. 
Die Pyramidenbauer verharren bei jedem Auftauchen einen Augenblick „unter der Haustüre“; die Pereiopoden der Kleinen-Scheren-Seite befinden sich dabei noch in der Höhle, die Augen können die Umgebung überblicken (Abb. 14). Um zu prüfen, ob sich das Tier jetzt und hier entscheidet, verlegten wir

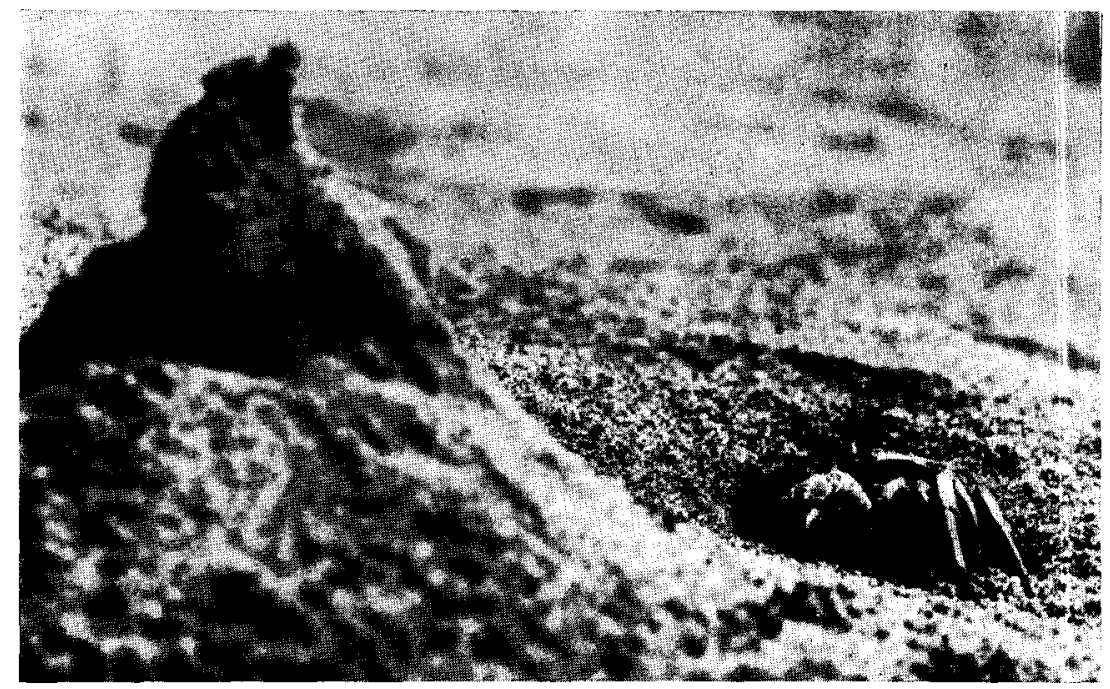

Abb. 14: Das gerade „aufgetauchte“ ô einen Augenblick „unter der Haustüre" verharrend

vor, während oder nach dem Bauen den immer schräg nach außen mündenden Eingang so, daß er sich in eine andere Himmelsrichtung öffnete.

Daß die Krabbe den Eingriff sofort bemerkt, erkennt man an ihrem besonders langen Verharren am Eingang in der Stellung "unter der Haustüre“, oft auch an ihrem häufig wiederholten Zurückkriechen. Die Versuchstiere verhalten sich nach einem Verlegen der Offnungsrichtung der Höhle immer genau so, wie bei einer entsprechenden Verschiebung der Pyramide (S. 422 ff). Diese Tatsache beweist, daß die Reiterkrabben bei der optischen Orientierung zur eigenen Pyramide nicht photomenotaktisch oder mit Hilfe von Landmarken (vgl. S. 422) laufen. Deshalb ist der Schluß berechtigt, daß der Pyramidenbesitzer nur eine Pyramide als eigene anerkennt, die bei einer bestimmten Stellung am Höbleneingang in einem bestimmten Sektor seines Sebbereiches liegt.

\section{Die Weglänge}

Der Abstand zwischen Spiralhöhleneingang und Pyramidenmittelpunkt ( = Weglänge) beträgt beim Neubau im Mittel $52 \pm 11 \mathrm{~cm}(\mathrm{n}=250)$. Unter natürlichen Umständen variiert sie erstens in Abhängigkeit von der verfügbaren Materialmenge, die ihrerseits von der Länge des geraden Anfangsabschnitts bestimmt wird; diese wechselt je nach der Tiefe, in der nasser Sand gefunden wird (S. 407). Z Zweitens beginnen die $O^{7} O^{\pi}$ mit der Wegaufschüttung in von 5 bis $30 \mathrm{~cm}$ wechselnder Entfernung von dem Höhleneingang, und drittens verkürzt heftiger Wind die Weglänge. 35 bei einem Wind von $9-10 \mathrm{~m}$ / Sek. angelegte Neubauten hatten im Mittel halbsolange Wege $(26 \pm 5 \mathrm{~cm})$ wic sonst üblich. Beide Mittelwerte sind mit $\mathrm{p}=0,001$ gegeneinander gesichert. Dabei war aber die ausgetragene Menge nicht geringer, sondern die Krabben begannen mit dem Aufschütten immer sogleich am Eingang und liefen zudem nicht mit jeder Ladung ein Stückchen weiter, da sie der aufgewirbelte Sand sehr störte, und sie versuchten, so schnell wie möglich wieder in die schützende 
Höhle zu gelangen. (Bei derartigen Windgeschwindigkeiten bauen die Krabben nur, wenn sich ein Sandsturm auch am Abend nicht legt.)

Vergrößert man die Weglänge zu Beginn des Wiederaufbaus um bestimmte Beträge, so erhält man die in Tab. 7 zusammengefaßten Werte: Je länger der Weg, um so seltener wird die Pyramide an seinem Ende angenommen; doch ist nicht ersichtlich, welche Rolle die absolute Länge des Weges spielt. Bei Nachprüfung und Wiederholung der Versuche (Tab. 8) auf diese Fragestellung hin ergab sich, daß es auch bei der Weglänge einen für alle Pyramidenbesitzer annehmbaren Bereich gibt $(20-65 \mathrm{~cm})$, unabhängig von der urTab.7: Prozentsatz. $(\%+)$ der, die eine Verlängerung ihres Wegs um bestimmte Beträge dulden; $\mathrm{n}$ je $=40$

7 a ab. 8: Prozentsatz $(\%+)$ der, die eine Pyramide in einer bestimmten Entfernung annehmen.

Die individucll verschiedene ursprüngliche Entfernung wurde außer Acht gelassen

\begin{tabular}{|c|c|}
\hline $\begin{array}{c}\text { Wegvertängerung in } \\
\mathrm{cm}\end{array}$ & $\%+$ \\
\hline 10 & 100 \\
\hline 20 & 95 \\
\hline 30 & 50 \\
\hline 40 & 25 \\
\hline 50 & 5 \\
\hline 60 & 0 \\
\hline
\end{tabular}

Tab. 7

\begin{tabular}{|c|c|c|}
\hline $\begin{array}{c}\text { Pyramidenentfernung vom Eingang in } \\
\mathrm{cm}\end{array}$ & $\%+$ & $n$ \\
\hline $20-65$ & 100 & 30 \\
\hline 75 bzw. 5 & 60 & 30 \\
\hline 85 & 47 & 20 \\
\hline 90 & 20 & 25 \\
\hline 100 & 7 & 25 \\
\hline 110 und mehr & 0 & 25 \\
\hline
\end{tabular}

Tab. 8

sprünglichen individuell verschiedenen Weglänge. Mit anderen Worten: Die Wahrscheinlichkeit, mit der eine bestimmte Wegverlängerung "gebilligt" wird, hängt nur von der absoluten und nicht von der relativen, individuell verschiedenen ursprünglichen Länge $a b$. In den Grenzbereichen führt oft schon eine Verschiebung um nur wenige $\mathrm{cm}$ zu einer Ablehnung. Dieselbe Wirkung wie bei einer Wegverlängerung kann man auch durch künstliche Rückverlegung des Eingangs erzielen (Abb. 15).

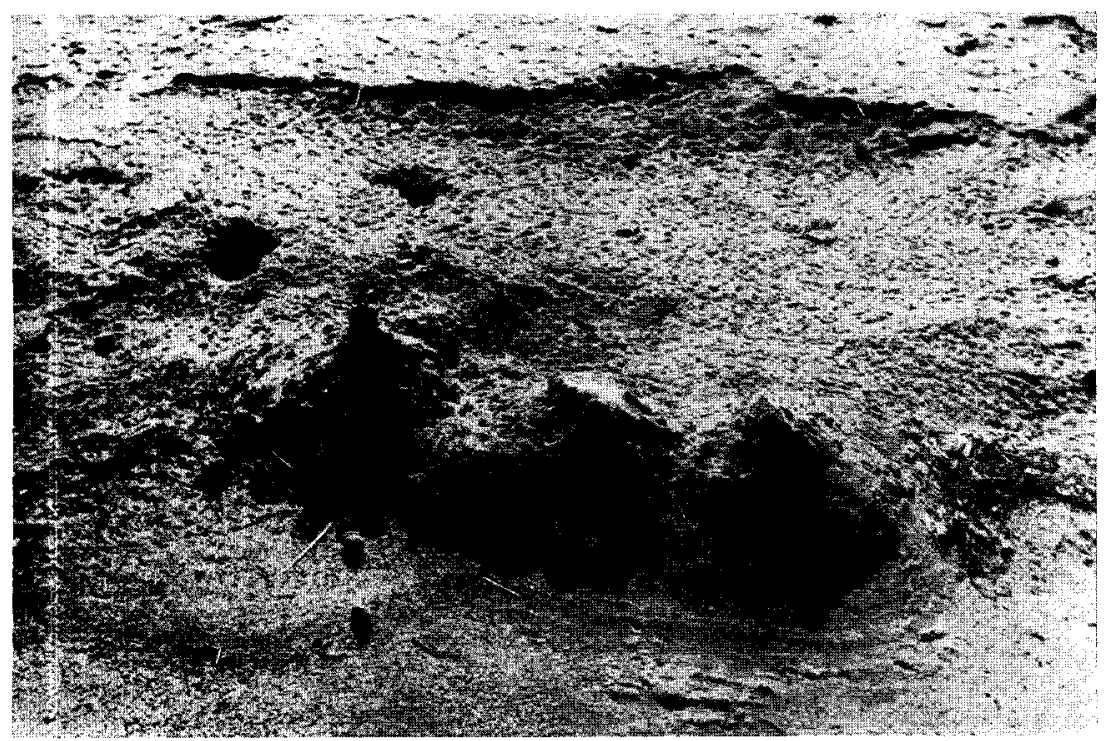

Abb. 15: Pyramidenneubau als Reaktion aııf zweimal wiederholtes Zurückverlegen des Höhlencingangs. Dic rechte der drei Pyramiden ist die ursprüngliche 
Ein Einfluß der Wegaufschüttung auf die Bereitschaft, eine verzogene Pyramide anzunehmen, war nicht feststellbar.

In weiteren Versuchen schütteten wir vor Beginn des turnusmäßigen Wiederaufbaus verschieden lange Wegchen auf und entfernten etwa vorhandene alte Pyramidenreste vollständig. Bis zu einer Weglänge von $55 \mathrm{~cm}$ bauten 14 von 15 Versuchstieren ihre Pyramiden am Wegende, bei einer Verlängerung auf $75 \mathrm{~cm}$ immer noch 12 von 15. Eines errichtete seine Pyramide sogar am Ende eines $95 \mathrm{~cm}$ langen Weges (vgl. dagegen die Ergebnisse beim Wegneubau S. 418).

Demnach wirkt der Weg bei fehlender Pyramide stark richtend, allerdings nur bei richtiger Lagebeziehung zur Höhle (S. 420).

Beim Wiederaufbau einer Pyramide wird nur sehr selten der ebenfalls zerstörte Weg neu angelegt (S. 417). Die mittlere Weglänge bei 63 Neubauten unterschied sich von der bei ebensovielen, unter denselben Bedingungen entstandenen weglosen Wiederaufbauten nur wenig. Die Differenz beider Werte, nämlich $47,5 \pm 12 \mathrm{~cm}$ bei den Neubauten und $42,2 \pm 16 \mathrm{~cm}$ bei weglosem Wiederaufbau, ist statistisch nicht signifikant. Hieraus und aus den Versuchen, in welchen die Krabben eine Wegverlängerung zwar erkannten, aber nicht annahmen, ergab sich, daß sie Entfernungen auch unabhängig vom Wegbau schätzen können, und zwar, wie unsere Beobachtungen in Massawa (S. 445) zeigten, auch ohne Hilfe des Gesichtssinnes.

Da aber die tagaktiven ägyptischen Reiterkrabben in allen Versetzungsversuchen sowohl Veränderungen der Entfernung als auch des Pyramidenwinkels vom Eingang aus bemerkten, lag die Vermutung nahe, daß die Entfernung vom Eingang aus optisch geschätzt werden kann. Zur Prüfung auf echtes Entfernungssehen bauten wir 20 Versuchstieren anstatt ihrer eigenen etwa $50 \pm 5 \mathrm{~cm}$ entfernten Pyramiden $1 \mathrm{~m}$ vom Höhleneingang auf $40 \times 70 \mathrm{~cm}$ vergrößerte Pyramiden auf, die die Krabben vom Eingang aus unter demselben Gesichtswinkel sehen müssen wie ihre eigene in $40 \mathrm{~cm}$ Abstand. Während Pyramiden in $40 \mathrm{~cm}$ Entfernung vom Eingang unabhängig von ihrer ursprünglichen Lage ausnahmslos angenommen wurden (d.h. die Krabben bauten an den versetzten Pyramiden weiter), blieben alle vergrößerten und auf $1 \mathrm{~m}$ versetzten Pyramiden unbeachtet. Sämtliche Versuchstiere waren schon beim ersten Anblick der versetzten, vergrößerten Pyramide sehr beunruhigt und schleuderten den mitgebrachten Sand bereits am Eingang weg. Keines der Versuchstiere ist mit oder ohne Baustoff zuerst zur versetzten Pyramide gelaufen, wonach es auf Grund der zurückgelegten Wegstrecke die Entfernung hätte beurteilen können. Vielmehr fiel die Entscheidung immer schon am Eingang der Spiralhöhle (vgl. auch S. 426).

Auch im Entfernungsbereich von $65-100 \mathrm{~cm}$ gelang es nicht, den Prozentsatz der Versuchstiere, die eine derartig weit verschobene Pyramide noch annehmen, durch Vergrößern der Pyramide zu erhöhen.

Alle Versuchstiere duldeten Verschiebungen ihrer Pyramiden von 20 auf $65 \mathrm{~cm}$ in 10-cm-Schritten, ohne ihr Austragen längere Zeit zu unterbrechen. Verschiebt man die Pyramide aber um weitere $10 \mathrm{~cm}$, so baut schon die Hälfte der Versuchstiere nicht mehr weiter und zeigt die bekannten Zeichen der Unruhe (S. 415); eine Verschiebung um $25 \mathrm{~cm}$ auf 90 beunruhigt alle Krabben. Bevor der kritische Wert von $100 \mathrm{~cm}$ nicht überschritten ist, entschließt sich immerhin ein bestimmter Prozentsatz zum Weiterbauen. Die übrigen errichten ihre eigene Pyramide neu und erheblich näher am Eingang, ohne in der Regel auch nur ein einziges Mal zur verschobenen Pyramide zu laufen.

Das plötzliche Einsetzen der Beunruhigung bei Versetzungen der Pyramide um nur wenige $\mathrm{cm}$ und die Wahl eines neuen Bauplatzes, der in den allerseltensten Fällen am noch angenommenen vorletzten Pyramidenstandort liegt, sondern oft um $40-50 \mathrm{~cm}$ näher dem Eingang, zeigen, daß $O$. saratan über ein echtes $E \mathrm{n} t \mathrm{f}$ e $\mathrm{r}$ u ngs se h e nerfügt.

e) Form und Größse der Pyramide

Weiterhin war zu fragen, wie weit sich Form und Größe der Pyramide verändern lassen, wenn sie in günstiger Lage bei Fehlen der eigenen Pyramide noch als solche annehmbar bleiben soll.

\section{Vergrößern der Pyramide}

Der Größe sind nach oben praktisch keine Grenzen gesetzt. Sandberge von $1,60 \times 3,00 \mathrm{~m}$, die bereits die Aufmerksamkeit der ägyptischen Grenzpolizei 
erregten, wurden ohne allzu langes Zögern angenommen und „wiederaufgebaut". Bis zu dieser Größe kann eine Pyramide das Austragen von Baustoff nicht unterdrücken, wenn sie einmal angenommen wurde (Abb. 16). Genau wie bei der normal-großen Pyramide versuchen sie, ihre Ladungen auf der Spitze

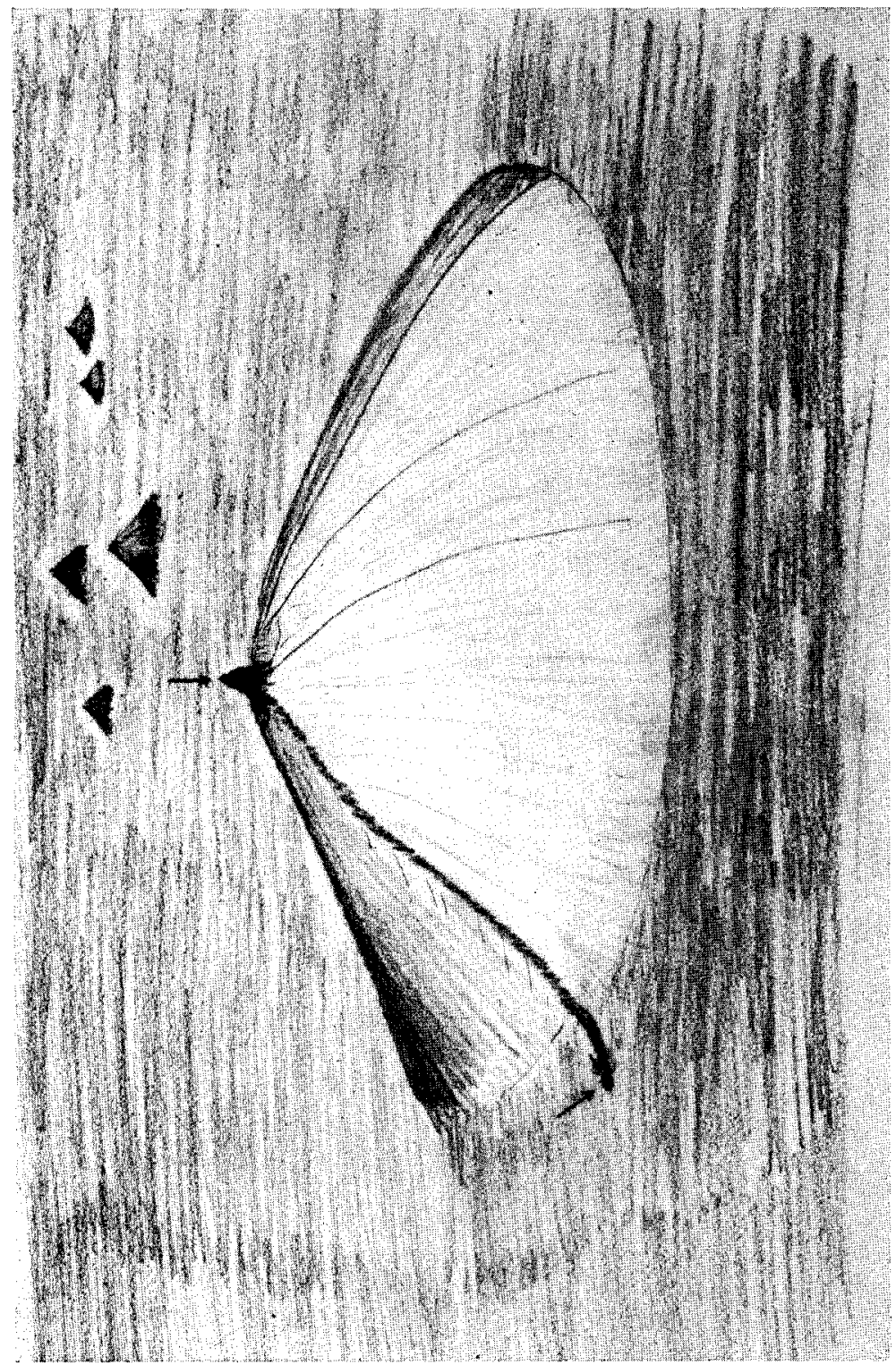

Abb. 16: Noch 4 Tage nach Errichtung dieses ursprünglich 1,50 $\mathrm{m}$ hohen Sandberges wurde die "Riesenpyramide“ vom Besitzer „wiederaufgebaut". Der linke Pfeil zeigt auf den Höhlencingang, der rechte auf die vom Besitzer gebaute Pyramidenspitze, dazwischen die Laufspuren des Besitzers. Der Vorderrand der Aufschüttung ist $20 \mathrm{~cm}$ vom Höhleneingang entfernt, der "Weg" bis zur Spitze ist ungefähr $1,80 \mathrm{~m}$ lang. Im Hintergrund normalgroße Pyramiden. Linientreue Nachzeichnung eines Photos

Zu Abb. 17, 18, 19: Baureaktionen bei atypischem Pyramidenersatz. Der zugehörige Eingang ist jeweils durch einen Pfeil markiert 
abzusetzen. Gelingt ihnen dies nicht, so pressen sie den Sand seitlich dort an, wo sie nicht mehr weiter hochsteigen können. Auf diese Weise können Stufen entstehen, die es den Tieren bei entsprechender Bausandmenge ermöglichen, doch noch die Spitze zu erklimmen.

\section{Teilzerstörungen an der Pyramide}

Ocypode saratan kann Teilzerstörungen an der Pyramide nicht gezielt ausbessern. Wohl werden Schäden bemerkt, die man nach dem ersten Auftauchen gesetzt hat, sie werden betastet und „betrachtet“, lösen aber kein spezifisches Bauverhalten aus.

\section{Atypische Pyramidenformen}

Folgende Formen wurden als Ersatz geboten: Würfel (Abb. 17), Quader (Abb. 18), Kugeln und Zylinder (Abb. 19). Alle Kunstpyramiden wurden in zwei Grössenklassen geboten: Höhe bzw. $\varnothing$ um $10 \mathrm{~cm}$ und um $20 \mathrm{~cm}$. Jeweils beide Größenklassen wurden in 10 Einzelversuchen getestet.

Das wichtigste Ergebnis: Keines dieser künstlichen Gebilde veranlaßt Ocypode, endgültig abzulehnen. (Wir prüften nur Pyramidenbesitzer, die höchstens zweiTage und mindestens eine Bauphase lang eine Pyramidenanlage besaßen. Sowohl Neubauer als auch $\sigma^{\prime}$, die schon länger als 4 Tage eine Spiralhöhle bewohnen, neigen dazu, auf starke Störungen hin, ihre Pyramidenanlage zu verlassen.) Die Größe der Attrappen spielt insofern eine Rolle, als kleine Würfel, Kugeln etc. immer relativ schnell angenommen wurden (d. h. noch während der ersten Bauphase), da sie bestiegen werden können. Sehr stark störten sich die Krabben an Formen, die wegen ihrer Größe oder Gestalt ein Besteigen unmöglich machten.

Sämtliche unnatürliche Formen lösen - ebenso wie starkes Vergrößern - sehr regelmäßig Orientierungsgänge aus, die sich durch größere zeitliche (bis 3 Min. gegenüber knapp einer) und räumliche (bis $5 \mathrm{~m}$ gegenüber $1-2 \mathrm{~m}$ ) Ausdehnung von den üblichen am Ende eines Neubaus unterscheiden (S. 409).

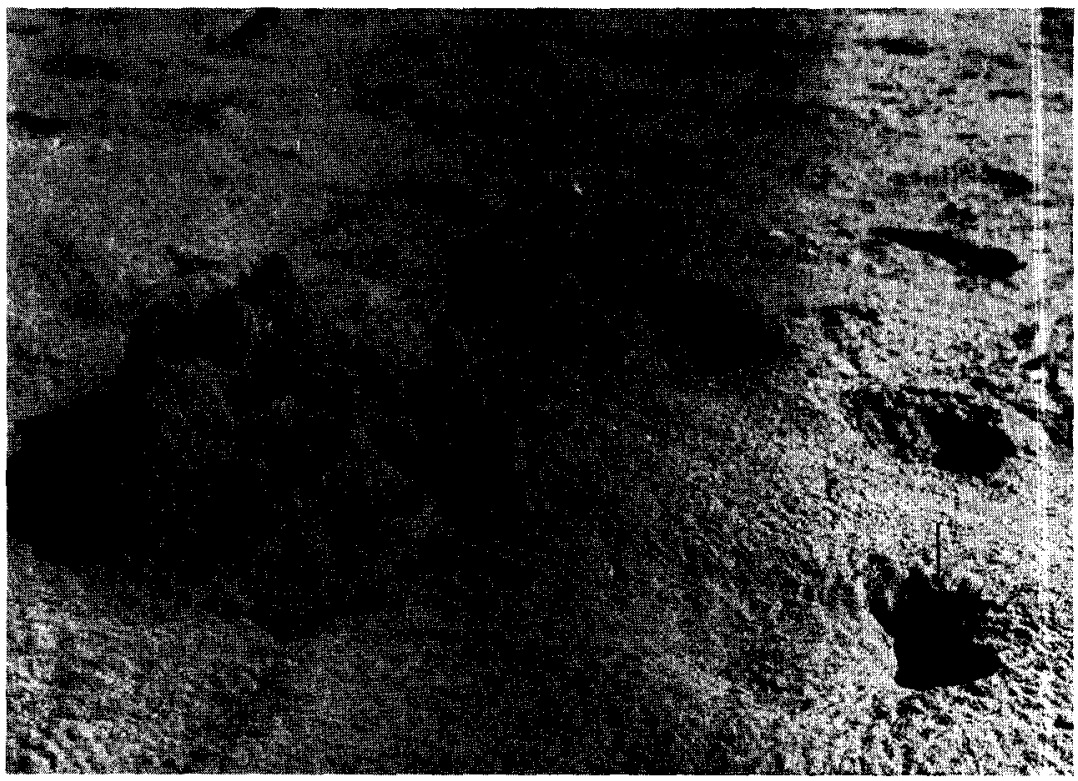

Abb. 17: Relativ schnell werden Formen angenommen, die cin Ersteigen ermöglichen, wie dieser Würfel mit $20 \mathrm{~cm}$ Kantenlänge. Die neue Pyramide wird nicht in die Mitte der erhöhten Filäche gebaut, sondern an den Rand 


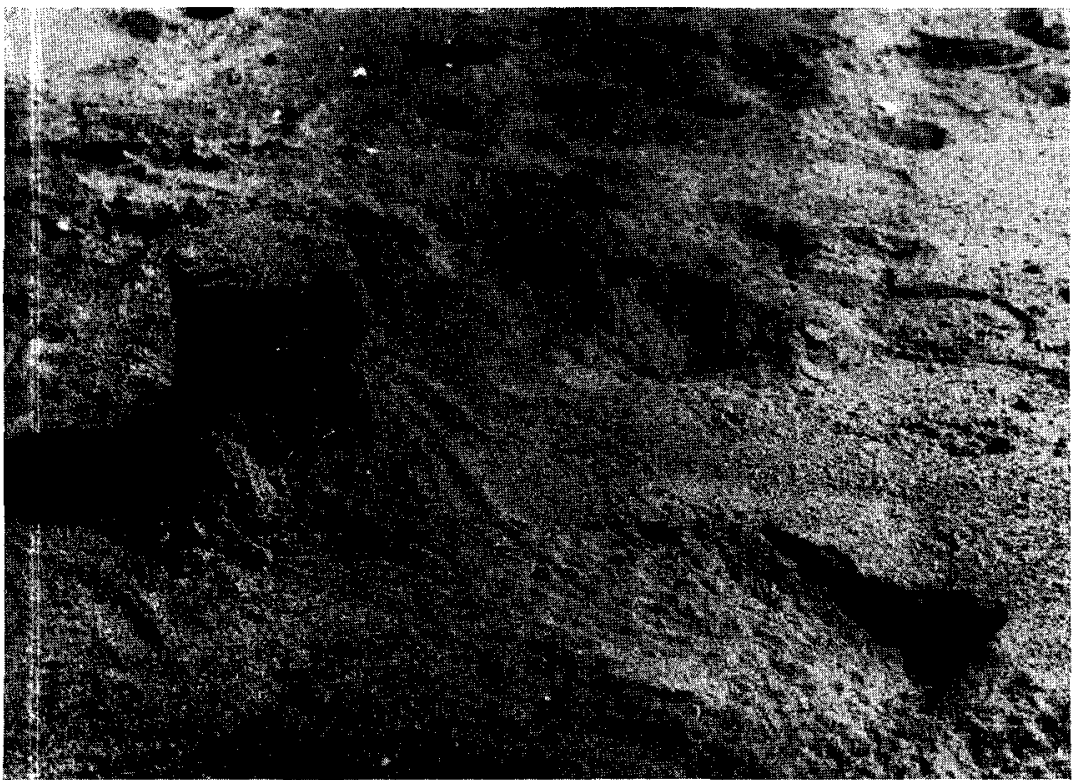

Abb. 18: Bei Quadern (20 cm Höhe), die nicht bestiegen werden können, wird bevorzugt an einer Kante gebaut (linker Pfeil)

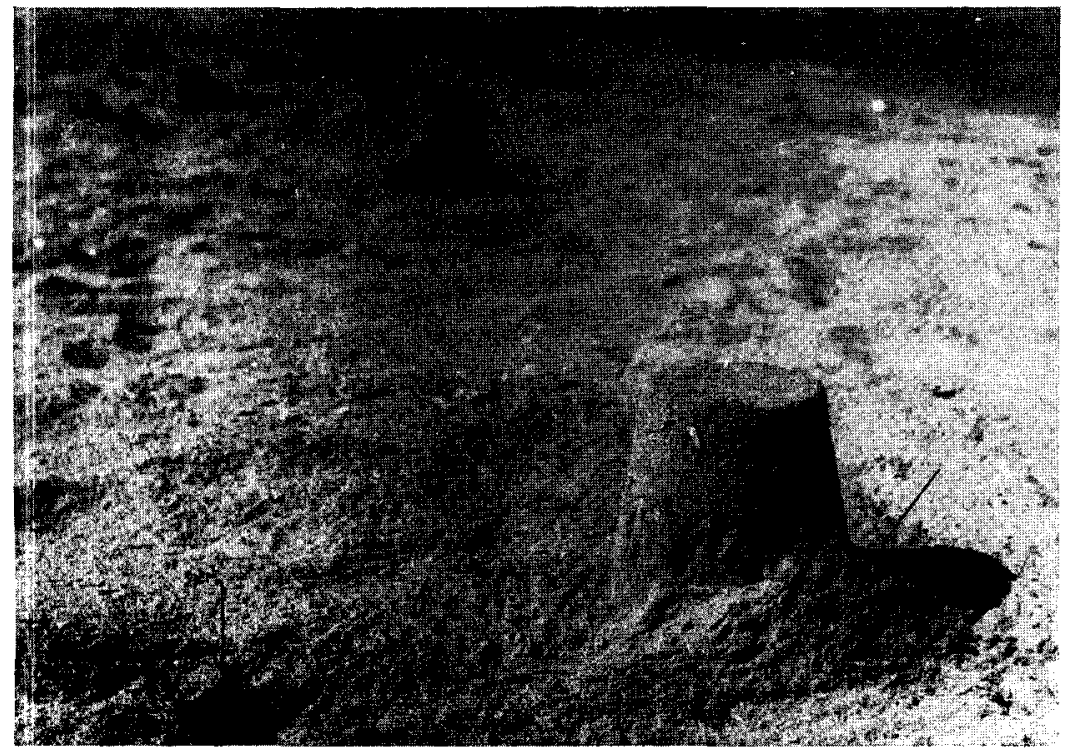

Abb. 19: Große Zylinder (Höhe $25 \mathrm{~cm}$ ) werden immer erst nach langem Zögern angenommen, die neue Pyramide wird dann direkt angebaut (rechter Pfeil)

\section{f) Farbe und Konsistenz der Pyramide}

Die Farbe (oder der Helligkeitsgrad) der Pyramide haben keinen merklichen Einfluß auf das Verhalten des Besitzers (vgl. dagegen Eindringlinge S. 438), wie Versuche mit verschieden gefärbtem Sand bewiesen.

Da die Reiterkrabben ihre Pyramiden sehr oft mit den Dactylopoditen betasten, liegt es nahe, die Bedeutung des Faktors Konsistenz zu untersuchen. 
Pyramiden aus hartem Material, Holz, Stein und Blech haben alle 10 daraufhin geprüften Höhlenbesitzer abgelehnt. Dagegen haben Neubauer mehrfach Büchsen, Korallenbruchstücke, Holz, Schildkrötenpanzer und ähnliches, das zufällig innerhalb des Siedlungsgebietes lag, zunächst als Richtmarken und dann als Sockel benutzt.

Insgesamt läßt sich sagen:

Die eigene Pyramide - als Signalreizkombination für das Bauverhalten - ist für den Besitzer eine Erhebung sehr variabler Höhe und Breite, beliebiger Farbe (oder Helligkeit), von sandähnlicher Konsistenz, in recht genau festgelegter Winkel- und Entfernungslage zum Eingang (vgl. Abb. 11), die in einer bestimmten Stellung vom Höbleneingang aus optisch beurteilt wird.

\section{DIE SOZIALEN FUNKTIONEN DER PYRAMIDENANLAGE}

Nur geschlechtsreife $0^{\pi} O^{\pi}$ graben Spiralhöhlen. Da es außerdem noch Schlaf-, Freß-, Brut-, Häutungs- und Wohnhöhlen gibt, lag es nahe, die Funktion der Pyramidenanlage im Bereich des Fortpflanzungsverhaltens zu suchen (vgl. LinsenMair 1965).

Parenzan deutet die Pyramiden von $O$. saratan (die er fälschlich als $O$. ceratophthalma bezeichnet) als "Wachtiirme"; außerdem sollen sie dem aus seiner Höhle auftauchenden Krebs noch einen Sichtschutz gegenüber seinen ärgsten Feinden, den am Strand entlangfliegenden Meeresvögeln, bieten! Beide Vermutungen sind unzutreffend.

a) Die sozial gleichstimmende Wirkung der Pyramiden

\section{Die Ursachen der Koloniebildung}

Die Pyramidenbauten liegen in kleineren und größeren, voneinander mehr oder weniger weit entfernten Kolonien beisammen. Daß hieran ökologische Faktoren weit geringeren Anteil haben als soziologische, ergibt sich aus folgenden Beobachtungen und Versuchen:

a) Kolonien als Ganzes, wie auch kleinere Kolonien innerhalb einer größeren, verändern dauernd, d. h. während jeder Bauphase ihre Lage und können nach einiger Zeit (falls die Wohnfläche groß genug ist) an eine andere, vorher völlig unbesiedelte Stelle schrittweise „umgezogen “ sein, ohne daß jemals ökologische Bedingungen die Umzugsrichtungen hätten voraussehen lassen.

b) Durch Errichten künstlicher Pyramiden kann man den Krabben Bauplätze an jedem beliebigen Ort innerhalb der Zone 4 (S. 406) vorschreiben (S. 433). Unter natürlichen Umständen sind es die ersten Pyramidenbauer, die in jedem Frühjahr durch ihre Pyramidenanlagen das Bildungszentrum für eine neue Kolonie festlegen. Es ist deshalb nicht überraschend, daß die Siedlungsschwerpunkte zur selben Jahreszeit 1963 und 1965 (Juli, August) innerhalb der etwa $3 \mathrm{~km}$ langen Kolonie im Hauptbeobachtungsgebiet nicht an derselben Stelle lagen.

a) Die Bedeutung der Pyramiden bei der aktiven Koloniegründung

Es zeigte sich im Frühjahr 1964 mit aller Deutlichkeit, daß neugebaute Pyramiden weitere Baulustige anlocken, obwohl sehr weite, unbesiedelte Küstenabschnitte - soweit erkennbar - genau die gleichen ökologischen Bedingungen boten. Schon am zweiten Tag nach Baubeginn siedelten sich 6 von 11 Neubauern in unmittelbarer Nähe von am Vortag gebauten Pyramidenanlagen (Abb. 20 a) an. Der Prozentsatz derer, die ihre Bauten in der Nähe 
schon vorhandener anlegten, d. h. höchstens $10 \mathrm{~m}$ vom nächsten entfernt, stieg sehr rasch an. Am 8. Tag nach Baubeginn fanden wir nur noch 6 isolierte Pyramidenbauten, bei einer Gesamtzahl von 119 an einem Strandabschnitt von
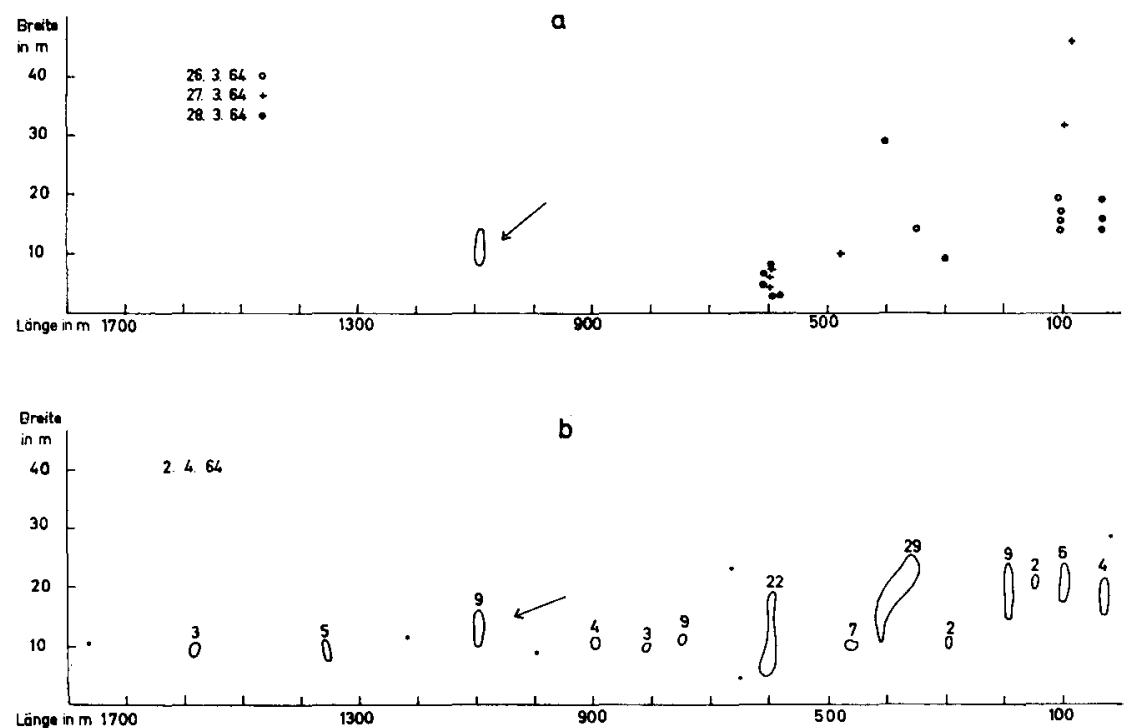

Abb. 20a: Beginn der Kolonicbildung 1964 auf 1,7 km Strandlänge im Hauptbeobachtungs gebiet. Die Zeichen geben dic Lage einzelner Pyramidenbauten an. Der Pfeil markiert die Versuchsfläche mit künstlichen Pyramiden (s. Text). b: Die Pyramidenbauten werden immer in der Nähe schon vorhandener angelegt, wodurch zunächst eine Reihe kleiner Kolonien entsteht (umrandete Flächen; Zahlen = Anzahl der Pyramiden)

$1800 \mathrm{~m}$ Länge (Abb. $20 \mathrm{~b}$ ). Die anziehende Wirkung vorhandener Pyramiden auf baulustige Männchen wurde mit künstlichen Sandkegeln geprüft: Am 28. 3. 64, als im gesamten $1800 \mathrm{~m}$ Küste umfassenden Beobachtungsgebiet erst 22 Pyramiden (Abb. 20 a) errichtet worden waren, wurden in $500 \mathrm{~m}$ Entfernung zu den nächsten natürlichen Pyramiden 10 künstliche im Abstand von etwa $3 \mathrm{~m}$ gesetzt.

3 Std. später (am Ende der Bauphase) hatte die Kolonie schon zwei Einwohner, die gleichzeitig mit dem Bauen begonnen hatten. Einer benutzte einen der künstlichen Sandkegel als Sockel für seine Pyramide. Der zweite errichtete seine Pyramide mitten zwischen den von uns gebauten, 1,90 und $2,00 \mathrm{~m}$ von ihnen entfernt. Innerhalb der folgenden drei Tage kamen noch 6 Ansiedler hinzu. 5 bauten ihre Pyramiden in die Nähe künstlicher, die ich immer wieder herrichtete; der 6. benutzte wieder eine schon vorhandene, künstliche Pyramide als Sockel. Am 3. April zählte diese Kolonie 9 Einwohner (Pfeil in Abb. 20 b).

Der gleiche Versuch wurde am 6.4.1964 mit 20 künstlichen Pyramiden an einem dünn besiedelten Strandabschnitt wiederholt.

Innerhalb der ersten beiden Bauphasen benutzten $6 \sigma^{7} \sigma^{7}$ künstliche Pyramiden als Sockel und gruben eine Spiralhöhle dazu; 3 siedelten sich zwischen den Pyramiden oder am Rande der Kolonie an; ihre Pyramiden waren 70, 230 und $250 \mathrm{~cm}$ vom nächsten Sandkegel entfernt.

Diese Versuchsergebnisse beweisen, daß allein schon Pyramiden als „Kristallisationskeime" für Männchenkolonien dienen können. Derartige Versuche glücken nur zu Beginn der Pyramidenbausaison, denn nur innerhalb von 10-14 Tagen nach Baubeginn kann man günstige Bauplätze finden, die ge- 
nügend weit von schon vorhandenen Pyramidenanlagen entfernt sind, um eine Anregung der wandernden, baulustigen $\sigma^{x} \sigma^{\pi}$ durch diese Pyramidenbauten ausschließen zu können. Außerdem verlieren künstliche Pyramiden bei dichter Besiedlung an sozialem Auslösewert: Die Neuansiedler bauen dann bevorzugt in der Nachbarschaft natürlicher Pyramidenbauten.

B) Diesozialen Funktionender Pyramiden in der be wohnten Kolonie

Es blieb noch zu prüfen, inwieweit höhlenbesitzende Artgenossen oder die Spiralhöhlen allein ebenso anziehend wirken können wie die Pyramiden.

In einem Versuchsgebiet wurden während 5 Bauphasen sämtliche Pyramiden zerstört; um einseitige Auswirkungen dieser notwendigen Störung zu vermeiden, hielten wir uns immer ebenso lange in beiden Kontrollgebieten auf und verglichen die Zahl der Neubauten auf der Versuchsfläche mit der auf den Kontrollflächen, sowie unmittelbar die Zahl der Eindringlinge und die Zahl der Kämpfe um eine Höhle. Bei jedem Kampf achteten wir besonders darauf, ob der Besitzer oder der Eindringling begann (Tab. 9 und 10).

Tab. 9: Reaktion auf das Entfernen der Pyramiden in einem Teil der Kolonic. Als Reaktionsmaß gilt die Zahl der in jeder Bauphase von Neuankömmlingen errichteten Pyramidenbauten im Vergleich zur entsprechenden Zahl von zwei ungestörten Kontrollgebieten

\begin{tabular}{|c|c|c|c|}
\hline Bauphase & $\begin{array}{l}\text { Versuchsgebiet } 30 \times 18 \mathrm{~m} . \\
\text { Ursprüngliche Zahl der } \\
\text { Pyramidenbauten } 82 \\
\text { Neubauten }\end{array}$ & $\begin{array}{l}\text { 1. Kontrollgebiet } 30 \times 18 \mathrm{~m} . \\
\text { Ursprüngliche Zahl } 86\end{array}$ & $\begin{array}{l}\text { 2. Kontrollgebiet } 30 \times 18 \mathrm{~m} . \\
\text { Ursprïngliche Zahl } 50\end{array}$ \\
\hline 1. & 2 & Neubauten & Neubauten \\
\hline 2. & 3 & 12 & 4 \\
\hline 3. & 2 & 10 & 3 \\
\hline 4. & 2 & 4 & 6 \\
\hline 5. & 0 & 7 & 6 \\
\hline$\sum$ & 9 & 38 & 25 \\
\hline
\end{tabular}

T'ab. 10: Zahl der Eindringlinge und der Kämpfe in einem experimentell pyramidenlos genachten Kolonieteil im Vergleich mit einem Kontrollgebiet, s. Text

\begin{tabular}{|l|l|l|}
\hline $\begin{array}{l}\text { Versuchsgebiet } \\
30 \times 18 \mathrm{~m}\end{array}$ & $\begin{array}{l}\text { Kontrollgebiet } \\
30 \times 18 \mathrm{~m}\end{array}$ \\
\hline Zahl der Eindringlinge & $\begin{array}{l}\text { Eindringlinge kommen an: } \\
10 \text { aus Kolonje } \\
17 \text { vom Strand }\end{array}$ & $70 \quad \begin{array}{l}18 \text { aus Kolonie } \\
52 \text { vom Strand }\end{array}$ \\
\hline Zahl der Kämpfe & begonnen vom: & $36 \quad 12$ vom Besitzer \\
13 & 3 vom Besitzer & $24 \quad$ Eindringting \\
\hline
\end{tabular}

Nach Entfernen sämtlicher Pyramiden in einem bewohnten Kolonieteil fällt die Zuzugsrate Baulustiger:

Von den 9 Neubauten im Versuchsgebiet (Tab. 9) sind nur 3 voll auswertbar. 4 lagen an der Grenze zu Kontrollgebiet I, waren also noch der Zahl 38 zuzuschlagen. 2 Neubauten wurden an der entgegengesetzten Koloniegrenze errichtet. Auch war der Zuzug auf der ziemlich dünn besiedelten Kontrollfläche II wesentlich stärker, als auf der Versuchsfläche.

Es haben sich also baulustige $\sigma^{\top} \bigcirc^{\top}$ auch innerhalb einer großen Kolonie bevorzugt in der Nähe vollständiger Pyramidenbauten angesiedelt, wobei die Pyramide am stärksten anlockt. Deshalb bleiben die Zahlen der Zuwanderer in 
der Versuchsfläche hinter denen für die Kontrollfläche so stark zurück, so vor allem die Zahl jener, die vom Strand her nach der Pyramidenzone (Zone 4, S. 406) suchen (Tab. 10). Diejenigen, die schon vor der pyramidenlosen Versuchsfläche die Zone 4 gefunden hatten, wandern oft ungefähr parallel zum Strandverlauf; sie durchqueren fast immer das Versuchsgebiet (vgl. S. 436 und Abb. 22).

Verschieden waren aud die Kampfauslösungen verteilt: In der Kolonie mit natürlichen Pyramiden beginnt der Eindringling, nachdem er auf eine bestimmte Höhle, deren Lage er an der Pyramide erkannt hatte, zugelaufen ist, zumindest ${ }^{2} / 3$ der Auseinandersetzungen. Beim Fehlen von Pyramiden fehlt auch der Anreiz, eine Spiralhöhle zu suchen, und damit entfällt natürlich auch der Eroberungsversuch. Im Versuchsgebiet eröffnen Eindringlinge nur Kämpfe um Höhlen, auf die sie zufällig gestoßen waren.

Auf der pyramidenfreien Fläche begann der Besitzer $77 \%$ der Kämpfe, dagegen auf der Kontrollfläche nur $33 \%$ (Tab. 10).

Die Pyramiden sind für die Eindringlinge „erstarrte Imponiersignale“; sie motivieren Rivalenkampf, wobei schwächere Pyramidenbesitzer das Feld räumen müssen.

\section{Rivalenkampf und Drebsinn der Höble}

$10-20 \%$ der Pyramidenbauten einer Kolonie wechseln in jeder Bauphase nach dem Sieg eines Eindringlings den Besitzer. Direktbeobachtungen und die Zahl der umgebauten (S. 422) Spiralhöhlen machten deutlich, daß ein Eindringling gewöhnlich nur eine Höhle erobert, die seiner Händigkeit entspricht. Hat sie den falschen Drehsinn, so baut er sie um und dann liegen zwei Pyramiden bei seiner Höhle (Abb. 10).

Bei weit über 500 Spiralhöhlenausgrabungen stimmten Händigkeit und Drehsinn der Höhle ausnahmslos überein. 90-100\% der eroberten Spiralhöhlen werden nicht umgebaut, was beweist, daß kein Wechsel zwischen verschiedenhändigen Besitzern stattgefunden hat. (Da hier beide Händigkeiten gleich häufig sind, wären bei zufälliger Auswahl der eroberten Pyramidenbauten $50 \%$ Doppelpyramiden zu erwarten gewesen.)

Die Umbaurate ist abhängig von der Siedlungsdichte; je geringer der Pyramidenbestand, um so größer ist der prozentuale Anteil eroberter Höhlen mit nicht entsprechendem Drehsinn, z. B. fanden wir am 2. 4. 1964 bei einem Gesamtbestand von 108 bewohnten Pyramidenbauten im Beobachtungsgebiet 3 mit 2 Pyramiden, und 14 Tage später waren von über 1000 nur 4 umgebaut.

Fragen wir weiter, wann und wie der Drehsinn der Spiralhöhle erkannt wird, so ergeben sich auf Grund des Verhaltens während der aggressiven Wanderphase folgende Denkmöglichkeiten:

1. Der Eindringling erkennt ihn an der Lagebeziehung der Pyramide zur Höhle, erfährt also schon auf dem Weg zum Höhleneingang, was er „wissen will".

2. Er ertastet den Drehsinn beim Einkriechen in die Höhle und wählt sich dann einen gleichhändigen Gegner aus, oder

3. er "ruft" ohne Wissen vom Drehsinn den Besitzer aus seiner Höhle und stellt erst beim Kampf dessen Händigkeit fest.

$\mathrm{Zu}$ 1. Um die erste Möglichkeit zu prüfen, wurde die Händigkeit von 200 Eindringlingen mit dem Drehsinn der von ihnen inspizierten Höhlen verglichen: 96 suchten eine Höhle auf, die ihnen entsprach, 104 eine falsche. Damit entfällt die erste Deutung: Vor dem Höbleneingang ist der Drebsinn unbekannt. 
Zu 2. Zur Prüfung der zweiten Annahme wurden die Scherenverhältnisse bei 100 Kämpfen um Spiralhöhlen festgestellt.

Das Ergebnis ist eindeutig (Tab. 11): Eindringlinge prüfen beim In-dieHöble-Kriechen den Drehsinn und fordern in $93 \%$ der Fälle nur einen gleichbändigen Besitzer zum Kampf heraus. Bei den verbleibenden $7 \%$ handelt es sich zum Teil wohl um echte Irrtümer, denn manchmal wurde eine gerade eroberte Höhle mit dem falschen Drehsinn wieder verlassen.

Zu 3. Es ließen sich keine Anhaltspunkte dafür finden, daß die Händigkeit erst beim Kampf festgestellt wird (vgl. Tab. 11, Zeile 2). In der Intensität und Dauer der Auseinandersetzungen zwischen Gleich- und Verschiedenscherigen gibt es keinen Unterschied.

Die Pyramide ist für $\sigma^{\prime} O^{\top}$ in der aggressiven Wanderphase der wichtigste Signalreiz: Sie zeigt als „Aushängeschild“ den Weg zu einer Spiralhöhle und löst beim Eindringling das Aufsuchen des Eingangs und das Ertasten des Drehsinns aus. Entspricht der Drehsinn der Händigkeit des Eindringlings und zeigt der Besitzer durch "Imponierstridulieren" seine Anwesenheit an, so antwortet der Eindringling mit "Drohklopfen" u. U. auch mit „Drohgraben“; das "zwingt" den Besitzer, aus seiner Höhle aufzutauchen. Ein Kommentkampf entscheidet über die künftigen Besitzverhältnisse.

Im Frühjahr zu Beginn der Pyramidenbauzeit wandern die $\sigma^{\pi} \sigma^{\prime}$ nur selten aggressiv umher, vermutlich weil die spezifischen Reize, die Pyramiden, fehlen. Später im Jahr wird in der Regel erst durch das Verhalten während der aggressiven Wanderphase der Bautrieb aktiviert.

\section{Das Erkennen der Pyramide durch Eindringlinge}

Versuche zur Frage, woran der Eindringling eine Pyramide erkennt, werden vor allem dadurch erschwert, daß er häufig von einer Pyramide zur nächsten geht (Abb. 21), wobei die Nähe Vorrang vor der Form und dem Zu-

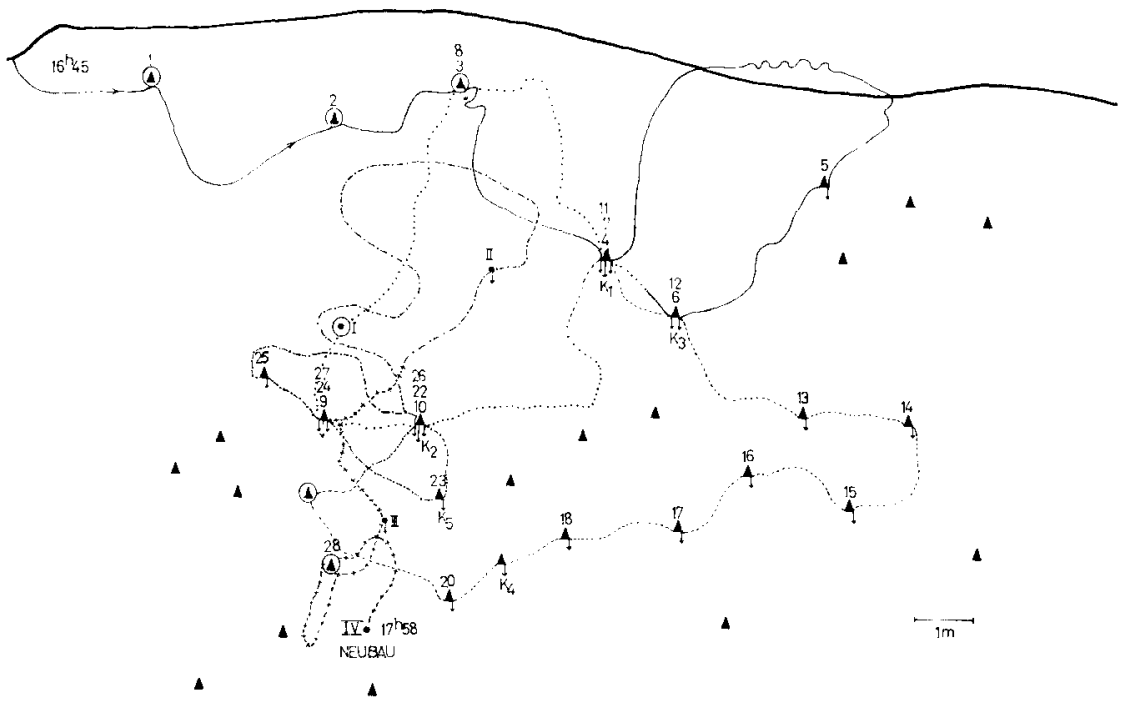

Abb. 21: Weg eines Eindringlings durch die Pyramidenkolonie, der immer zur nächsten Pyramide geht (Zeichen wie in Abb. 22) 
stand der Pyramide hat; zudem hält er beim Durchwandern der Kolonie eine bestimmte Richtung ein und beachtet nur die Pyramiden, die ungefähr auf seinem Weg liegen (Abb. 22). Doch erkennt man nach einiger Übung wirkliche,

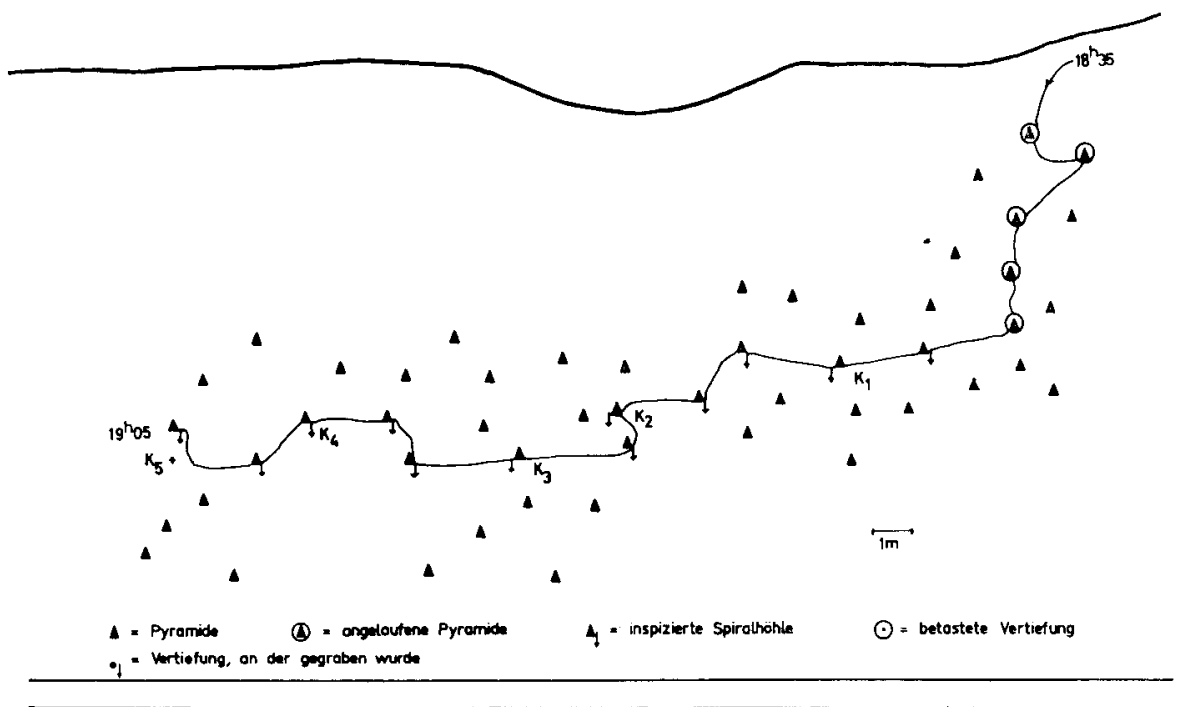

Abb. 22: Weg cines erfolgreichen Eindringlings durch die Pyramidenkolonie, der eine bestimmte Richtung einhält. K. Kampf

echte Wahlen zwischen zwei Pyramiden, und nur sie wurden gewertet. Die Krabbe kann eine Pyramide noch aus $5 \mathrm{~m}$ Entfernung erkennen, was man an deutlichen Änderungen der Laufrichtung zur Pyramide hin feststellen kann.

Tab. 11: Scherenverhältnisse (= Händigkeit) bei 100 Kämpfen unter Berücksichtigung des Kampfbeginns. In Klammern die Zahl der erfolgreichen Eindringlinge

\begin{tabular}{|c|c|c|c|c|}
\hline \multirow[t]{2}{*}{ Auslösung } & \multicolumn{4}{|c|}{ Händigkeit } \\
\hline & \multicolumn{2}{|c|}{ gleich } & \multicolumn{2}{|c|}{ ungleich } \\
\hline Eindringling lockt Besitzer aus Höhle & 61 & (9) & 5 & (1) \\
\hline $\begin{array}{l}\text { Es kommt zum Kampf, bevor der Eindring- } \\
\text { ling die Möglichkeit hatte, den Drehsinn zu } \\
\text { ertasten }\end{array}$ & 19 & (0) & 15 & (1) \\
\hline
\end{tabular}

E rgebn is se (vgl. Tab. 12 und 13):

1. Größe: Übernormalgroße Pyramiden wirken anziehender als kleine, das gilt auch noch für $160 \mathrm{~cm}$ hohe Sandberge (Abb. 16, S. 429). Sie werden besonders häufig und gründlich betastet und bestiegen. Einzelne Krabben klet-

Tab. 12: Reaktion von 34 Eindringlingen auf normalgroße und vergrößerte Pyramide bei Wahlversuchen während einer Bauphase

\begin{tabular}{|l|c|c|}
\hline Handlungen & $\begin{array}{c}\text { Pyramide } \\
90 \times 40 \mathrm{~cm}\end{array}$ & $\begin{array}{c}\text { Pyramide } \\
\text { normalgros }\end{array}$ \\
\hline Anlaufen & 26 & 8 \\
\hline Besteigen & 12 & 1 \\
\hline Höhleneingang aufsuchen & 5 & 7 \\
\hline Kämpfe & 2 & 3 \\
\hline
\end{tabular}


Tab. 13: Anlaufhäufigkeiten der Eindringlinge bei Wahlversuchen. Im 2. bis 5. Versuch wurde die geprüfte Form immer mit einer normalgroßen, frischen Pyramide verglichen

\begin{tabular}{|c|c|c|c|}
\hline $\begin{array}{l}\text { Anlaufh } \\
\text { normale } \\
\text { Pyramide }\end{array}$ & & $\begin{array}{l}\text { in } \% \\
\text { geprïfte } \\
\text { Form }\end{array}$ & Pyramidenbeschaffenheit \\
\hline 50 & : & 50 & $\begin{array}{l}\text { 1. Frische, während der jeweiligen Bauphase errichtete Pyramiden } \\
\text { (aus noch feuchtem Sand). Diese wurden mit künstlichen, } \\
\text { ebenfalls frischen Sandkegeln verglichen. }(n=50)\end{array}$ \\
\hline 70 & : & 30 & $\begin{array}{l}\text { 2. Pyramiden der letzten Bauphase oder im Versuch Pyramiden } \\
\text { aus hellem, trockenem Sand. }\end{array}$ \\
\hline 87 & : & 13 & 3. Spitzenlose Pyramiden, Würtel, Quader, Zylinder und Kugeln. \\
\hline 91 & : & 9 & $\begin{array}{l}\text { 4. Nur wenige Portionen feuchten Sandes, unter natürlichen } \\
\text { Bedingungen Neubaubeginn. }\end{array}$ \\
\hline 93 & : & 7 & $\begin{array}{l}\text { 5. Vollkommen fehlende Pyramide, es wurde der Besitzer an } \\
\text { seinem Höhleneingang angelaufen. }\end{array}$ \\
\hline
\end{tabular}

tern bis über $10 \mathrm{Min}$. lang ununterbrochen auf ihnen herum. Aber trotz ihrer sehr stark anlockenden Wirkung lösten sie nur selten die Folgehandlungen aus: Aufsuchen des Eingangs, Ertasten des Drehsinns, Drohen. Beide Kämpfe um die $90 \times 40 \mathrm{~cm}$ große Pyramide (Tab. 12) hat der Besitzer begonnen, für den die Riesenpyramide einen vollwertigen Ersatz darstellt; im Gegensatz dazu erfüllt sie für den Eindringling nur eine Teilfunktion, die Anlockung.

Sicher spielt bei der Reaktion gegenüber der vergrößerten Pyramide das bei Ocypode stark ausgeprägte "Neugierverhalten" mit. Mehrfach besahen sich Mitglieder von Eßgesellschaften (auch $\bigcirc 9$ ) die vergrößerten Pyramiden und ebenso die Besitzer benachbarter Pyramiden. Ganz ähnlich laufen sie auch zu einem ruhig sitzenden Menschen, einem Stuhl, einer angetriebenen Kiste, kurz, zu jedem optisch auffälligen Gegenstand. Diese Objekte werden regelmäßig betastet; sie lösen aber kein Suchen nach dem Höhleneingang aus, das als das sicherste Kriterium dafür angesehen werden muß, ob eine geprüifte Form als Pyramide betrachtet wird.

2. Form: $87 \%$ der Eindringlinge ziehen bei erkennbarem Wahlverhalten den Kegel einem anderen Sandgebilde vor (Tab. 13). Die Höhe hat dabei innerhalb der natürlichen Variationsbreite von 12 bis $18 \mathrm{~cm}$ keinen Einfluß.

3. Der Besitzer einer Spiralhöhle obne die zugehörige Pyramide hat nur eine geringe Anziehungskraft für Artgenossen (Tab. 13, 5). Im Gegensatz dazu wirkt bei der Futtersuche der Artgenosse oft anziehender als die Nahrung selbst.

4. Frische und alte Pyramiden derselben Form können anscheinend unterschieden werden (Tab. 13, 2), vermutlich am Aussehen trockenen und nassen Sandes.

Pyramiden werden von den Eindringlingen häufig betastet. Verändert man deren Konsistenz wesentlich - Holz-, Blech-oder Steinpyramiden -, so werden sie noch angelaufen und ausgiebig untersucht, Folgehandlungen bleiben aber aus. $\sigma^{\prime} O^{\prime}$, die eine derartige Pyramide ausnahmsweise nicht betasteten, suchten nach dem Eingang, was die Bedeutung der Form klar unterstreicht.

Andererseits lösten nicht pyramidenförmige Sandanhäufungen, wenn überhaupt, immer erst nach dem Betasten Suchen nach dem Höhleneingang aus, offenbar ist neben der Form auch die Konsistenz ein Signalreiz, der Suchen nach dem Eingang auslösen kann. Die Folgehandlungen kann man auch dadurch verhindern, daß man die Pyramide z. B. mit Fischsaft tränkt: dann verliert sie ihren Signalcharakter und bleibt nur noch Nahrungsobjekt. 


\section{Zusammenfassend läßt sich sagen:}

Jede 3 bis $160 \mathrm{~cm}$ bohe Erbebung erfüllt einen Teil der Signalfunktion der Pyramide, nämlich die Fernanlockung, wobei allerdings stets eßmotiviertes Neugierverhalten mitsprechen mag. Der genaueren Nabunterscheidung dienen die gesehene Form, Größe und vermutlich Farbe (oder Helligkeit s. o.), außerdem die ertastete Konsistenz. Zur Auslösung des Suchens nach dem Eingang ist keine Kombination dieser Signalreize unerläßlich, vielmehr genügt oft schon ein einziger (s. o. Form oder Konsistenz).

Tab. 14: Zahl der Pyramiden und deren mittlere Entfernung zueinander an einem Küstenabschnitt von $100 \mathrm{~m}$ Länge im Sommer 1965. n bew. Py: Zahl der bewohnten Pyramidenbauten; mittl. P-e m: mittlere Entfernung benachbarter Pyramiden in $\mathrm{m}$; $\mathrm{n}$ : Zahl der ausgemessenen Pyramidenabstände

\begin{tabular}{|c|c|c|c|c|c|c|c|}
\hline Datum & $\mathrm{n}$ bew. Py & mittl. $\mathrm{P}-\mathrm{e} \mathrm{m}$. & $n$ & Datum & n bzw. Py. & mittl. P-e m & $n$ \\
\hline 24. 5. & 274 & $1,9 \pm 0,6$ & 100 & 9. 7. & 43 & & \\
\hline 27. & 260 & & & 12. & 61 & & \\
\hline 28. & 209 & & & 13. & 78 & & \\
\hline 29. & 182 & & & 14. & 93 & & \\
\hline 30. & 148 & & & 15. & 90 & & \\
\hline 9. 6. & 48 & & & 17. & 71 & & \\
\hline 10. & 60 & $2,4 \pm 1,0$ & 50 & 18. & 64 & & \\
\hline 11. & 64 & & & 19. & 42 & & \\
\hline 12. & 62 & & & 20. & 81 & & \\
\hline 13. & 111 & & & 21. & 90 & $1,8 \pm 0,5$ & 15017 \\
\hline 14. & 111 & & & 22. & 90 & & \\
\hline 15. & 113 & & & 23. & 137 & & \\
\hline 16. & 98 & & & 24. & 152 & & \\
\hline 17. & 52 & & & 25. & 181 & & \\
\hline 18. & 54 & $2,8 \pm 1,2$ & 50 & 26. & 219 & & \\
\hline 19. & 51 & & & 27. & 267 & & \\
\hline 20. & 42 & & & 25. 8. & 224 & & \\
\hline 21. & 40 & & & 26. & 226 & $1,3 \pm 0,4$ & 100 \\
\hline 22. & 38 & & & 27. & 231 & & \\
\hline 23. & 34 & & & 28. & 149 & & \\
\hline 24. & 48 & & & 29. & 119 & & \\
\hline 25. & 69 & & & 30. & 118 & & \\
\hline 26. & 102 & $1,5 \pm 0,4$ & 50 & 31. & 155 & & \\
\hline 27. & 119 & & & 23. 9. & 148 & $1,9 \pm 0,6$ & 100 \\
\hline 28. & 140 & & & 24. & 138 & & \\
\hline 29. & 109 & & & 25. & 138 & & \\
\hline 30. & 90 & & & 26. & 145 & & \\
\hline 4. 7. & 42 & & & 27. & 136 & & \\
\hline 5. & 53 & & & 28. & 98 & & \\
\hline \multirow[t]{5}{*}{8.} & 41 & & & 29. & 131 & & \\
\hline & & & & 30. & 111 & & \\
\hline & & & & 1. 10. & 89 & & \\
\hline & & & & 2. & 119 & & \\
\hline & & & & 3. & 69 & & \\
\hline
\end{tabular}

1) Am 21.7. wurden auch Messungen aus dem gleich dicht besiedelten Nachbargebiet verwertet. 
b) Die Siedlungsdichte innerhalb der Kolonie

\section{Die natürlichen Pyramidenabstände}

Die nachweislich anziehende Wirkung der Pyramiden erklärt zwar, warum im allgemeinen ein bestimmter Höchstabstand zwischen den einzelnen Pyramiden nicht überschritten, nicht aber, warum ein bestimmter Abstand nicht unterschritten wird.

Während die Zahl der Pyramiden in einer Kolonie oder in einem Teil derselben bis zum Zahlenverhältnis 1 : 10 schwankt, bleibt die mittlere Entfernung der Pyramiden untereinander vergleichsweise konstant (Tab. 14). (Eingang zu Eingang haben im Mittel dieselbe Entfernung wie Pyramide zu Pyramide.)

Der Mittelwert der 620 Messungen liegt bei $188 \mathrm{~cm}$.

Durch Markieren aller Pyramiden einer Kolonie während eines längeren Zeitraumes kann man erkennen, daß die Mittelwerte der Pyramidenbestände um so stärker schwanken, je weniger sich $\mathrm{Ab}$ - und Zuwanderungen der Koloniebewohner die Waage halten (vgl. Tab. 14).

Als "freiwillig gewäblte Entfernung" bezeichnen wir dicjenige, dic Ncubauer in dünn besiedelten Gebieten bei der Anlage ihrer Bauten von schon vorhandenen Pyramiden ein. halten. Der Mittelwert von 100 Abständen betrug $134 \pm 44 \mathrm{~cm}$. Selbst bei dichtester Besiedlung wird dieser Wert nur unwesentlich unterschritten - am 26. 8. 1965 waren es $125 \pm 42 \mathrm{~cm}$. Höhere Abstandswerte ergeben sich bei großen Auswanderungsquoten und geringer Zuwanderung, indem sich die Abstände rein passiv vergrößern (vgl. Tab. 14: 18. 6. 1965).

Nur $6 \%$ der 830 kontrollierten Pyramiden lagen näher als $90 \mathrm{~cm}$ zusammen; folgende Gründe können eine so enge Nachbarschaft bedingen:

1. 2 Neubauer begannen gleichzeitig mit dem Neubau, oder

2. der Neubauer begann mit dem Pyramidenbau, bevor sein Nachbar aufgetaucht war, dies kommt nicht so selten nach Sandstïrmen vor.

3. Nahe bei einer Pyramide verlockt eine mindestens $2 \mathrm{~cm}$ tiefe und höchstens $8 \mathrm{~cm}$ breite Vertiefung, z. B. eine menschliche Fußspur, zum Bau der Spiralhöhle oder

4. 2 Pyramiden liegen „Rücken an Rücken“ mitten auf der Verbindungslinie der beiden zugehörigen Höhleneingänge.

$80 \%$ der engen Nachbarschaften fallen unter Punkt 1 und 2, nur $20 \%$ unter 3 und 4 .

\section{Die Bedeutung der Pyramiden bei der Regelung der Wobndichte in der Kolonie}

Wir fragen weiter, welche Faktoren der Anlockung durch die Pyramiden entgegenwirken und dadurch eine Übervölkerung verhindern.

Zur Prüfung der aus den Punkten 1 und 2 (s. o.) sich ergebenden Vermutung, daß die Pyramiden nicht nur anlocken, sondern auch abstoßen, dienten Versuche mit künstlichen Pyramiden:

25 Neubauer hielten von solchen im Mittel $125 \pm 58 \mathrm{~cm}$ Abstand, 37 „eroberten" sie, d. h. verwendeten sie als Sockel für ihre eigene Pyramide.

Ferner bauten wir zwischen die 17 Pyramiden eines vergleichsweise dünn besiedelten Gebietes von $15 \times 8 \mathrm{~m} 86$ künstliche, so daß alle Pyramiden nur ungefähr $1 \mathrm{~m}$ voneinander entfernt waren. Während der 4 folgenden Bauphasen wurde die Zahl der Neuansiedler und die Lage ihrer Bauplätze registriert und mit entsprechenden Kontrollflächen verglichen (Tab. 15). 5 Neu- 
ansiedler (eingeklammerte Zahlen in Tab. 15) benutzten eine vorhandene Pyramide als Sockel, 6 siedelten sich am Kolonierand an; im Mittel hielten die Neubauer $108 \pm 41 \mathrm{~cm}$ Abstand von der nächsten Pyramide.

7'ab. 15: Zahl der Neuansiedlungen in einem Versuchsgebiet von $15 \times 8 \mathrm{~m}$ mit 17 natürlichen und 68 künstlichen Pyramiden, sowic in 2 gleichgroßen Kontrollgebieten mit 23 und 17 natürlichen Pyramiden. In Klammern Neuansiedler, die eine Kunstpyramide als Sockel benutzten

\begin{tabular}{|c|c|c|c|}
\hline Bauphasen & Versuchsgebiet & Kontroligebiet 1 & Kontrollgebiet 2 \\
\hline 1. & $(1)+2$ & 7 & 6 \\
2. & $(2)+1$ & 3 & 3 \\
3. & $(2)+2$ & 8 & 6 \\
4. & 1 & 3 & 5 \\
\hline Summe & 11 & 21 & 22 \\
\hline
\end{tabular}

Die Pyramiden locken demnach nicht nur an, sondern stoßen auch ab. Sie sichern das Zustandekommen kolonialen Wohnens und verhindern gleichzeitig zu große Siedlungsdichten, indem sie Neubauer "zwingen", durchschnittlich mindestens $134 \mathrm{~cm}$ Abstand $\mathrm{zu}$ halten.

Das Gesagte gilt nur für Neuansiedler, dagegen lassen sich Pyramidenbesitzer durch eine künstliche Verdichtung des Pyramidenbestandes rund um ihre Höhle nicht stören.

\section{Das Territorialverbalten ${ }^{1}$ ) von Ocypode saratan}

Die vielen Hunderte von Kämpfen zwischen Besitzern und Eindringlingen, die wir mitansahen, gingen fast ausschließlich um den Besitz der Höhle.

Wer diese erobert oder verteidigt, hat damit zugleich auch einen bestimmten, kleinen Bezirk um seine Pyramidenanlage herum, das

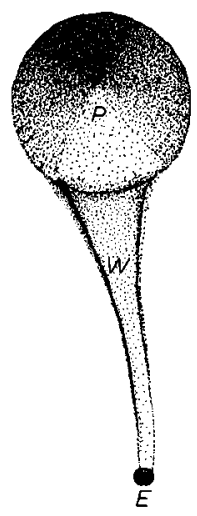
„engere Territorium" gewonnen oder verteidigt (Abb, 23). Gegen baulustige Eindringlinge ist es meist schon allein durch die Pyramide geschützt; normalerweise braucht der Besitzer es nicht zu verteidigen (s. u.).

Abb. 23: Das "engere Territorium". Dieser Raum muß normalerweise nicht aktiv yom Besitzer verteidigt werden, er wird von der Pyramide gegen Baulustige abgegrenzt.

$\mathrm{E}=$ Eingang, $\mathrm{W}=$ Wegchen, $\mathrm{P}=$ Pyramide

1) Unter Territorium sei hier verstanden: ein Bezirk um den Pyramidenbau herum, den sein Erbauer oder Eroberer, solange er sich in seinem Besitz befindet, notfalls gegen Artgenossen aktiv verteidigt. 
Den meisten Besitzern genügt das Areal, das von ihrer Pyramide abgegrenzt wird. Nur sehr kampfbereite verteidigen vorübergehend - nach bisherigen Beobachtungen nie länger als eine Stunde - ein etwas größeres Revier.

In solch seltenen Fällen oder wenn ein Baulustiger sich ausnahmsweise innerhalb des engeren Territoriums ansiedeln wollte, wurde ausschließlich um das Territorium und nicht um die Pyramidenanlage selbst gekämpft. Auch der Besitzer „wußte" dies, wie folgende mehrfach beobachtete Reaktion es zeigt: Unterliegt ein Höhlenbesitzer im Kampf zur Wahrung seiner Territoriumgrenzen, so flüchtet er immer in seine Höhle, wogegen er bei verlorenem Kampf um die Pyramidenanlage seine eigene Höhle stets aufgibt. Beiderlei Kämpfe können sich in derselben Entfernung vom Höhleneingang abspielen.

Festliegende Territoriumsgrenzen gibt es nicht. Die Größe des verteidigten Areals hängt von der jeweiligen Kampfbereitschaft des Besitzers ab, die ihrerseits wieder damit wechselt, ob der Besitzer gerade baut und wann und wie oft er gekämpft hat; der kleinste von uns beobachtete Radius mit dem Höhleneingang als Mittelpunkt lag bei $90 \mathrm{~cm}$; Neubauer, die diese Entfernung unterschritten, wurden regelmäßig angegriffen - Ausnahmen S. 440, der größte bei etwa $2,5 \mathrm{~m}$. Nie sahen wir einen Besitzer, der versucht hätte, einen Neuansiedler in größerer Entfernung abzuwehren.

Es gibt immer einzelne Pyramidenbesitzer, die ohne ersichtlichen Grund die Höhle eines bestimmten Nachbarn mehrfach zuscharren. Sehr selten kommt es dabei zu kämpferischen Auseinandersetzungen, bei denen dann u. U. die jeweilige Lage der Territoriumsgrenze deutlich wird. Dazu folgender Protokollauszug:

Ein Pyramidenbesitzer läuft in Drohhaltung zur Höhle eines seiner Nachbarn. Als er sie gerade zuscharren will, erscheint der Besitzer am Eingang. Minutenlang stehen sich die beiden reglos gegenüber. Plötzlich geht der Angegriffene in Drohhaltung auf seinen Gegner los, dieser weicht etwas über die Mitte des $2,2 \mathrm{~m}$ langen Weges zwischen den beiden Pyramiden zurück. Dann bleibt er ruckartig stehen, droht nun seinerseits kurz durch Klopfen, greift an und gewinnt den kurzen Kampf.

Ähnlich hängen bei allen territorialen Tieren Angriffs- bzw. Fluchtbereitschaft vom augenblicklichen Standort innerhälb oder außerhalb des eigenen Territoriums ab.

Für die Reiterkrabben- $\sigma^{\top} \sigma^{\top}$ ist die Pyramidenanlage kampfmotivierend. Nie beginnen Krabben, die an demselben Bauplatz bauen möchten, einen Kampf, bevor einer zu bauen begonnen hat; dabei genügt, wie mehrfach beobachtet werden konnte, allein schon die Pyramide ohne zugehörige Spiralhöhle.

In Ägypten werden die Spiralhöhlen und damit die Territorien etwa 4 bis 8 Tage vom selben Tier bewohnt, das in dieser Zeit normalerweise hungert (vgl. die gegensätzlichen Beobachtungen in Äthiopien S. 444): 50 sezierte ägyptische Pyramidenbesitzer, die schon länger als zwei Tage eine Höhle innehatten, hatten alle vollständig leere Mägen. Nach diesen 4-8 Tagen verlassen sie ihre Höhle und das entsprechende Territorium und gehen einige Tage auf Nahrungssuche. Danach streifen sie wieder als aggressive Eindringlinge durch die Kolonie und siedeln sich irgendwo - in einem Fall in $5 \mathrm{~km}$ Entfernung vom alten Platz - wieder an.

Nach ihrer biologischen Bedeutung dienen die Pyramidenterritorien als Wohnung, zur Balz und zur Paarung (S. 443). 


\section{c) Die Bedeutung der Pyramiden für die 우우}

59 Male während der gesamten Beobachtungszeit sahen wir 90 in Spiralhöhlen eindringen und aktiv den Geschlechtspartner aufsuchen, nie dagegen bei $O^{x} O^{x}$ außer dem Pyramidenbau ein Verhalten, das sich als zusätzliches Balzverhalten hätte deuten lassen; ja, es zeigte sich sogar, daß das $O^{\prime 1}$ sich an der Oberfläche gar nicht zu zeigen brauchte, sondern eher störend wirkte. Die Höhlenbauer behandeln auch $q Q$ zunächst immer wie Eindringlinge. Nur die Reaktion der $q O$ auf ihr Drohen ermöglicht es den Höhlenbesitzern, ein $q$ zu erkennen. In jedem Fall ist das $\sigma^{7}$ erst nach Abschluß des Pyramidenbauens paarungsbereit. Während des Bauens sind sie so aggressiv, daß sie jeden Artgenossen, der sich ihrer Höhle nähert, als Eindringling abweisen.

In mehr als 50 Fällen sahen wir $q 9$ Höhlen anlaufen, ohne daß das $\sigma^{7}$ an der Oberfläche war. Die Vermutung, daß lediglich der Anblick der Pyramiden paarungsbereite 우 zu den Spiralhöhlen lockt, ließ sich mit künstlichen Sandkegeln erhärten. In 9 Wahlversuchen entschieden sich 4 우 für eine künstliche, 5 für eine natürliche Pyramide.

Das Verhalten der $q Q$ am Pyramidenbau unterscheidet sich zunächst in nichts von dem männlicher Eindringlinge: Die Pyramide löst das Suchen nach dem Eingang aus; dann kriecht es in die Höhle und ertastet ihren Drehsinn. Das Stridulieren des Besitzers als Antwort auf das In-die-Höhle-Kriechen wirkt auf paarungsbereite $O Q$ anlockend, während es bei männlichen Eindringlingen Drohen und bei vagabundierenden, nichtaggressiven Ocypoden, die sich bei Gefahr oft in irgend einer Spiralhöhle zu verstecken suchen, Flucht auslöst.

Ich habe versucht Belege dafür zu erbringen, daß nur wirklich paarungsbereite $Q Q$ in die Höhle eindringen.

18 우, die eine Spiralhöhle aufgesucht hatten, wurden spätestens eine Std. danach ausgegraben und seziert. Alle zeigten nach Größe und Farbe beurteilt darauf soll an anderer Stelle genauer eingegangen werden - voll reife Ovarien, ebenso die 6 sezierten $\not \subset$, die beim Anlaufen von Pyramiden gefangen werden konnten, und leere oder höchstens $1 / 4$ gefüllte Samenblasen. 5 nach frühestens 2 Std. ausgegrabene $\$$ 우 wiesen denselben Ovarienzustand auf, die receptacula seminis waren aber prall gefüllt.

Alle 28 ausgegrabenen 9 ㅇ waren gleichhändig mit den Höhlenbesitzern, was zeigt, daß sich offensichtlich nur Gleichscherige miteinander paaren.

\section{d) Die Pyramide als kurzzeitige Orientierungshilfe}

Die bisher beschriebenen Signalfunktionen der Pyramide bezogen sich nur auf den Sozialpartner. Aber auch dem Besitzer leistet sie kurzzeitige Orientierungshilfe.

In natürlichen Ablauf der Bauhandlungen unternehmen die Pyramidenbauer kurz vor oder nach Abschluß des Bauens Orientierungsgänge (S. 409). Im Versuch lassen sich diese durch starkes Verändern von Form und Größe der Pyramide auslösen.

Der experimentelle Nachweis der biologischen Bedeutung dieses Verhaltens war schwierig. Die Pyramidenbesitzer behalten während der Orientierungsgänge ihre Pyramiden ständig im Auge, und sic beantworten die geringste Versetzung derselben mit blitzschneller Flucht. Nie glückte cs, sie während der Orientierungsgänge hinter ein $15 \mathrm{~cm}$ hohes Brett oder in eine Vertiefung zu locken, um dann die Pyramide versetzen zu können. Immerhin ist es viermal doch gelungen, während eines Orientierungsganges des Besitzers seine Pyramide um ungefähr 25, 30 und zweimal $40^{\circ}$ zu verschieben (vgl. Lagebeziehung der Pyramide zum Höhleneingang S. 420).

Während der Besitzer jeweils durch einen Eindringling oder Nachbarn abgelenkt war, zogen wir die auf einem unter dem Sand verborgenen Blech sitzende Pyramide mit einer Angelschnur zur Seite. Alle vier Besitzer fanden ihre Höhle nicht wie üblich beim ersten Anlauf von der Pyramide her, sondern immer erst nach langem, aufgeregtem, zickzackförmigem Hin- und Herlaufen; immer wieder rannten sie zur Pyramide zurück und suchten von ihr aus den Eingang, ohne dabei den ungefähren Abstand zwischen Pyramide und Höhle wesentlich $z u$ überschreiten. 
Siegreiche Eindringlinge verfolgen manchmal den flichenden Besitzer einige in weit. Da sie sich nach der Pyramide zur entsprechenden Höhle orientieren, unterlaufen ihnen zwischen anderen Bauten nicht selten Irrtümer. Dazu folgender Protokollauszug:

Ein Eindringling marschiert auf eine Pyramide zu, geht von dieser aus zum Eingang, kriecht in die Höhle, erscheint sofort wieder und klopft heftig auf dem Vorplatz. Augenblicklich kommt der Besitzer heraus. Nach längerem Kampf gewinnt der Eindringling die Oberhand und verfolgt den Besitzer mehr als $2 \mathrm{~m}$ weit, dreht dann um und läuft zu einer falschen Pyramide zurück. Auf dem Weg zum Eingang bemerkt er seinen Irrtum, bleibt zögernd stehen und marschiert dann langsam weiter zur nächsten, auch falschen Pyramide. Drohend geht deren Besitzer auf ihn zu, aber der Eindringling läßt sich auf keinen Kampf ein. Der vertriebene alte Besitzer beobachtete dies, etwa $4 \mathrm{~m}$ vom Eingang seiner Höhle entfernt sitzend, und während der desorientierte Sieger zur zweiten falschen Pyramide ging, rannte er in seine Höhle zurück.

Wie sich bei der Beobachtung vieler Orientierungsgänge zeigte, macht der Bauherr nur während der ersten 2-4 Erkundungsgänge den Umweg über die Pyramide zur Höhle (S. 409); weiterhin läuft er immer direkt nachhause. Ohne daß weitere Orientierungsgänge stattfänden, findet der Besitzer, selbst wenn keine Pyramide mehr vorhanden ist, den Eingang mit sehr großer Sicherheit wieder. Das sahen wir besonders oft nach Kämpfen vor Wiederaufbaubeginn der Pyramiden, bei denen der besiegte Eindringling meterweit verfolgt wurde. Sehr selten gehen auch einzelne Individuen vor Wiederaufbaubeginn zum Strand, um sich Atemwasser zu holen, und auch dann fanden die Zurückkommenden ihren Höhleneingang ganz ohne Schwierigkeiten.

Demnach dürfte die Pyramide während der Orientierungsgänge wohl als kurzzeitige Orientierungshilfe dienen. Was sie bei diesen Orientierungsgängen erkunden, bleibt noch zu untersuchen, vermutlich Landmarken und die Lagebeziehung des Höhleneingangs zur Pyramide. Wie weit sie sich beim direkten Anlaufen des Eingangs bei fehlender Pyramide nach der Sonne oder auch dem polarisierten Licht (Daumer, Jander und Waterman 1963, Altevogt und v. Hagen 1964, Altevogt 1965) orientieren, wurde nicht untersucht.

\section{E BEOBACHTUNGEN AN O. saratan in ATHIOPIEN}

$\mathrm{Da}$ O. saratan in Ägypten überwiegend tagaktiv ist, war es höchst überraschend, bei Massawa - bei eindeutig derselben Art (vgl. GUINOT) - eine fast ausschließlich nachtaktive Population vorzufinden. Nur wenige Tiere sahen wir früh morgens oder spät abends bei Tageslicht auf Nahrungssuche. Das gesamte Fortpflanzungsverhalten (im weitesten Sinne) war rein auf die Nacht beschränkt, ohne daß sich Bindendes über die Ursachen und einen etwaigen Selektionsvorteil dieses Unterschiedes sagen ließe. Die Annahme einer vom Klima, besonders der Temperatur induzierten Aktivitätsverlagerung erscheint mir dabei am wahrscheinlichsten. Noch im Dezember, dem „kältesten“ Monat, lagen in Massawa die Durchschnittstemperaturen an einem regenlosen Tag bei ungefähr $40^{\circ} \mathrm{C}$ und sanken in der Nacht kaum unter $30^{\circ} \mathrm{C}$. In Ägypten erlosch die Aktivität bei etwa $40^{\circ} \mathrm{C}$ im Schatten.

\section{a) Zur Ơkologie des Beobachtungsplatzes}

In Massawa besiedelt die Art nur einen 2-7 $\mathrm{m}$ breiten Feinsandstreifen (Abb. 24), an den sich landeinwärts entweder 3-10 $\mathrm{m}$ hohe bewachsene Sanddünen (an deren Fuß zahlreiche $O$. cordimana leben) oder ausgedehnte, sehr tief liegende Quellerflächen mit Massenvorkommen von Uca tetragonon anschließen.

Die Pyramidenbauten liegen ausschließlich in der $1-3$, im Mittel $2 \mathrm{~m}$ breiten Spritzwasserzone. Wie in Ägypten war auch hier der untersuchte, etwa $4 \mathrm{~km}$ lange Küstenabschnitt nicht gleichmäßig besiedelt, sondern es gab zwei kleine Kolonien, am 23.12. 1965 mit 59 bzw. 15 bewohnten Pyramidenbauten und eine große mit weit über 1000 Einwohnern.

Infolge der hier herrschenden Strömungs- und Windverhältnisse liegt das Wohngebiet noch innerhalb des Weide- und Jagdgebietes (Abb. 24). Mehrfach beobachteten wir Pyramidenbesitzer bei der Nahrungsaufnahme, während die ägyptischen Pyramidenbesitzer hungerten (S. 422). 


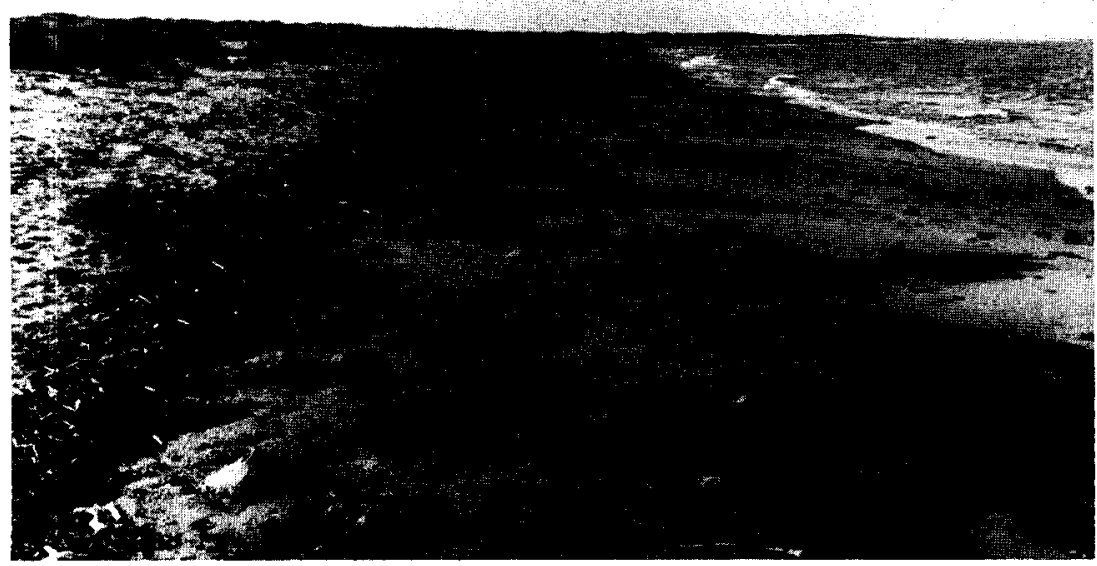

Abb. 24: Kolonie von O. saratan an unserem Beobachtungsplatz bei Massawa. Das Pyramidenbaugebiet liegt noch innerhalb des Nahrungsgebietes (vgl. dagegen Abb. 1)

b) Pyramidenbauverhalten und Vibrationserzeugung in Athiopien

Wie Beobachtungen bei völlig bedecktem Himmel zeigten, wird hier auch bei vollständiger Dunkelheit gebaut, ohne daß die Anlagen wesentlich anders ausfielen als die tags gebauten ägyptischen. Nur in der Lage der Pyramide zur Höhle gab es Unterschiede:

Der Weg ist in Äthiopien signifikant $(\mathrm{p}=0,001)$ kürzer als in Agypten $(M=36 \pm 9,5, n=100$, gegenüber $52 \pm 11 \mathrm{~cm}, \mathrm{n}=250)$. Ein ebenso signifikanter Unterschied besteht bei der Lagebeziehung der Pyramide zum Höhleneingang. Während die unter natürlichen Umständen in Ägypten gebauten Pyramiden bei $43 \pm 13,6^{\circ}$ liegen, betrug der mittlere Richtungswinkel in Äthiopien $52 \pm 11,1^{\circ}$ (beidemale $\mathbf{n}=100$ ).

Wie die ägyptischen Versuche zur Lageprüfung der Pyramide zeigten, fallen die Annahme- und die Bauvorzugsrichtung nicht zusammen (vgl. S. 425). Erstere wird bei Vorhandensein richtender optischer Reize möglichst nahe zur Nullinie hin verschoben, wogegen - wenn solche Marken fehlen oder wie in Athiopien im Dunkeln unsichtbar sind - die Austragrichtung stärker von der Nullinie abweicht.

Daß die Bewegungskoordination auch im Dunkeln gut gesteuert werden kann, zeigte sich beim Ausmessen der Weglänge und Pyramidenrichtung. Beide Größen streuten in Athiopien signifikant weniger als in Ägypten.

Da weder das Entfernen des Wegs noch das Aufschütten von lockerem Sand in der Höhlenumgebung die Krabben störte, können sie sich nicht rein taktil orientiert haben. Auch Abschirmen des Windes ließ die Orientierung zur Pyramide unbeeinflußt. Zwang man die Krabben aber auf dem Rückweg zur Höhle zu einem Umweg (es wurde bei schwachem Taschenlampenlicht beobachtet, auf das die Krabben nicht reagierten), so verloren sie die Orientierung vollständig und liefen solange im Zickzack umher, bis sie offensichtlich zufällig eine Höhle ertasteten: In 23 Einzelversuchen fanden nur 2 die eigene Höhle, 21 verschwanden in einer fremden oder liefen zum Wasser und gruben sich dort in den lockeren Sand ein. 
Diese Befunde sprechen für kinaesthetische Richtungs- und Entfernungsorientierung beim Pyramidenbau während völliger Dunkelheit (vgl. v. HageN 1967). Sehr wahrscheinlich ist dieselbe kinaesthetische Orientierungskomponente auch dafür verantwortlich, daß bei fehlenden richtenden Erhebungen auch die tagaktiven ägyptischen Reiterkrabben in der Richtung so stark von der Nullinie abweichen (S. 424).

Angesichts dieser Befunde fragt es sich natürlich, ob die Pyramide unter diesen Umständen dieselben Signalfunktionen wie in einer tagaktiven Population hat.

Nachtaktive, fressende Reiterkrabben in Agypten reagierten erkennbar optisch nur bei Mondschein, nicht bei sternklarem und erst recht nicht bei ganz bedecktem Himmel. Ein ruhig stehender Mensch löste erst Flucht aus, wenn ihn die Krabben berührten, ein gehender nur durch die Erschütterungen des Bodens durch seine Schritte. Die äthiopischen Pyramidenbesitzer und Eindringlinge unterscheiden sich in dieser Beziehung nicht von bei Dunkelheit futtersuchenden ägyptischen.

Niemals konnte beobachtet werden, daß Eindringlinge bei Dunkelheit Pyramiden gerichtet anliefen (zu Beobachtungen in mondhellen Nächten war bisher noch keine Gelegenheit). Nur wenn der Eindringling zufällig an eine Pyramide gestoßen ist, kann sie auch bei Dunkelheit ebenfalls nur taktiles Suchen nach dem Höhleneingang auslösen. Aber dazu kommt es nur selten: nach unseren bisherigen Beobachtungen liefen 16 von 21 Eindringlingen, die eine Höhle suchten, zum Eingang ohne Umweg über die Pyramide.

Demnach haben die Pyramiden - zumindest in mondlosen Nächten ihre optische Signalfunktion verloren, und auch ihre taktilen Signalreize haben nur untergeordnete Bedeutung.

Beim umweglosen Aufsuchen des Höhleneingangs stießen die Eindringlinge ( $q Q$ beobachteten wir in Äthiopien nie beim Aufsuchen einer Spiralhöhle) meist nicht zufällig darauf, sondern liefen ihn aus Entfernungen von 40$110 \mathrm{~cm}$ gerichtet an.

Es sind das Klopfen und Stridulieren des Besitzers, also Vibrationssignale, die bei Dunkelheit fremden Krabben den Weg zur Höhle zeigen.

Der Besitzer klopft oft spontan, häufig auch erst, wenn eine Krabbe in unmittelbarer Nähe seiner Höhle vorbeiläuft. (Die Vibrationserzeugung soll an anderer Stelle ausführlich behandelt werden.)

Wie bei einigen $U c a-A r t e n$ (vgl. vor allem v. HAgen 1962, SALMON 1962, Salmon und Stout 1962) treten auch bei O. saratan, wenn optische Signale versagen, vibratorische an ihre Stelle.

Wie das Verhalten der Eindringlinge bei Dunkelheit, so weist auch die gleichartige Koloniebildung - die mittleren Abstände neuerbauter Pyramiden innerhalb der äthiopischen Kolonie betrugen $147 \pm 53 \mathrm{~cm}$, vgl. dazu Tab. 14 und S. 440 - darauf hin, daß die Vibrationssignale die wichtigsten Signalfunktionen der Pyramide zu ersetzen vermögen, jedoch nur in einem engeren Entfernungsbereich: In Ägypten wurden bei Tage Pyramiden aus $5 \mathrm{~m}$ Entfernung gerichtet angelaufen, während das Klopfen in Äthiopien auf höchstens $1,1 \mathrm{~m}$ Abstand gerichtetes Aufsuchen des Höhleneingangs ermöglichte.

\section{F ZUR FRAGE DER STAMMESGESCHICHTE DES PYRAMIDENBAUVERHALTENS}

Beim eng-fächerförmigen Sandauswurf in Höhleneingangsnähe dürfte es sich um eine der ältesten Austragweisen handeln. Bei den meisten Ocypode- 
und $U c a-A r t e n$ finden wir es, und konnten es auch bei $O$ cordimana und $O$. cursor beobachten. Aus der Literatur ist es u. a. von O. albicans (Cowles) und O. quadrata (MiLNE und MiLNE) bekannt. Bei O. saratan tritt es am häufigsten beim Bau der stammesgeschichtlich wahrscheinlich sehr alten Schlafhöhlen auf, die im Infralitoral oder am Spülsaum gebaut werden. Da meines Wissens sämtliche Ocypodidae Höhlen bauen und sehr viele Arten nur im Höhleninneren kopulieren, dürften Kopulationshöhlen stammesgeschichtlich alt sein.

Als die Krabben begannen, statt Höhlen in jedem Fall selbst zu bauen, sie auch zu erobern und dann zusätzlich - vermutlich auf dem Umweg über das Neugierverhalten, das ja auf fast jede Erhöhung anspricht - die Fähigkeit ausgelesen wurde, Höhlen am frischen Auswurf zu erkennen, da konnte eine disruptive Selektion am Austrageverhalten ansetzen und die Differenzierung zweier gegensätzlicher Verhaltensweisen bewirken: Erstens das breit-fächerförmige Austragen, bei welchem im typischen Fall keine zwei Ladungen Sand an dieselbe Stelle geworfen werden (Abb. 25). Am ebenmäßigsten sind die

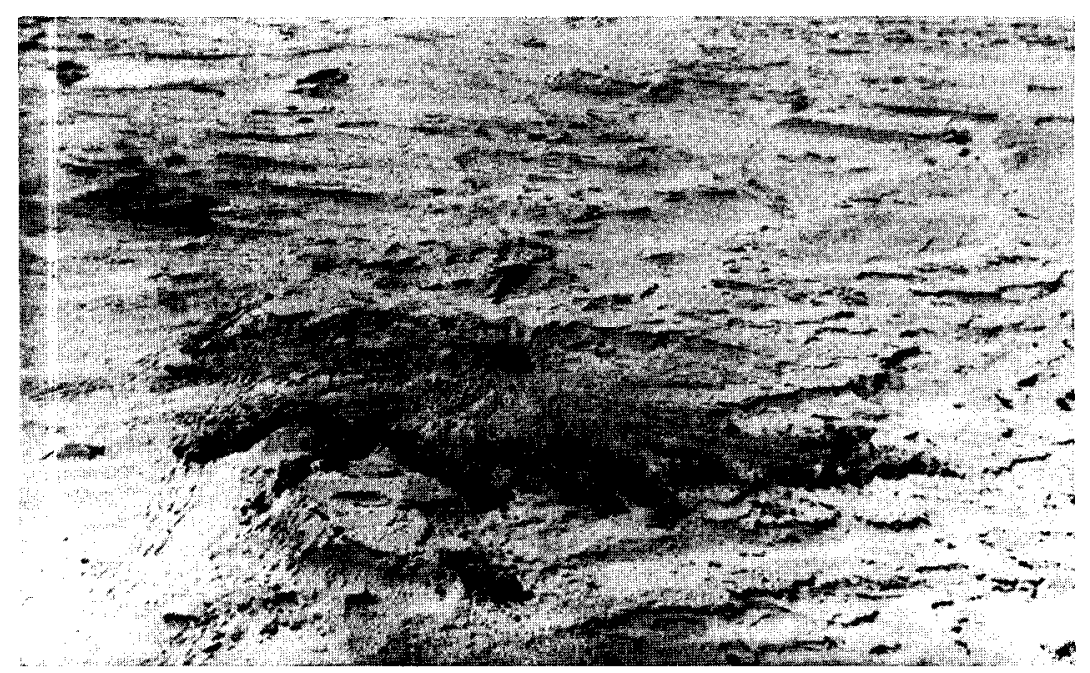

Abb.25: Breitfächerförmig ausgetragener Sand bei einer Schlafhöllle. Beim schwungvollen Wegschleudern zerbrechen die Klumpen. Trotzdem noch entstandene Erhöhungen werden of $t$ gezielt einplaniert

Fächer bei der am längsten, bis zu 18 Tage bewohnten Häutungshöhle, die lange Zeit nicht verteidigt werden kann. Der gleichmäßig verteilte Sand ist nachgewiesenermaßen wenig auffällig. Dieses Verhalten tarnt also die Höhle (in der Regel wird sie auch noch verschlossen).

Das genau konträre Verhalten ist der Pyramidenbau, bei dem der größte Teil des anfallenden Baustoffs zu einer möglichst hohen Anhäufung aufgeschichtet wird.

$\mathrm{Da}$ die Bewegungskoordination des fächerförmigen Austragens bei allen untersuchten Arten genau gleich ist, handelt es sich dabei mit großer Wahrscheinlichkeit um eine stammesgeschichtlich alte und homologe Verhaltensweise. Das Pyramidenbauverhalten, das bisher nur von O. saratan bekannt ist und mehreren Arten sicher fehlt, dürfte sich erst später entwickelt haben.

Leider wissen wir noch zu wenig über das Verhalten der anderen Ocypodearten. Bei $O$. cursor fanden wir bei den Höhlen adulter $O^{\pi} O^{\pi}$, die ihrer Größe nach als Paarungshöhlen hätten dienen können, als Austragform immer durch 
eng-fächerförmigen Auswurf entstandene "Maulwurfshaufen" (Abb. 26). Ein Nachweis, daß diese anlockende und orientierende Wirkung haben, konnte noch nicht erbracht werden. Immerhin haben wir aus den zugehörigen Höhlen immer nur $O^{7} O^{7}$ ausgegraben. Die $q Q$ verteilen ihren ausgegrabenen Sand über eine größere Fläche, planieren sorgfältig und verschließen den Höhleneingang (Abb. 27).

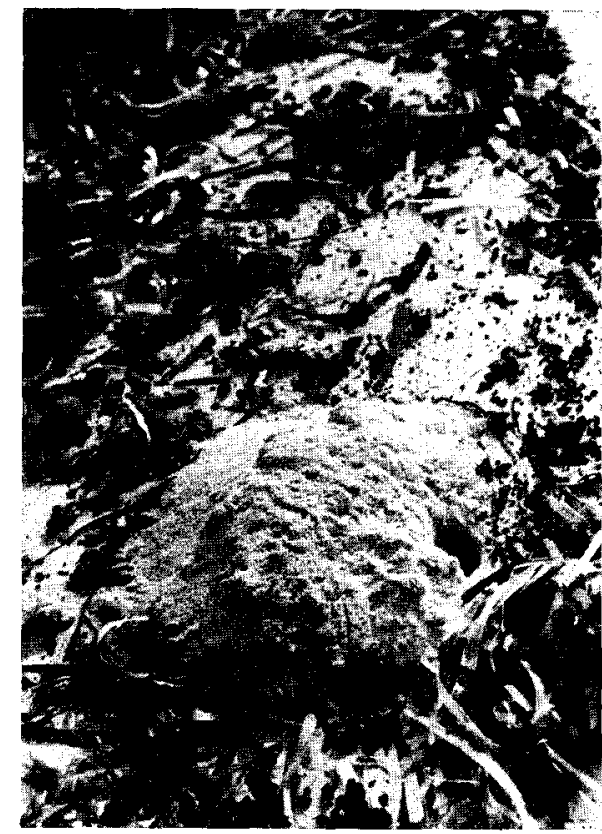

Abb. 26 (links): Austragweise bei Höhlen der ôे von O. cursor Abb. 27 (rechts): Austragweise eines 9 von 0. cursor

Nimmt man an, das Pyramidenbauverhalten habe sich aus der eng-fächerförmigen Austragweise - in Form und Austragweise entsprechen sich Sockelbau (Abb. 28) und Maulwurfshaufen - entwickelt, so bleibt noch unverstanden, wie es zum Wegbauverhalten kam. Es ist zwar vorteilhaft, daß die Pyramide nicht direkt beim Eingang steht, weil sonst dauernd Sand von ihr in die Höhle rieseln würde; unklar ist aber bislang, welchen Selektionsvorteil die $\sigma^{\prime \prime} \sigma^{x}$ durch die etwa $50 \mathrm{~cm}$ langen Wege gewonnen haben sollten.

Im Gegensatz zur Frage nach den selektionierenden Faktoren ist die nach der möglichen Evolution dieses Verhaltens theoretisch nicht schwer zu beantworten: Der Weg ist nach seiner Lagebeziehung zur Höhle eine verlängerte Projektion der Höhlenspirale auf die Sandoberfläche. Das $\sigma^{\top}$ trägt auf dem Weg ebenso aus wie in der Höhle, die Richtung des Austragens ist durch den Verlauf der Spiralhöhle in Grenzen festgelegt, und der Bauende schleudert seine Sandklumpen ebenso schwungvoll weg wie beim Bau des Maulwurfhaufens. Zwei Fähigkeiten mußten erworben werden, bevor der Wegbau die heutige Form gewann: erstens die innerhalb der Höhle erzwungene Austragrichtung außerhalb beizubehalten und zweitens die Austragweite schrittweise zu steigern.

Auf Grund der Schlüsse, die sich aus dem Vergleich von Sockel- und Wegbau mit dem Maulwurfshaufen ergeben, deute ich den Pyramidenbau von O. saratan als ein modifiziertes und differenziertes Austragverbalten, das sich 
- aus dem eng-fächerförmigen Sandauswerfen entstanden - in drei Richtungen zum Weg-, Sockel-und Spitzenbau weiterentwickelt bat.

Das Produkt dieses Austragverhaltens hat Signalwert gewonnen, wobei das Neugierverhalten, das auf alle möglichen Erhebungen anspricht, praedisponierend wirkte.
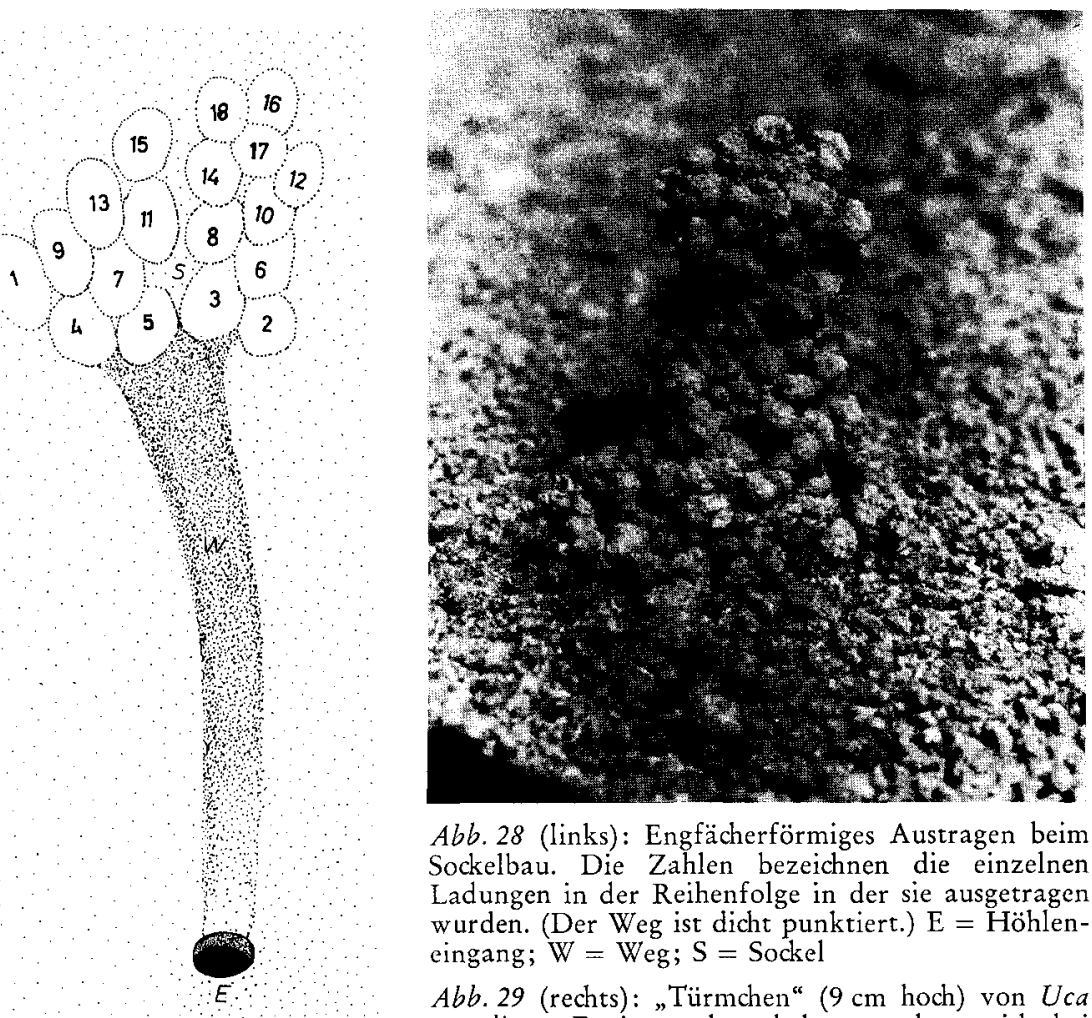

Abb. 28 (links): Engfächerförmiges Austragen beim Sockelbau. Die Zahlen bezeichnen die einzelnen Ladungen in der Reihenfolge in der sie ausgetragen wurden. (Der Weg ist dicht punktiert.) $\mathrm{E}=$ Höhleneingang; $\mathrm{W}=\mathrm{W}$ eg; $\mathrm{S}=$ Sockel

$A b b .29$ (rechts): "Türmchen" $(9 \mathrm{~cm}$ hoch) von Uca annulipes. Es ist noch unbekannt, ob es sich bei diesen Bauten um pyramidenanaloge Signale handelt

Das Pyramidenbauverhalten, als aktives, optisches Markieren des Kopulationsplatzes, welches dauerndes Signalisieren des Erbauers selbst überflüssig macht - ist in dieser hochentwickelten Form eine - soweit bekannt - einzigartige Erscheinung im Tierreich. Am ehesten noch vergleichbar sind die Balzplätze der Laubenvögel (z. B. A. J. MarshalL). Doch erhöhen die Lauben nur die unentbehrliche Wirkung des sichtbaren $C^{7}$ und seiner artgemäßen Balzweisen.

An einen anderen Sinn wenden sich als ebenfalls vom Körper losgelöste Signale die Duftmarken z. B. auf den Schwärmbahnen der Hummeln (Frank; HaAs 1949a, b, 1960; Krüger; Stein 1956, 1963), anderer Hymenopteren (vgl. Vogel) und in den Paarungsrevieren vieler Säugetiere.

Bei einigen Uca-Arten (z. B. Minuca latimana Crane 1941, Minuca stenodactyla und M.terpsichores PETERS; nach eigenen Beobachtungen vor allem bei Uca annulipes (Abb. 29) und Uca tetragonon) gibt es Bauten, die $\mathrm{da}$ sie nach eigenen Beobachtungen bei $U$. annulipes nur von balzenden (= winkenden) $\sigma^{\prime \prime} \sigma^{\prime}$ errichtet werden - pyramidenanaloge Signalfunktion haben könnten. Nach Literaturangaben sollen sie dieses Bauverhalten nur sporadisch 
(Crane spricht von einer "Mode“) und regellos zeigen. Die Form der Bauten wechselt stark von Art zu Art; häufig sind es Ringwälle um den Eingang, die zu relativ hohen Schornsteinen werden können, igluartige Strukturen, wie auch Dotilla sie gelegentlich baut (AltevoGt 1957 und eigene Beobachtungen), Hauben oder mehr oder weniger säulenförmige Materialanhäufungen. Über etwaige Funktionen aller dieser Bauten ist nichts bekannt.

Bei den $U c a$-Arten herrscht, soweit wir wissen, am Tag im freien Gelände immer die optische Signalgebung vor, die nachts - oder auch bei Tag z. B. in dichtem Bewuchs (v. HAGEN 1962) - durch Vibrationssignale ersetzt wird.

Mit einer Ausnahme haben alle Ocypode-Arten Stridulationsleisten; bei O. cordimana, der sie fehlen, konnte ich Klopfsignale feststellen. So dürften wohl alle Ocypode-Arten Vibrationssignale erzeugen können. Optische Signalgebung ist dagegen bisher nur von $O$. saratan bekannt und in dieser spezifischen Form - dem Pyramidenbau - sicher nicht weit verbreitet. Deshalb scheint die Annahme berechtigt, daß in der Gattung Ocypode die Vibrationserzeugung phylogenetisch älter ist als der Pyramidenbau, ja vielleicht älter als die Gattung Ocypode selbst.

Fassen wir kurz zusammen, so mögen 5 aufeinanderfolgende Schritte zum Pyramidenbau geführt haben:

1. Eroberung des Infralitoral als Lebensraum.

2. Entwicklung der Grundkoordinationen des den Gattungen Uca und Ocypode gemeinsamen Höhlenbauverhaltens.

3. Kopulationsplätze wurden ausschließlich oder zumindest bevorzugt die erweiterten Männchenhöhlen. So mußten paarungsbereite $Q$ 오 Männchenhöhlen finden und die paarungsbereiten $\sigma^{7} \sigma^{7}$ hatten einen Vorteil, wenn sie auf ihre Höhlen hinweisen konnten; zunächst geschah dies wahrscheinlich über Vibrationssignale.

4. Funktionserweiterung des freßmotivierten Neugierverhaltens: Auch in Höhlensuchstimmung werden Erhöhungen angelaufen, wie sie durch den Auswurf beim Höhlenbau entstehen. So wurde das Nebenprodukt des Höhlenbauverhaltens zum optischen Signalreiz.

5. Die Selektion setzte an diesem Signalreiz an und bewirkte seine Entwicklung zu größerer Auffälligkeit hin, auf der anderen Seite - wahrscheinlich aber schon wesentlich früher - entstand das gegenteilige Höhlentarnverhalten, breit-fächerförmiges Austragen, da es für alle nicht paarungsbereiten Tiere lediglich Nachteile mit sich bringt, wenn sie auf ihre Höhlen "hinweisen“.

Es läßt sich bisher noch nicht sagen, zu welchem Zeitpunkt im Verlauf der Evolution dieses Verhaltens die Reiterkrabben das Supralitoral als Lebensraum eroberten. Mit Sicherheit hat sich das Pyramidenbauverhalten erst im Supralitoral in Wegchen-, Sockel- und Spitzenbauverhalten in der heutigen Form ausdifferenziert, denn nur ein Baustoff von der Konsistenz des Sandes im Supralitoral läßt sich so bearbeiten. Auch das Ausschachten und Ausscharren (S. 407), der Ausbau des Eingangs (S. 408) und wohl auch das Offenlassen der Spiralhöhlen dürften sich erst entwickelt haben, als die Krabben im Supralitoral zu bauen begannen.

\section{A. Der Bau der Pyramidenanlage}

1. Nur erwachsene $\sigma^{\prime} \sigma^{\prime}$ von $O$. saratan bauen Pyramidenanlagen. bestehend aus Sandpyramide, Weg, Vorplätzchen und Spiralhöhle (Abb. 2). Letztere ist im oder entgegen dem Uhrzeigersinn gedreht, je nachdem, ob die kleine 
Schere links oder rechts sitzt. Alle übrigen Höhlentypen sind nicht spiralig gewunden und haben keine Pyramide neben sich.

2. Das Pyramidenbauverhalten besteht aus einer Kette von Einzelbauhandlungen. Durch bestimmte Signalreize (S. $409 \mathrm{ff}$ ), die nur in kurzen sensiblen Phasen, nämlich beim „ersten Auftauchen “ (S. 415 ff) zu Beginn einer Bauphase oder bei einem Inspektionsbesuch wirken, kann das Verhalten beim Wiederaufbau der Pyramide an jedem Glied der Kette „angestoßen“ werden; dann aber läuft die Folge weitgehend unbeeinflußbar ab.

3. Die Einzelhandlungen und die sie auslösenden Reize sind folgende:

a) Das „Ausschachten“ wird durch trockenen Sand ausgelöst. Die Richtung, in die das $\sigma^{7}$ den Sand schleudert, bestimmt auch die Richtung des Wegchens und die Offnungsrichtung der Höhle, die meist meerwärts zeigt (Abb. 9). Somit ist der Küstenverlauf ein das Ausschachten richtender Reiz; auch eine schon vorhandene Erhöhung kann richtend wirken.

b) Feuchter Sand im „geraden Anfangsabschnitt" der Spiralhöhle löst den Wegbau aus. Außer den genannten richtenden Reizen bestimmt die Händigkeit den Verlauf des Weges (vgl. Abb. 8). Zum Neubau einer Pyramidenanlage gehört auch in jedem Fall der Wegbau; dagegen wird beim Neuerrichten einer Pyramide nur dann ein Weg gebaut, wenn mindestens $1200 \mathrm{~cm}^{3}$ Füllstoff verfügbar sind. Ferner unterbleibt der Wegbau, wenn beim ersten Auftauchen zu Beginn einer Bauphase Sodkel- oder Spitzenbau ausgelöst wird.

c) Das wegbauende $\sigma^{7}$ schleudert seine herausgeschafften Sandladungen so weg, daß jede ungefähr an die vorhergehende anschließt; beim Sockelbau schüttet es sie dagegen eng-fächerförmig auf (Abb. 28). Beim Neubau löst feuchter Sand im „Knick“ (S. 408) Sockelbau aus, richtend wirkt das Wegende. Beim Wiederaufbau bestimmen 2 Faktoren, ob und in welcher Größe ein Sockel gebaut wird: 1 . der Zustand der Pyramide, den das $\sigma^{\prime \prime}$ optisch vom Eingang aus beurteilt, und 2. die Menge verfügbaren Baustoffes. Es wird immer eine möglichst hohe Pyramide gebaut. Sockel- und Wegbau wirken triebreduzierend.

d) Dem Sockelbau folgt immer der durch vorsichtiges Aufsetzen der Sandladungen unterschiedene „Spitzenbau“. Auslösend wirkt feuchter Sand im Knick und dem Endabschnitt der Spiralhöhle, aber erst nach Erschöpfung des Sockelbautriebes. Spitzenbau ist keine triebreduzierende Handlung; es fehlt auch jede hemmende "Pyramidenreafferenz".

e) Das „Ausbauen des Eingangs“ wechselt normalerweise mit „Planieren“ ab. Der "Vorplatz" entsteht dabei als Nebenprodukt (S. 408).

4. Ein Wiederaufbau der Pyramide läßt sich sowohl durch mindestens $200 \mathrm{~cm}^{3}$ Füllsel als auch durch Abtragen der Pyramide auslösen (S. 409).

5. Nur aus der Höhle ausgegrabener Sand dient dem Pyramidenbau. Da die Spiralhöhle auch bei Sandsturm normalerweise nicht verschlossen wird, ist die Windzerstörung der Pyramide mit Baustoffgewinn verbunden.

6. Die tageszeitlich schwankende Baubereitschaft wird weder über einen Triebstau noch über eine Triebreduktion von den Bauhandlungen her beeinflußt.

\section{B. Die Lagebeziebung der Pyramidenelemente zueinander}

7. Die Pyramide liegt immer auf der auf die Oberfläche projizierten Verlängerung der Höhlenspirale. Der Winkelbereich, in dem sich eine Pyramide quer zu dieser verschieben läßt, ohne abgelehnt zu werden, ist bei allen Pyramidenanlagen gleichscheriger Besitzer derselbe (Abb. 11). Bei fehlenden optisch richtenden Reizen werden Lage und Entfernung kinaesthetisch bestimmt. 
8. Alle Pyramiden lassen sich in einem Bereich von $20-65 \mathrm{~cm}$ vom Höhleneingang verschieben, ohne abgelehnt zu werden. Die tagaktiven ägyptischen Reiterkrabben beurteilen die Entfernung mittels eines echten Entfernungssehens.

\section{Das Erkennen der eigenen Pyramide} Höhle.

9. Der Besitzer erkennt seine Pyramide nur an ihrer Lagebeziehung zur

10. In Form, Größe und „Farbe“ der Pyramide erträgt der Besitzer weit stärkere Veränderungen als solche der Konsistenz ihres Baustoffes.

\section{Die sozialen Funktionen der Pyramidenanlage}

11. Pyramiden sind der wichtigste Signalreiz bei der Koloniegründung (S. 432).

12. Für aggressive Eindringlinge, die versuchen, sich eine Pyramidenanlage zu erobern, sind die Pyramiden „erstarrte Imponiersignale“, welche Rivalenkampf motivieren.

13. Die Pyramiden „zwingen“ Neubauer, bei ihrer Bauplatzwahl einen durchschnittlichen Mindestabstand von $134 \mathrm{~cm}$ von den nächsten Pyramiden einzuhalten.

14. Die Pyramiden zeigen den $\$ Q$ den Weg zu den Paarungsplätzen, d. h. den Spiralhöhlen. Außer dem Pyramidenbau verfügen die Reiterkrabben über kein der Fernanlockung dienendes weiteres Balzverhalten. Vibrationssignale gaben die $O^{7} O^{x}$ in Ägypten erst, wenn das $q$ schon dicht beim Höhleneingang war.

15. Aggressive Eindringlinge und paarungsbereite $Q 9$ 9 erkennen die Pyramide an der Größe, Form, Konsistenz und wahrscheinlich auch der Farbe (bzw. dem Helligkeitsgrad). Sie löst über optische und taktile Signalreize ein Suchen nach dem Eingang der Höhle aus, deren Drehsinn beim Hineinkriechen ertastet wird. Eindringlinge kämpfen normalerweise nur um Höhlen, die einen ihnen entsprechenden Drehsinn aufweisen, auch paarungsbereite $q+{ }^{\circ}$ suchen so nach einem gleichscherigen Partner.

16. Die Pyramidenbesitzer verteidigen ein Territorium rund um ihre Pyramidenanlage. Es dient als Wohn-, Balz- und Paarungsort.

17. Pyramidenanlagen bewohnt derselbe Besitzer in Ägypten 4-8 Tage lang; in dieser Zeit hungert er.

\section{E. Unterschiede im Verbalten bei den äthiopischen Reiterkrabben}

18. Die in Äthiopien beobachteten Reiterkrabben waren fast rein nachtaktiv. Von einigen geringen Unterschieden (S. 445) abgesehen entsprechen die bei vollständiger Dunkelheit gebauten äthiopischen Pyramidenanlagen den ägyptischen.

19. Zumindest in mondlosen Nächten haben die Pyramiden dort ihre Signalfunktion verloren. Infolgedessen spielen die phylogenetisch wahrscheinlich älteren Vibrationssignale eine viel größere Rolle im Sozialverhalten der nachtaktiven äthiopischen Reiterkrabben.

\section{F. Die Evolution des Pyramidenbauverbaltens}

20. Das Pyramidenbauen wird als ein modifiziertes und dreifach - in Weg-, Sockel- und Spitzenbau - differenziertes Austragverhalten gedeutet, 
das sich aus der eng fächerförmigen Austragweise, dem "Maulwurfshaufen“, entwickelt hat. Das Produkt dieses Austragverhaltens hat Signalcharakter bekommen.

Aus dem deutlich ausgeprägten "Neugierverhalten“, das von fast jeder Erhöhung ausgelöst wird, und der Beschränkung der Paarungen auf die Höhlen erwuchs eine Prädisposition zum Pyramidenbau, andererseits aber auch zu dem konträren, die Höhle tarnenden Verhalten des breit fächerförmigen Austragens (S. 447 und Abb. 25).

21. Das Pyramidenbauverhalten - als aktive optische Markierung des Paarungsplatzes mit körperfremdem Baustoff, die ohne weiteres Mitwirken des O anlockt - hat, soweit bisher bekannt, keine Parallelen im Bereich optischer wirksamer Balzverhaltensweisen (vgl. aber Uca S. 449).

\section{Summary}

\section{A. Construction of the Pyramid-Complex}

1. Pyramid-complexes consisting of a sand-pyramid, pathway, vestibule and spiral burrow (fig. 2) are only constructed by adult $\sigma^{\prime \prime} \sigma^{\prime \prime}$ of Ocypode saratan. The burrow rotates clockwise or counterclockwise according to whether the small chela is the left or the right. All other types of burrows are nonspiral and lack pyramids.

2. Pyramid-constructing consists of a chain of single building behaviour patterns. In reconstruction of pyramids, the behaviour can be "set off " at any given link in the chain by specific sign stimuli (p. 409), which only operate in a brief, sensitive period during the 'first emergence' (p. 415) at the beginning of a building phase or during an inspection visit. Once started, however, the continuing sequence is not subject to outside influences.

3. The single building patterns and the relevant releasing stimuli are the following:

a) 'Scraping' is elicited by dry sand. The direction in which the $\sigma^{\text {T }}$ discards the sand determines the later direction of the pathway and the direction of the burrow aperture, which is usually directed towards the sea (fig. 9). The coast profile is therefore one of the stimuli directing excavation, and a preexisting prominence can also have a directing effect.

b) Damp sand in the 'straight section' of the spiral hole releases construction of the pathway. The direction of the pathway is determined by the handedness of the $O^{x}$ as well as by the stimuli already mentioned. A pathway is always included in the initial construction of a pyramid-complex, but a pathway is built during reconstruction of a pyramid only if more than $1200 \mathrm{~cm}^{3}$ of construction material is available. Construction of a pathway can also be suppressed when elicitation of base- or peak-construction occurs at the initial emergence at the beginning of a building phase.

c) A $\sigma^{1}$ building a pathway piles the excavated lumps of sand roughly one behind the other. In base-construction, on the other hand, the sand lumps are distributed in a narrow fan-shape (fig. 28). During reconstruction, damp sand in the 'angle' of the burrow (p. 408) releases base-construction, and the end of the pathway exerts a directing influence. During reconstruction, two factors determine whether a base will be built and what size it will achieve: 1 . the condition of the pyramid, which the $\sigma^{\prime \prime}$ determines by looking at it from the entrance, and 2. the quantity of available building material. The pyramid is always built as large as possible. Pathway- and base-constructing are drivereducing activities. 
d) Base-construction is always followed by 'peak-construction', which differs from the former by the careful manner of deposition of sand lumps. The releasing factor is damp sand in the angle and terminal section of the burrow, but this operates only after exhaustion of the base-construction drive. Peak-construction is not a drive-reducing activity and there is no inhibitory 'pyramid reafference'.

e) 'Completion of the entrance' normally alternates with 'levelling'. 'The vestibule is produced as a by-product (p. 408).

4. Reconstruction of the pyramid can be released by a minimum of $200 \mathrm{~cm}^{3}$ of construction material or by removal of the pyramid (p. 409).

5. Only sand which has been excavated from the hole can be employed in pyramid construction. Since the spiral burrow usually is not plugged even during a sandstorm, destruction of the pyramid by wind automatically leads to a gain in building material.

6. The building activities have no influence on the regular diurnal variation in building motivation, neither by damming up or by reducing the drive.

\section{B. Mutual spatial Relationship of the Pyramid Elements}

7. The pyramid always lies on the continued projection of the tunnel spiral on the surface of the sand. The angle through which a pyramid can be deflected from this projection without being rejected is the same for all pyramid-systems owned by $\sigma^{7} \sigma^{\prime \prime}$ with the same handedness (fig. 11). If visually directing stimuli are lacking, angular position and distance are determined kinaesthetically.

8. All pyramids can be displaced within a range of $20-65 \mathrm{~cm}$ from the burrow entrance without rejection. The diurnal Egyptian Ghost Crabs estimate the distance by means of a genuine distance perception.

\section{Recognition of the own Pyramid}

9. The owner recognises his pyramid solely on the basis of its spatial relationship to the burrow.

10. The owner tolerates far greater alterations in the form, size and 'colour' of the pyramid than in the consistency of the construction material.

\section{The Social Functions of the Pyramid-Complex}

11. The pyramids are the most important sign-stimulus in colony foundation (p. 432).

12. For aggressive intruders attempting to conquer a pyramid-complex, the pyramids represent 'petrified display signals', which motivate rival fighting.

13. Pyramids 'force' new constructors to maintain a minimum distance of $134 \mathrm{~cm}$ from the nearest pyramid when selecting a site.

14. The pyramids show the $O \bigcirc$ the way to the mating sites, i.e. the spiral burrows. Apart from pyramid-construction, the Ghost Crabs possess no further courtship behaviour which attracts $\$ O$ at a distance. The Egyptian $\sigma^{7} \sigma^{\prime \prime}$ used vibration signals only when the $q$ was already quite close to the burrow entrance.

15. Aggressive intruders and sexually receptive $\bigcirc Q$ recognise the pyramids by their size, form, consistency and probably also by their colour or brightness. The pyramid elicits, through optical and tactile sign stimuli, a 
search for the nearest entrance, where the direction of the spiral is perceived by tactile means when the animal crawls in. Intruders normally fight only for holes with an appropriate spiral, and receptive $q Q$ similarly search only for a partner of like handedness.

16. Pyramid owners defend a territory surrounding the pyramid-complex. This territory serves as a site for living, courtship and mating.

17. A given owner will inhabit the same pyramid-complex in Egypt for $4-8$ days, during which time it does not feed.

\section{E. Different Behaviour of Ethiopian Ghost Crabs}

18. The Ghost Crabs observed in Ethiopia were almost entirely nocturnal. The Ethiopian pyramid-complexes constructed in complete darkness correspond to the Egyptian type apart from a few minor details (p. 445).

19. The Ethiopian pyramids have almost entirely lost their signal function, at least during moonless nights. As a result, the vibration signals (probably phylogenetically much older) are more important.

\section{F. The Evolution of Pyramid-Construction Behaviour}

20. Pyramid-construction behaviour is interpreted as a modified form of sand-removal behaviour, differentiated into pathway-, base- and peak-construction. This behaviour has evolved from sand-disposal over a narrow, fanlike area which is probably phylogenetically much older. The final product of this sand-removal behaviour has acquired signal character. The conspicuously developed 'curiosity behaviour', which is elicited by almost every prominence, and the restriction of mating to the burrows led to a predisposition towards pyramid-construction and also to the contrasting, wide fan-like sand-disposal (p. 447 and fig. 25), which conceals the entrance.

21. Pyramid-construction behaviour, which marks the mating place visually with an object other than the body itself and attracts conspecifics (indeed without any further participation of he $\sigma^{7}$ ), has, as far as is known, no parallel in the realm of visually effective display behaviour patterns (but cf. Uca, p. 449).

\section{Literaturverzeichnis}

Altevogt, R. (1955): Beobachtungen und Untersuchungen an indischen Winkerkrabben. Z. Morph. Okol. Tiere 43, 501-522 - Ders. (1957 a): Untersuchungen zur Biologie, Okologie und Physiologie indischer Winkerkrabben. Z. Morph. Okol. Tiere 46, 1-110 - Ders. (1957 b): Beiträge zur Biologie und Ethologie von Dotilla blanfordi Alcodk und D. myctiroides MilneEdwards. Z. Morph. Okol. Tiere 46, 369-388 - Ders. (1959): Okologische und ethologische Studien an Europas einziger Winkerkrabbe Uca tangeri Exdoux in Südspanien. Z. Morph. Okol. Tiere 48, 123-146 - Ders. (1962): Akustische Epiphänomene im Sozialverhalten von U/ca tangeri in Südspanien. Verh. dtsch. zool. Ges. 309-315, Wien - Ders (1963): Wirkung polarisierten Lichtes bei $U_{c a}$ tangeri. Naturwissenschaften 50, 697-698 - Ders. (1964): Ein antiphoner Klopfcode und eine neue Winkfunktion bei Uca tangeri. Naturwissenschaften 51, 644-645 - Ders. (1965): Lichtkompaß- und Landmarkendressuren bei Uca tangeri in Andalusien. Z. Morph. Okol. Tiere 55, 641-655 - Ders., und H.-O. v. HageN (1964): Über die Orientierung, von Uca tangeri Exdoux im Freiland. Z. Morph. Okol. Tiere 53, 636-656 • BaEREnd, G. F. (1941): Fortpflanzungsverhalten und Orientierung der Grabwespe Ammophila campestris jur. Tijdschr. Entomol. 84, 68-275 • Cotr, H. (1930): Observations on the natural history of the racing-crab Ocypoda ceratophthalma from Beira. (Zool. Soc. Exp. Zambesi, 1927, 3). Proc. Zool. Soc., London 4, 755-765 • Cowles, R. P. (1908): Habitats, reactions and associations in Ocypoda arenari.t. Pap. Tortugas Labor. Carn. Inst. Washington 2, 3-41 - Crane, J. (1941 a): Crabs of the genus U/ca from the west coast of Central America. Zoologica 26, 145-207 - Dies. (1941 b): On the growth and ecology of brachyuran crabs of the genus Ocypode. Zoologica 26, 297-310 - Dies. (1943): Display, breeding and relationship of fiddler crabs (Brachyura, Genus $U c a$ ) in the North-eastern United States. Zoo- 
logica 28, 217-223 - Dies. (1957): Basic patterns of display in fiddler crabs (Ocypodidac, genus Uca). Zoologica 42, 69-82 - Dies. (1958): Aspects of social behavior in fiddler crabs, with special reference to Uca maracoani. Zoologica 43,113-130 - Daumer, K., R. Jander, und T. H. WATERMan (1963): Orientation of the ghost-crab Ocypode in polarized light. Z. vgl. Physiol. 47, 56-76 - Frank, A. (1941): Eigenartige Flugbahnen bei Hummelmännchen. Z. vgl. Physiol. 28, 467-484 - Gordon, H. R. S. (1958): Synchronous claw-waving of fiddler crabs. Anim. Behav. 6, 238-241 - Guinot, D. (1962): Sur un collection des Crustaces Décapodes Brachyures de Mer Rouge et de Somalie. Boll. Mus. Civ. Venezia 15, 7-63 • HaAs, A. (1949a): Gesetzmäßiges Flugverhalten der Männchen von Psithyrus silvestris Lep. und einiger solitärer Apiden. Z. vgl. Physiol. 31, 671-683 - Ders. (1949 b): Arttypische Flugbahnen von Hummelmännchen. Z. vgl. Physiol. 31, 281-307 • v. HAgen, H.-O. (1961 a): Nächtliche Aktivität von Uca tangeri in Südspanien. Naturwissenschaften 48, 140 - Ders. (1961 b): Experimentelle Studien zum Winken von Uca tangeri in Südspanien. Verh. dtsch. zool. Ges. 424-431, Saarbrücken - Ders. (1962): Freilandstudien zur Sexual- und Fortpflanzungsbiologie von Uca tangeri in Andalusien. Z. Morph. Ókol. Tiere 51, 611-725 - Ders. (1967): Nachweis einer kinästhetischen Orientierung bei Uca rapax. Z. Morph. Ơkol. Tiere 58, 301-320 - KoepcKe, M. (1953): Contribucion al conocimiento de la forma de vida de Ocypode gandichaudii Milne-Edwards et Lucas. (Decapoda, Crustacea). Publ. Mus. hist. nat. Javier Prado (Lima). Ser. A. Nr. 13 • KRüGER, E. (1951): Uber die Bahnflüge der Männchen der Gattung Bombus und Psithyrus, Z. Tierpsychol. 8, 61-75 - Linsenmair, K. E. (1965): Optische Signalisierung der Kopulationshöhle bei der Reiterkrabbe Ocypode saratan Forsk. (Decapoda brachyura Ocypodidae). Naturwissenschaften 52, 256-257 - Magnus, D. (1960): Zur OOkologie des Landeinsiedlers Coenobita jousseaumei Bouvier und der Krabbe Ocypode aegyptiaca Gerstäcker am Roten Meer. Verh. dtsch. zool. Ges. 316-329, Bonn - Marshall, A. J. (1960): Die Laubenvögel. Endeavour 19, 202-208 - MILNE, L. J., and M. J. MiLne (1946): Notes on the behavior of the ghost crab. Am. Nat. 80 (792), 362-379 - Parenzan, P. (1931): Osservazioni biologiche sull Ocypoda ceratophthalma Fabr. Atti Inst. Veneto 90, 1001 - 1008 Peters, H. M. (1955): Die Winkgebärde von Uca und Minuca (Brachyura) in vergleichend ethologischer, -ökologischer und -morphologischer-anatomischer Betrachtung. Z. Morph. Okol. Tiere 43, 425-500 - SAlmoN, M. (1962): Courtship and sound production in the sand fiddler, Ulca pugilator. American Zoologist 2, 553 - SAlmon, M., and J. F. STOUT (1962): Sexual discrimination and sound production in Uca pugilator. Zoologica 47, 15-21 - SCHÖNE, H., und H. ScHöNe (1963): Balz und andere Verhaltensweisen der Mangrove-Krabbe Goniopsis cruentata Latr. und das Winkverhalten der eulitoralen Brachyuren. Z. Tierpsychol. 20, 641-656 SterN, G. (1956): Beiträge zur Biologie der Hummel. Zool. Jb. Abt. Syst. 84, 439-462 - Ders. (1963): Untersuchungen über den Sexuallockstoff der Hummelmännchen. Biol. Zbl. 82, 343 bis 349 - T'AkAhasi, S. (1935): Ecological notes on the ocypodian crabs (Ocypodidae) in Formosa, Japan. Annot. Zool. Japon. 15, $78-87$ - VERWEY, J. (1930): Einiges uiber die Biologie ostindischer Mangrove-Krabben. Treubia 12, 168-261 - Vogel, St. (1966): Pollination neotropischer Orchideen durch duftstoff-höselnde Prachtbienen-Männchen. Naturwissenschaften 53, 181-182. 